\title{
Impact of Urbanization on Surface Energy Balance Components Over Metropolitan Cities of India During 2000-2018 Winter Seasons
}

\section{Sabiha Sultana}

Indian Institute of Technology Kharagpur

Dr A.N.V. Satyanarayana ( $\square$ achanta.satya@gmail.com )

Indian Institute of Technology Kharagpur https://orcid.org/0000-0002-2875-6403

\section{Research Article}

Keywords: Surface Energy Balance, Net Radiation Flux, Sensible Heat Flux, Latent Heat Flux

Posted Date: July 20th, 2021

DOl: https://doi.org/10.21203/rs.3.rs-709565/v1

License: (c) (i) This work is licensed under a Creative Commons Attribution 4.0 International License.

Read Full License

Version of Record: A version of this preprint was published at Theoretical and Applied Climatology on February 12th, 2022. See the published version at https://doi.org/10.1007/s00704-022-03937-5. 
Impact of Urbanization on Surface Energy Balance Components over Metropolitan

Cities of India during 2000-2018 winter seasons

\author{
Sabiha Sultana and A.N.V. Satyanarayana* \\ Centre for Oceans, Rivers, Atmosphere and Land Sciences \\ Indian Institute of Technology Kharagpur,
}

Kharagpur-721 302

India

*Corresponding Author:

Dr A N V Satyanarayana

Associate Professor Centre for Oceans, Rivers, Atmosphere and Land Sciences

Indian Institute of Technology Kharagpur

Kharagpur-721 302

India

E-mail: anvsatya@coral.iitkgp.ac.in , achanta.satya@gmail.com

Tel: +91 $3222281820 / 281821$

Fax: +91 3222282208 


\begin{abstract}
The present study attempts to evaluate the urban energy balance components with respect to increasing urbanization over Indian metropolitan cities during 2000 - 2018 winter seasons by using Landsat 7 and 8 satellite imageries. The impact of increasing artificial surfaces on different energy fluxes is analyzed for the study period over these cities. The results indicate that the estimated ranges of the energy fluxes are in the range of typical values that are reported in the earlier literatures over cities. The Sensible Heat Flux (SHF) is observed to be increased considerably whereas the Latent Heat Flux (LHF) is noticed to slightly decreasing. The mean SHF over the buildup areas and the dry lands of Delhi noticed to record maximum increase of 28.2 $\mathrm{Wm}^{-2}$ and $39.7 \mathrm{Wm}^{-2}$ respectively during the study period. The SHF (LHF) shows positive (negative) correlation with the land surface temperature. The SHF (LHF) is observed to be about $19 \%-33 \%(1.9 \%-15 \%)$ of the net radiation flux and the residual heat flux is found to be about $60 \%$ to $80 \%$ of the net radiation flux. The study advocates the substantiate changes of the surface energy balance parameters would have profound influence on the energy exchange mechanism and which in turn affects regional climatic change.
\end{abstract}

Keywords: Surface Energy Balance, Net Radiation Flux, Sensible Heat Flux, Latent Heat Flux 


\section{Introduction}

The explosive population rise and fleeting industrialization in the developing countries of tropical and subtropical climate has lead to brisk and abrupt expansion of the artificial surfaces and in turn warmer environment over the cities, the phenomena of urban heat island (UHI) (Oke, 1982; Voogt and Oke, 2003; Sobrino et al., 2012; Roth, 2013). The impact of expanding cities is not just limited to the city scale, but influences the regional and the global climate through radiation balance and greenhouse gas emission (Roth, 2007; Grimmond, 2007; Seto et al., 2012; Kuang et al., 2014). The higher temperature experienced due to UHI effect over the cities is mostly the result of the declining vegetation cover, replacement of natural surfaces by artificial materials, anthropogenic heating and the increasing pollution in the atmosphere (Grimmond, 2007; Grimmond, Ward and Kotthaus, 2016). The artificial materials (such as asphalt, concrete, marbles, tiles etc) of high heat capacities and conductivities store more heat and increase the surface temperature (Yang et al., 2019) whereas reduction in the surface temperature through evapotranspiration is declined due to the loss of the vegetation cover (Kato and Yamaguchi, 2005, 2007; Kuang et al., 2014). The artificial impervious surface has significant contribution in altering the surface energy fluxes and hence impacts the regional climate dynamics. It is essential to analyze the surface heat balance over urban and rural domain to understand the boundary layer dynamics over the fast developing cities (Grimmond, 1992; Hanna et al., 2011; Kotthaus and Grimmond, 2014) and quantitatively investigate the influence of heat fluxes on the temperature rise associated with UHI (Kato et al., 2008).

The concept of surface energy balance was utilized in studying the surface dynamics as early as in the end of the nineteenth century and many significant work has been spotted regarding urban climatology in terms of the heat balance involving observation data and numerical modelling 
during the second half of the twentieth century (Sundborg, 1951; Munn 1966; Tag, 1968; Myrup, 1969; Probald, 1971; Oke et al., 1972) indicating that the observational results were coarse and incomplete and the model results were rather simple. The first study over any tropical or subtropical city related to energy balance was executed for Mexico City (Oke et al., 1992) and for next couple of decades very few and selective studies related urban energy balance (UEB) are noticed (Goldreich, 1992; Salmond, 1999, 2005; Roth, 2007). At the beginning of the twentyfirst century many scientific researchers focused on deducing the energy balance components over the urban regions using the ground observations and the numerical modeling (Pearlmutter et al., 1999; Crawford and Bluestein, 2000; Moriwaki and Kanda, 2004; Offerle et al., 2005; Pearlmutter et al., 2005, 2006; Hanna et al., 2011; Kotthaus and Grimmond, 2014; Templeton et al., 2018)

The urban geometry, structure and the spread plays important role in quantifying the changes in the fluxes into and out of the surface and the storage changes as well. The high-resolution remote sensing techniques are found to be extremely useful in the recent years for monitoring the changes in the land use land cover (LULC) patterns and map the abrupt and rapid changes in the urban areas that influencing the corresponding surface heat fluxes (Kato et al., 2008). Kato and Yamaguchi (2005) separated the artificial increase in the sensible heat fluxes using the surface heat balance assumption over an urban area of Nagoya, Japan using ASTER and Landsat data. In 2007, Kato and Yamaguchi proposed to consider the storage heat as the heat flux between the surface and the canopy layer and the results reasonably agreed to earlier reported studies (Oke et al., 1999; Spronken-Smith, 2002; Grimmond et al., 2004; Moriwaki and Kanda, 2004; Christen and Vogt, 2004; Offerle et al., 2005). Roupioz et al., (2016) attempted to generate a time series of radiation fluxes of better spatial and temporal resolution using remote sensing data over the 
heterogeneous topography of Tibetan Plateau. Yang, Wong and Menetti (2016) estimated the land surface temperature (LST) from remotely sensed data with and without considering the urban geometry to evaluate the turbulent heat flux. Consideration of urban geometry appears to lower the values of sensible heat. Brenner et al. (2017) used a high resolution thermal imager mounted on an unmanned aircraft to estimate LST and turbulent energy fluxes. In 2018, Chrysoulakis et al. investigated the potential of the satellite observations data (MODIS and Sentinel 3) downscaled to $100 \mathrm{~m} \times 100 \mathrm{~m}$ to estimate UEB fluxes at a local scale along with the suitable ground observations. In 2019 Yang et al. employed a numerical microclimate model TUF-3D (Temperatures of Urban Facets in 3-D) to obtain radiometric and complete surface temperatures for better estimation of SHF. Hrisko et al., (2021) utilized multispectral satellite radiance for quantifying the storage heat through gradient-boosted regression trees method. Wetherley et al., (2021) investigated the variability of urban energy fluxes for land cover and climate gradient over Los Angeles, USA using remote sensing and energy balance model. Many remote sensing modeling methodologies are adapted in the recent studies to estimate the influence of urbanization over the surface heat fluxes (Kuang et al., 2014; Eswar et al., 2017) and address the energy-balance-closure problem (Nelli et al., 2019; Mauder et al., 2020). Both earth observation and the ground measurements can be utilized in the estimating the surface energy balance over the urban areas but, the ground observation method requires sufficient number of weather stations, vast amount of data, lots of manpower, huge cost within a small observational area for a productive study (Hanna et al., 2011; Kotthaus and Grimmond, 2014; Templeton et al., 2018) whereas the earth observation data is easily accessible and covers larger area. Recent studies indicated the potential of earth observation in accounting the changes in the fluxes is high 
(Weng et al., 2014; Chen and Hu, 2017; Eswar et al., 2017; Rahman and Zhang, 2019; Liang et al., 2019).

The phenomena of UHI have been studied widely using the earth observations and the remote sensing tool but the corresponding heat fluxes studies appears to be limited to only few selective studies (Chrysoulakis et al, 2018). Considering the review of literature, it is noticed that the study corresponding to surface energy fluxes are mostly emphasized on western tropical or subtropical cities. India being the seventh-largest country by area and the second-most populated country in the world, it has many highly populated metropolitan cities with rapidly spreading infrastructure. The smaller cities are developing widely for recent couple of decades leading to modifications in the regional climate and hence summons a thorough investigation of energy fluxes over Indian metropolitan cities. In our earlier studies the pattern of land surface temperature (LST) and UHI intensities over the different LULC class changes are analyzed over 11 (7) Indian metropolitan cities for winter (summer) seasons during 2000 - 2018 (Sultana and Satyanarayana, 2018, 2019, 2020). Considering the fast development of the cities in India, it is essential to quantify the surface energy balance and investigate its influence on the temperature rise associated with UHI over these cities. The present study attempts to quantify the various surface energy balance components over the different Indian metropolitan cities and investigate the influence of rapid urbanization on variation in the UEB, specifically on sensible and latent heat fluxes, using Landsat-7 and 8 satellite data.

\section{Study area and Data}

\subsection{Study area}

India is a fast developing tropical country with around 400 cities of population one lakh or more and about 53 urban agglomerations with one million or above residents (Census of India, 2011). 
Urban population in India is increasing in a tremendous rate of around 34\% as estimated in 2017 (World Bank, 2017). The urbanization rate over the developing cities (viz.Lucknow, Chandigarh, Jaipur, Nagpur) is much higher than the developed ones with close-packed high density urban areas (viz. Mumbai, Delhi, Kolkata, Bengaluru). It is essential to monitor the urban expansion over the developing cities along with the developed cities, in order to assess the variation in the urban climate dynamics. Present study includes 11 Indian metropolitan cities of different climatic zones, such as Kolkata $\left(22^{\circ} 34^{\prime} 21^{\prime \prime} \mathrm{N}, 88^{\circ} 21^{\prime} 50^{\prime \prime} \mathrm{E}\right)$ and Visakhapatnam $\left(17^{\circ} 41^{\prime} 12^{\prime \prime} \mathrm{N}\right.$, $\left.83^{\circ} 13^{\prime} 07^{\prime} \mathrm{E}\right)$ in the east coast, Mumbai $\left(1^{\circ} 04^{\prime} 34^{\prime \prime} \mathrm{N}, 72^{\circ} 52^{\prime} 40^{\prime \prime} \mathrm{E}\right)$ and $\mathrm{Kochi}\left(9^{\circ} 55^{\prime} 52^{\prime \prime} \mathrm{N}\right.$, $76^{\circ} 16^{\prime} 02^{\prime}$ 'E) in the west coast, the northern inland cities Delhi $\left(28^{\circ} 42^{\prime} 15^{\prime} ' \mathrm{~N}, 77^{\circ} 06^{\prime} 09^{\prime \prime} \mathrm{E}\right)$, Chandigarh $\left(30^{\circ} 43^{\prime} 59^{\prime \prime} \mathrm{N}, 7^{\circ} 46^{\prime} 46^{\prime \prime} \mathrm{E}\right)$, Jaipur (26 54'45' $\left.\mathrm{N}, 7^{\circ} 47^{\prime} 14^{\prime \prime} \mathrm{E}\right)$ and Lucknow $\left(26^{\circ} 50^{\prime} 48^{\prime}{ }^{\prime} \mathrm{N}, 80^{\circ} 56^{\prime} 46^{\prime}\right.$ 'E),Nagpur $\left(21^{\circ} 08^{\prime} 45^{\prime}{ }^{\prime} \mathrm{N}, 7^{\circ} 05^{\prime} 18^{\prime \prime} \mathrm{E}\right)$ the city in the central India and southern peninsular cities Hyderabad $\left(17^{\circ} 23^{\prime} 06^{\prime}{ }^{\prime} \mathrm{N}, 78^{\circ} 29^{\prime} 12^{\prime}\right.$ 'E) and Bengaluru $\left(12^{\circ} 58^{\prime} 18^{\prime}{ }^{\prime} \mathrm{N}\right.$, $77^{\circ} 35^{\prime} 41^{\prime \prime} \mathrm{E}$ ) (Fig 1).The particulars of the cities such as locations, area, population, climatic conditions can be referred in Sultana and Satyanarayana 2018 (Table 1) and Sultana and Satyanarayana 2020.

\subsection{Data}

Landsat 7 and Landsat 8 imageries (cloud-free conditions) of the representative day of the winter seasons (December - February) in 3 to 6 years' intervals during 2000-2018 are utilized for the present study over each study regions. The Landsat images are obtained from the USGS Earth Explorer user interface (https://earthexplorer.usgs.gov/).The details of the data used for the present study are given in Table 1. For the purpose of the present study, the imageries are preprocessed through spatial, spectral and radiometric corrections using ERDAS IMAGINE 2014. 
The LULC classification of the study areas for the study periods is retrieved using the multispectral bands of the Landsat (Sultana and Satyanarayana, 2018, 2019, 2020). The reflectance and the spectral radiance are also estimated for the multi-spectral bands (Band $1-5$ and 7 of Landsat 7 and Band $2-7$ of Landsat 8) which are used for estimating the albedo (Allen et al., 2002) and the Normalized Difference Vegetation Index (NDVI) (Carlson and Ripley, 1997; Sultana and Satyanarayana, 2018).The at-satellite brightness temperature can be calculated using the infrared (IR) thermal bands (Band 6 of Landsat 7 and Band 10 and 11 of Landsat 8). The brightness temperature along with the NDVI is employed in estimating the emissivity-corrected LST over the study regions for the study period. The estimated albedo, LST and LULC classification along with the meteorological data are utilized in evaluating the components of the surface energy balance as discussed in the section 3. The relative digital elevation model (DEM) data from the Advanced Space-borne Thermal Emission and Reflection radiometer (ASTER) is used for estimating the obstacle height (https://mirador.gsfc.nasa.gov/).

The meteorological data parameters such as the near surface air temperature ( $\boldsymbol{T}_{\text {near surface air }}$ ) data are collected from NCEP/DOE 2 Reanalysis data products, Physical Science Division (PSD), NOAA Earth System Research Laboratory. The available data are 4 times daily averaged with a spatial coverage of $2.5 \times 2.5$ degree grids, where the temperature is collected at $2 \mathrm{~m}$ height. (https://psl.noaa.gov/data/gridded/data.ncep.reanalysis2.html/). Precipitable water (w) data has been obtained from University of Wyoming (http://weather.uwyo.edu/upperair/sounding.html/), the upper air soundings data. Other Meteorological data (Wind speed, Atmospheric temperature, Relative humidity, Dew point temperature, etc.) has been obtained from local weather stations present approximately at center of our chosen study region from Weather Underground atmospheric soundings (https://www.wunderground.com/). 


\section{Methodology}

Investigating the influence of rapid urbanization on the surface energy balance requires different methodologies to estimate the energy components. The expression for the surface balance can be presented as (Oke, 1982, 1988; Masson et al., 2002),

$$
\boldsymbol{Q}^{*}+\boldsymbol{Q}_{F}=\boldsymbol{Q}_{H}+\boldsymbol{Q}_{E}+\Delta \boldsymbol{Q}_{S}+\Delta \boldsymbol{Q}_{\boldsymbol{A}}
$$

where, $Q^{*}$ is the net all-wave radiation flux $\left(W m^{-2}\right), Q_{H}$ and $Q_{E}$ are the turbulent sensible and latent heat flux $\left(W m^{-2}\right)$ and $Q_{F}$ is the anthropogenic heat flux $\left(W m^{-2}\right)$. The $\Delta Q_{S}$ is the total change in heat storage in the surface $\left(W m^{-2}\right)$ and $\Delta \boldsymbol{Q}_{A}$ is the total change in advected heat flux $\left(W m^{-2}\right)$, which is considered to be small in comparison to other components and could be neglected.

The net radiation flux can be calculated using the Surface Energy Balance Algorithms for Land SEBAL algorithm (Allen et al., 2002). The turbulent heat fluxes are estimated by the use of Aerodynamic Resistance Method- ARM (Nishida et al., 2003; Kato and Yamaguchi, 2005, 2007; Kato et al., 2008). The heat storage and anthropogenic heat flux over urban surfaces cannot be estimated separately by remote sensing data analysis as they depend on surface characteristics and anthropogenic activities. Hence, the $Q_{F}$ and $\Delta Q_{S}$ are combined as the residual heat flux, $Q_{R}$ and estimated from the energy balance equation as follows (Kato and Yamaguchi, 2005, 2007).

$$
\boldsymbol{Q}_{\boldsymbol{R}}=\Delta \boldsymbol{Q}_{S}-\boldsymbol{Q}_{\boldsymbol{F}}=\boldsymbol{Q}^{*}-\left(\boldsymbol{Q}_{\boldsymbol{H}}+\boldsymbol{Q}_{\boldsymbol{E}}\right)
$$

The net radiation, also called as net flux at the surface, is the actual radiant energy available to earth at its surface. It can be calculated by subtracting the total outgoing fluxes from the total incoming fluxes (Allen et al., 2002). It can be expressed as,

$$
\boldsymbol{Q}^{*}=\left(\boldsymbol{R}_{I S W}+\boldsymbol{R}_{I L W}\right)-\left(\boldsymbol{R}_{\text {osW }}+\boldsymbol{R}_{\text {oLW }}\right)
$$


where, $\boldsymbol{R}_{I S W}$ is the incoming short wave (SW) radiation reaching the earth surface $\left(W m^{-2}\right), \boldsymbol{R}_{\boldsymbol{I L W}}$ is the incoming long wave (LW) radiation emitted by the atmosphere $\left(W m^{-2}\right), \boldsymbol{R}_{\boldsymbol{O} \text { SW }}$ is the SW radiation reflected back to the atmosphere $\left(W m^{-2}\right), \boldsymbol{R}_{\boldsymbol{O} \boldsymbol{L} W}$ is the outgoing LW radiation that emitted by earth surface into the atmosphere $\left(\mathrm{Wm}^{-2}\right)$. The equation (3) can be rewritten as,

$$
Q^{*}=(1-\alpha) \times R_{I S W}+\left(R_{I L W}-R_{O L W}\right)-\left(1-\epsilon_{0}\right) \times R_{I L W}
$$

where, $\boldsymbol{\alpha}$ is the albedo of earth surface and $\boldsymbol{\epsilon}_{\boldsymbol{0}}$ is the planetary surface emissivity. The additional final term in the Eq. $(2),\left(1-\varepsilon_{0}\right) \mathrm{R}_{\mathrm{ILW}}$, represents the fraction of incoming $\mathrm{LW}$ radiation that is reflected back (Allen et al., 2002).

$\boldsymbol{R}_{\text {ISW }}$ is estimated using the relation given in the following (Allen et al., 2002),

$$
R_{I S W}=G_{s c} \times \tau \times D_{r} \times \cos \theta
$$

where, $\boldsymbol{G}_{\boldsymbol{s}}$ is the solar constant $\left(1367 \mathrm{Wm}^{-2}\right), \boldsymbol{\tau}$ is the atmospheric transmissivity, $\boldsymbol{D}_{\boldsymbol{r}}$ is the EarthSun distance corrected for eccentricity of planet orbit and $\boldsymbol{\theta}$ is the Zenith angle. The $\boldsymbol{D}_{\boldsymbol{r}}$ and $\boldsymbol{\theta}$ can be obtained using Meta data available with the Landsat- 8 imageries. The atmospheric transmissivity can be estimated by the equation as follows (Allen et al., 2007),

$$
\tau=0.35+0.627 \times e^{\left[-\left(\frac{0.00146 \times P}{K_{t} \times \cos \theta}\right)-0.075 \times\left(\frac{w}{\cos \theta}\right)^{0.4}\right]}
$$

where, $\boldsymbol{P}$ is the local atmospheric pressure $(K P a), \boldsymbol{w}$ is the precipitable water $(\mathrm{mm})$ and $\boldsymbol{K}_{\boldsymbol{t}}$ is the unit less air turbidity coefficient $\left(0<\boldsymbol{K}_{t} \leq 1\right.$; for clear air, 0.5 for polluted air).

Surface albedo can be defined as the ratio of reflected solar radiance to the amount of irradiance received. The albedo $(\boldsymbol{\alpha})$ is estimated using the following expression used by Allen et al. (2002),

$$
\alpha=\frac{\left(\alpha_{T O A}-\alpha_{a t m}\right)}{\tau^{2}}
$$


where, $\boldsymbol{\alpha}$ is the Planetary albedo corrected for atmosphere effects, $\boldsymbol{\alpha}_{T O A}$ is the Planetary albedo without correction for corresponding atmosphere effects and $\boldsymbol{\alpha}$ atm is the Atmospheric albedo (a typical constant value of 0.03 is taken based on Bastiaanssen, 2000).

The $\boldsymbol{\alpha}_{\text {TOA }}$ can be estimated using the method given by (Allen et al., 2002; Silva et al., 2015),

$$
\boldsymbol{\alpha}_{T O A}=\sum\left(\omega_{\lambda} \times \rho_{\lambda}\right)
$$

where, $\rho_{\lambda}$ is the reflectivity of the multispectral bands and $\boldsymbol{\omega}_{\lambda}$ is the weighting coefficient for eachband, are computed using methods mentioned in the Landsat User Handbooks (Landsat 7 Data Users Handbook, 2019; Landsat 8 Data user Handbook, 2019).

Both the incoming and the outgoing LW radiation are estimated using the Stefan-Boltzmann equation given as follows (Allen et al., 2002; An, Hemmati and Cui, 2017),

$$
\begin{gathered}
R_{I L W}=\epsilon_{\text {air }} \times \sigma \times T_{\text {near surface air }} \\
R_{O L W}=\epsilon_{0} \times \sigma \times L S T
\end{gathered}
$$

where, $\boldsymbol{\sigma}$ is Stefan-Boltzmann constant $\left(5.67 \times 10^{-8}\right.$ in $\left.W m^{-2} K^{4}\right), \boldsymbol{\epsilon}$ airis the atmospheric emissivity computed using the relation which is a function of atmospheric transmissivity (Bastiaanssen, 1995; Allen et al., 2002),

$$
\epsilon_{\text {air }}=0.85 \times(-\ln \tau)^{0.9}
$$

The planetary surface emissivity, $\boldsymbol{\epsilon}_{0}$ is calculated using the NDVI (Carlson and Ripley, 1997) and LST is obtained using the thermal bands of Landsat data. The methodology to calculate LST and $\boldsymbol{\epsilon}_{0}$ from Landsat imageries is discussed in detail by Sultana and Satyanarayana (2018, 2019 and 2020).

Sensible heat flux is the conductive transfer of heat flux from the Earth's surface to the atmosphere. Sensible heat flux can be estimated using the equation, (Kato and Yamaguchi, 2005, 2007; Kato et al., 2008), 


$$
Q_{H}=\frac{\rho \times C_{P} \times\left(L S T-T_{a t m}\right)}{R_{a}}
$$

where, $\boldsymbol{\rho}$ is the air density $\left(1.225 \mathrm{~kg} \mathrm{~m}^{-3}\right), \boldsymbol{C}_{\boldsymbol{P}}$ is the Specific heat of air at constant pressure (1005 $\left.K J K^{-1} K^{-1}\right), \boldsymbol{T}_{a t m}$ is the Atmospheric air temperature $(K)$ and $\boldsymbol{R}_{\boldsymbol{a}}$ is the Aerodynamic resistance $\left(s m^{-1}\right)$ for heat and momentum exchange and can be estimated by using the equation as given by Brutsaert (1982),

$$
\boldsymbol{R}_{\boldsymbol{a}}=\frac{\left[\frac{\ln \left(Z_{r e f}-D_{0}\right)}{Z_{o m}}-\Psi_{m}\right] \times\left[\frac{\ln \left(Z_{r e f}-D_{0}\right)}{Z_{o h}}-\Psi_{h}\right]}{K^{2} U}
$$

where, $\boldsymbol{Z}_{\text {ref }}$ is the reference height $(m)$ at which wind speed and temperature are measured, $\boldsymbol{U}$ is the wind speed $\left(\mathrm{m} \mathrm{s}^{-1}\right)$ at the reference height, $\boldsymbol{D}_{\boldsymbol{0}}$ is the displacement height $(m), \boldsymbol{Z}_{\boldsymbol{o}}$ and $\boldsymbol{Z}_{\boldsymbol{o}}$ is the roughness length $(m)$ for heat and momentum exchange, $\psi_{m}$ and $\psi_{h}$ are the stability correction functions for heat and momentum exchange depending on Monin-Obukhov length and $\boldsymbol{K}$ is the von Karman constant (0.4). For the present study, typical values of $\boldsymbol{Z}_{\boldsymbol{o h}}$ and $\boldsymbol{Z}_{\boldsymbol{o m}}$ were considered for different LULC classes (Table 2) as proposed by Kato and Yamaguchi, (2005, 2007); Kato et al., (2008) as it is quite difficult to acquire specific required data to calculate the $\boldsymbol{Z}_{\boldsymbol{o}}$ and $Z_{o m}$ values by the methods proposed earlier (Macdonald et al., 1998; Grimmondand Oke, 1999; Duijm, 1999). The displacement height, $\boldsymbol{D}_{\boldsymbol{0}}$ is estimated by the expression given by Macdonald et al. (1988) and Kato and Yamaguchi (2005),

$$
D_{0}=z_{h}\left[1+A^{-\lambda P}(\lambda P-1)\right]
$$

where, $z_{h}$ is the obstacleheight $(m), \boldsymbol{A}$ is a constant (=4.43 for staggered arrays), and $\boldsymbol{\lambda P}$ is the plan areadensity of obstacles, i.e., the ratio of the build-up area tothe total area. The obstacle height is being estimated from ASTER DEM data. Stability correction function calculated as a function of Monin-Obukhov length by the proposed methodology (Paulson, 1970; Webb, 1970; Allen et al., 2002; Prueger and Kustas, 2005). 
Latent heat flux is the flux of energy associated with evaporation or transpiration of water from the Earth's surface to the atmosphere and vice versa. Latent heat flux can be estimated from the following equation (Kato and Yamaguchi, 2005, 2007; Kato et al., 2008),

$$
Q_{E}=\frac{\rho \times C_{P} \times\left(e_{s}-e_{a}\right)}{\gamma \times\left(R_{a}+R_{S}\right)}
$$

where, $\boldsymbol{\gamma}$ is the psychrometric constant $\left(0.67 \mathrm{hPa} K^{-1}\right), \boldsymbol{e}_{s}$ is the saturated water vapor pressure (hpa) at surface temperature, $\boldsymbol{e}_{\boldsymbol{a}}$ is the Atmospheric water vapor pressure (hpa) and $\boldsymbol{R}_{\boldsymbol{S}}$ is the stomatal resistance.Stomatal resistance can be computedusing the proposed method as follows (Nishida et al., 2003, Kato et al., 2008),

$$
\frac{1}{R_{S}}=\frac{f_{1}(P A R) \times f_{2}(P A R)}{R_{\text {Smin }}}+\frac{1}{R_{\text {cuticle }}}
$$

where, $\boldsymbol{R}_{\text {smin }}$ is the minimum stomatal resistance and $\boldsymbol{R}_{\text {cuticlel }}$ is the canopy resistance related to the diffusion through the cuticle layer of leaves $\left(10^{5} \mathrm{~s} \mathrm{~m}^{-1}\right)$. The typical values of $\boldsymbol{R}_{\text {smin }}$ over different LULC classes are considered as proposed by Kato et al., (2008); Kato and Yamaguchi, (2005, 2007), are summarized in Table 3. The $f_{1}$ (PAR) and $f_{2}$ (PAR) are given by (Nishida et al., 2003),

$$
\begin{gathered}
f_{1}(P A R)=\left(\frac{T_{a}-T_{n}}{T_{0}-T_{n}}\right) \times\left(\frac{T_{x}-T_{a}}{T_{x}-T_{0}}\right)^{\left(\frac{T_{x}-T_{0}}{T_{0}-T_{n}}\right)} \\
f_{2}(P A R)=\frac{P A R}{(P A R+A)}
\end{gathered}
$$

where, $\boldsymbol{T}_{\boldsymbol{n}}, \boldsymbol{T}_{\boldsymbol{x}}$ and $\boldsymbol{T}_{\boldsymbol{0}}$ and are the minimum, maximum and the optimal temperature for stomatal activity, and the typical values for them as considered are $2.7{ }^{\circ} \mathrm{C}, 45.3{ }^{\circ} \mathrm{C}$ and $31.1{ }^{\circ} \mathrm{C}$ respectively. $\boldsymbol{A}$ is the parameterconcerning photon absorption efficiency at low light intensity $\left(152 \mu \mathrm{mol} \mathrm{m}^{-2} \mathrm{~s}^{-1}\right), \boldsymbol{P A} \boldsymbol{R}$ is the Photosynthetic active radiation $\left(\mathrm{Wm}^{-2}\right)$, can be calculated as $\boldsymbol{f}^{*} \boldsymbol{R}$ ISW (where, $\mathrm{f}$ is $2.05 \mu \mathrm{mol} \mathrm{m}^{-2} \mathrm{~s}^{-1}$ ). 


\section{Results and Discussion}

In this section the energy components as estimated over the study region are analysed with respect to the changes in the LULC classes, specifically over BA and DL possessing the higher LST. Additionally, the mean of the energy balance components during the study period are analysed over the DL, BA and the vegetated areas. The proportional sharing of the net radiation flux in heat fluxes are estimated for each case and are compared with the earlier studies. In our earlier studies (Sultana and Satyanarayana, 2018, 2020) the cities under consideration are classified in to 5 LULC classes; water bodies (WB), built up areas (BA), dry lands (DL), crop/grass land (CGL) and dense vegetation (DV). The methodology for the classification, variation in the LULC classes and the accuracy assessment of these classes are also discussed in detail. The LST pattern and the UHI intensities in relation to the variation in LULC classes over the cities considered for the present study are also analysed.

\subsection{Estimated surface energy components}

During the study it is noticed that the net radiation flux and the latent heat flux (LHF) over the BA and the DL are comparatively lower than the vegetated areas and the water bodies have the highest values. On the other hand, the sensible heat flux (SHF) is observed to be higher over the BA and DL in comparison to the vegetation and the water bodies possess lowest SHF values (small positive or negative). As the present study focuses on the high LST possessing BA and DL, in this section the analysis is conducted over these LULC classes only and hence the Figures $2-12$ depict the energy balance components only over the DL and the BA and the portions over the vegetated areas and the water bodies are removed. 


\section{Kolkata}

Net Radiation Flux: The spatial distributions of the net radiation flux during the study period for BA and the DL are shown in Figure 2a. The figure indicates that the lower values of net radiation flux are observed over the DL and fallow lands in comparison to the BA. The ranges over the DL are $411.2-460 \mathrm{Wm}^{-2}, 407.4-465 \mathrm{Wm}^{-2}, 428.4-475 \mathrm{Wm}^{-2}$ and $438.4-495 \mathrm{Wm}^{-2}$ for the years 2002, 2007, 2012 and 2017 respectively whereas the ranges for BA are $445.1-495 \mathrm{Wm}^{-2}, 450.1$ $-530 \mathrm{Wm}^{-2}, 460.1-510 \mathrm{Wm}^{-2}$ and $480.1-530 \mathrm{Wm}^{-2}$ for the same years. It can be noticed in the Fig. 2a that more patches of higher values of net radiation flux appear over the outer regions of the BA due to appearance of DL in the later part of study period.

Sensible heat flux: The spatial distribution for sensible heat flux over the BA and the DL are depicted in Fig. 2b for the study period. The SHF over the central BA is observed to be highest followed by the DL and the fallow lands in the outer regions. The ranges of SHF over DL are $75.1-105 \mathrm{Wm}^{-2}, 75.1-110 \mathrm{Wm}^{-2}, 85.1-120 \mathrm{Wm}^{-2}$ and 85.1 - $120 \mathrm{Wm}^{-2}$ during 2002, 2007, 2012 and 2017 respectively. The values of SHF over BA ranged $95.1-125.2 \mathrm{Wm}^{-2}, 100.1-$ 138.4 $\mathrm{Wm}^{-2}, 110.1-166.3 \mathrm{Wm}^{-2}$ and $110.1-154.2 \mathrm{Wm}^{-2}$ respectively during the study period.

Latent heat flux: The Fig. $2 \mathrm{c}$ shows the spatial distribution of the LHF over the BA and the DL for the study period. The central BA shows the lowest range of values (blue shades) and the DL noticed have comparatively higher values (brown shades). The value of LHF over BA is observed to be $30 \mathrm{Wm}^{-2}$ or less during the study period due to artificial surfaces lack moisture content. The ranges over the DL during the study period are around $20.1-45 \mathrm{Wm}^{-2}, 20.1-45$ $W m^{-2}, 25.1-45 W^{-2}$ and $20.1-40 W^{-2}$.

Residual heat flux: The Fig. 2d shows the spatial distribution of the residual heat flux over BA and the DL and the ranges over these regions are noticed to be lower in comparison to the other 
LULC classes (vegetation and water bodies). The values are noticed to be higher in the outer region of the BA during the later part of the study period due to presence of the DL.

\section{Visakhapatnam}

Net Radiation Flux: The Fig. 3a depicts spatial distributions of the net radiation flux during the study period for BA and the DL over Visakhapatnam. The lower values are mostly noticed over the DL, the ranges during the study period being $374.3-440 \mathrm{Wm}^{-2}, 382.3-450 \mathrm{Wm}^{-2}, 386.7-$ $440 \mathrm{Wm}^{-2}$ and $391.6-450 \mathrm{Wm}^{-2}$. The ranges over the BA are little higher in comparison to the DL, which are $425.1-470 \mathrm{Wm}^{-2}, 435.1-485 \mathrm{Wm}^{-2}, 425.1-475 \mathrm{Wm}^{-2}$ and $440.1-490 \mathrm{Wm}^{-2}$ for year 2001, 2008, 2012 and 2017 respectively.

Sensible heat flux: The spatial distribution for sensible heat flux over the BA and the DL are depicted in Fig. $3 b$ for the study period. The highest values of SHF are noticed over the DL whereas the values over BA are comparatively lower. The ranges of SHF over DL are $90.1-$ 135.4 $\mathrm{Wm}^{-2}, 100.1-146.1 \mathrm{Wm}^{-2}, 105.1-164.5 \mathrm{Wm}^{-2}$ and $110.1-156.2 \mathrm{Wm}^{-2}$ during 2001, 2008, 2012 and 2017 respectively and the ranges of SHF over the BA are $40.1-100 \mathrm{Wm}^{-2}, 80.1-110$ $\mathrm{Wm}^{-2}, 85.1-115 \mathrm{Wm}^{-2}$ and $90.1-115 \mathrm{Wm}^{-2}$ respectively during the same years.

Latent heat flux: The Figure 3c shows the spatial distribution of the LHF over the BA and the DL over Visakhapatnam. The LHF over the DL are observed to be low in comparison to the BA. The ranges of LHF over DL are $5.1-30 \mathrm{Wm}^{-2}, 3.4-25 \mathrm{Wm}^{-2}, 2.9-25 \mathrm{Wm}^{-2}$ and $2.1-20 \mathrm{Wm}^{-2}$ during 2001, 2008, 2012 and 2017 respectively. The ranges over the BA during the study period are $25.1-55 \mathrm{Wm}^{-2}, 20.1-50 \mathrm{Wm}^{-2}, 20.1-45 \mathrm{Wm}^{-2}$ and $15.1-45 \mathrm{Wm}^{-2}$.

Residual heat flux: The Figure 3d depicts the spatial distribution of the residual heat flux over BA and the DL. The ranges of residual heat over the DL are observed to be lower than that of BA and the ranges over water and vegetation are higher than both the BA and DL ranges. 


\section{Mumbai}

Net radiation flux: Figure 4a shows the spatial distribution of net radiation flux over BA and DL of Mumbai. The dry barren lands, sandy region and pavements are observed to possess lower range of values (blue shades). The ranges for DL are $437.3-470 \mathrm{Wm}^{-2}, 439.1-480 \mathrm{Wm}^{-2}, 446.3$ $-485 \mathrm{Wm}^{-2}$ and $472.5-520 \mathrm{Wm}^{-2}$ for year 2002, 2008, 2012 and 2018 respectively. The ranges over BA are $460.1-500 \mathrm{Wm}^{-2}, 470.1-505 \mathrm{Wm}^{-2}, 475.1-510 \mathrm{Wm}^{-2}$ and $510.1-545 \mathrm{Wm}^{-}$ ${ }^{2}$ (yellow and brown shades) during the study period and are little higher than the DL.

Sensible heat flux: The spatial distribution for the SHF over Mumbai for BA and DL are depicted in Fig. 4b. In the figure the DL, sandy areas, pavements and the dense BA are noticed to possess highest SHF values (yellow and brown shades), the ranges being $120.1-158.3 \mathrm{Wm}^{-2}$, $120.1-163.7 \mathrm{Wm}^{-2}, 125.1-168.4 \mathrm{Wm}^{-2}$ and $140.1-180.7 \mathrm{Wm}^{-2}$ during the study period. The less dense BA, open lands with slight vegetation and regions close to water body (western boundary) possess lower ranges $80.1-130 \mathrm{Wm}^{-2}, 85.1-130 \mathrm{Wm}^{-2}, 90.1-135 \mathrm{Wm}^{-2}$ and $100.1-$ $150 \mathrm{Wm}^{-2}$ during 2002, 2008, 2012 and 2018 respectively (blue shades).

Latent heat flux: The spatial distribution of LHF over BA and DL during the study period is depicted in Fig. 4c. The LHF over the city appears to be mostly uniform except for some exceptions. The dry lands and the pavements are noticed to have lowest range of values less than $60 \mathrm{Wm}^{-2}$ during the study period whereas BA has little higher values of ranges $55.1-95 \mathrm{Wm}^{-2}$, $50.1-85 \mathrm{Wm}^{-2}, 40.1-80 \mathrm{Wm}^{-2}$ and $35.1-80 \mathrm{Wm}^{-2}$ during 2002, 2008, 2012 and 2018 respectively.

Residual heat flux: Figure 4d shows the spatial distribution of the residual heat flux over BA and the DL and the ranges over these regions are noticed to be lower, where the DL has lowest range of values followed by moderate values over the BA. 


\section{Kochi}

Net radiation flux: The spatial distribution of net radiation flux over BA and DL for Kochi is shown in Fig. 5a. The lowest range of net radiation is observed over the BA but the DL and fallow lands are noticed to have comparatively higher values. The ranges over the BA during 2002, 2007, 2013 and 2018 are $368.8-415 \mathrm{Wm}^{-2}, 358.4-415 \mathrm{Wm}^{-2}, 381.9-435 \mathrm{Wm}^{-2}$ and $382.4-440 \mathrm{Wm}^{-2}$ respectively. The DL observed to have the net radiation flux ranges $405.1-$ $445 \mathrm{Wm}^{-2}, 405.1-450 \mathrm{Wm}^{-2}, 425.1-465 \mathrm{Wm}^{-2}$ and $430.1-470 \mathrm{Wm}^{-2}$ for the years 2002,2007 , 2013 and 2018 respectively. The regions close to the water bodies are noticed to possess higher values.

Sensible heat flux: The spatial variation in the SHF over BA and DL is shown in the Fig. 5b. The highest values of the SHF are observed over the dense BA followed by the DL. The higher range of values is noticed to be more prominent during the later part of the study period indicate the increase in impermeability. The ranges of SHF over BA are $90.1-132.9 \mathrm{Wm}^{-2}, 100.1-139.9$ $W^{-2}, 105.1-145.4 W^{-2}$ and $110.1-154.6 W^{-2}$ for the years 2002, 2007, 2013 and 2018 respectively and the ranges over DL are $70.1-100 \mathrm{Wm}^{-2}, 75.1-110 \mathrm{Wm}^{-2}, 80.1-115 \mathrm{Wm}^{-2}$ and $80.1-120 \mathrm{Wm}^{-2}$ respectively for the same years.

Latent heat flux: Figure 5c depicts spatial distribution of LHF over BA and DL during the study period for Kochi. The BA observed to possess lowest values of LHF ranging $3.4-30 \mathrm{Wm}^{-2}, 1.6$ $-30 \mathrm{Wm}^{-2}, 2.7-25 \mathrm{Wm}^{-2}$ and $5.7-20 \mathrm{Wm}^{-2}$ for the year 2002, 2007, 2013 and 2018 respectively. The LHF over the DL and the open lands close to the water bodies have comparatively higher values ranging $25.1-60 \mathrm{Wm}^{-2}, 25.1-55 \mathrm{Wm}^{-2}, 20.1-50 \mathrm{Wm}^{-2}$ and $15.1-45 \mathrm{Wm}^{-2}$ respectively for the study period. 
Residual heat flux: Figure 5d shows the spatial distribution of the residual heat flux over BA and the DL for Kochi during the study period. The BA noticed to possess the lowest values of residual flux followed by the DL with moderate values.

\section{Delhi}

Net radiation flux: The spatial distribution of net radiation flux for Delhi over BA and DL is shown in Fig.6a. The DL have the lowest range of values $\left(284.9-325 \mathrm{Wm}^{-2}, 297.4-335 \mathrm{Wm}^{-2}\right.$, $317.3-370 \mathrm{Wm}^{-2}$ and $334.7-375 \mathrm{Wm}^{-2}$ ) during the study period. The BA has the moderate ranges of values (yellow shades) with zones of little higher values (brown shades) close to the water bodies or the vegetated areas. The ranges of net radiation flux over BA during the study period are $310.1-350 \mathrm{Wm}^{-2}, 320.1-365 \mathrm{Wm}^{-2}, 355.1-395 \mathrm{Wm}^{-2}$ and $365.1-405 \mathrm{Wm}^{-2}$.

Sensible heat flux: The spatial variation in the SHF over BA and DL is depicted in the Fig. $6 \mathrm{~b}$. The highest range of SHF values is noticed over the DL and the dense BA with lower values (blue shades) over the build up regions close to the water body and/or vegetation. During the years 2002, 2007, 2013 and 2017 the ranges over the DL and dense BA are $95.1-138.3 \mathrm{Wm}^{-2}$, $110.1-146.3 \mathrm{Wm}^{-2}, 125.1-161.4 \mathrm{Wm}^{-2}$ and $130.1-179.3 \mathrm{Wm}^{-2}$ respectively. The sparse BA noticed to have the ranges $65.1-105 \mathrm{Wm}^{-2}, 80.1-120 \mathrm{Wm}^{-2}, 85.1-135 \mathrm{Wm}^{-2}$ and $90.1-140$ $W m^{-2}$ respectively during the study period.

Latent heat flux: The spatial distribution of LHF over the BA and DL of Delhi is shown in Fig. 6c. The LHF values over the BA are ranged as $25.1-50 \mathrm{Wm}^{-2}, 20.1-40 \mathrm{Wm}^{-2}, 25.1-40 \mathrm{Wm}^{-}$ ${ }^{2}$ and $20.1-40 \mathrm{Wm}^{-2}$ during the study period. The zones of higher ranges are noticed increasing during the study period. The DL and the fallow lands over the outer edge of the BA are noticed to possess the lowest values $\left(\leq 35 \mathrm{Wm}^{-2}\right)$ during the study period. 
Residual heat flux: The DL and BA are noticed to store lesser residual heat in comparison to vegetated areas and water bodies during the study period. The residual heat flux over the DL is noticed to be lower than the BA in case of Delhi as shown in Fig. $6 \mathrm{~d}$.

\section{Chandigarh}

Net Radiation flux: The spatial distribution of net radiation flux for Chandigarh over BA and DL is depicted in Figure 7a. The figure indicates that the lowest range of values of net radiation flux is mostly over the DL, pavements and fallow lands (blue shades). The ranges over these areas are $229.5-275 \mathrm{Wm}^{-2}, 236.4-280 \mathrm{Wm}^{-2}, 247.6-285 \mathrm{Wm}^{-2}, 261.1-295 \mathrm{Wm}^{-2}$ and $276.1-$ $305 \mathrm{Wm}^{-2}$ during 2000, 2005, 2010, 2013 and 2018 respectively. The BA noticed to possess relatively higher ranges $265.1-300 \mathrm{Wm}^{-2}, 270.1-310 \mathrm{Wm}^{-2}, 285.1-325 \mathrm{Wm}^{-2}, 285.1-325$ $W m^{-2}$ and $295.1-335 W^{-2}$ during the study period.

Sensible heat flux: Figure 7b shows the spatial distribution of the SHF over the BA and the DL of Chandigarh city. The highest range of values is observed over the dense BA, pavements and DL. The ranges of SHF over these regions are $110.1-148.9 \mathrm{Wm}^{-2}, 115.1-155.5 \mathrm{Wm}^{-2}, 120.1-$ 159.2 $\mathrm{Wm}^{-2}, 125.1-164.3 \mathrm{Wm}^{-2}$ and $125.1-165.5 \mathrm{Wm}^{-2}$ for the years 2000, 2005, 2010, 2013 and 2018 respectively. The build-up regions possess moderate values with patches of lower values (blue shades) and the ranges are80.1 $120 \mathrm{Wm}^{-2}, 85.1-125 \mathrm{Wm}^{-2}, 90.1-130 \mathrm{Wm}^{-2}, 90.1$ $-135 \mathrm{Wm}^{-2}$ and $95.1-135 \mathrm{Wm}^{-2}$ during the years 2000, 2005, 2010, 2013 and 2018 respectively.

Latent heat flux: The spatial distribution of LHF over the BA and DL is shown in Fig. 7c. The figure indicates that the DL, industrial areas and the pavements possess very low range of LHF values. For the years 2000, 2005, 2010, 2013 and 2018 the ranges over these areas are $4.3-30$ $\mathrm{Wm}^{-2}, 3.1-25 \mathrm{Wm}^{-2}, 1.4-25 \mathrm{Wm}^{-2}, 2.4-20 \mathrm{Wm}^{-2}$ and $2.2-20 \mathrm{Wm}^{-2}$ respectively. The BA 
noticed to possess comparatively higher values in the ranges of $25.1-55 \mathrm{Wm}^{-2}, 20.1-50 \mathrm{Wm}^{-2}$, $20.1-45 \mathrm{Wm}^{-2}, 15.1-45 \mathrm{Wm}^{-2}$ and $15.1-40 \mathrm{Wm}^{-2}$ respectively during the study years.

Residual heat flux: The spatial distribution of the residual heat flux over the BA and the DL are depicted in the Fig.7d. The values of residual heat flux over the BA and the DL are noticed to be lower and the DL and the industrial areas have the lowest range of values.

\section{Jaipur}

Net radiation flux: Figure 8a shows the spatial distribution of net radiation flux over BA and DL of Jaipur. The dry barren lands, sandy-rocky region and fallow lands in the outer region are noticed to possess lower range of values. The ranges of net radiation over these regions are 323.4 - $385 \mathrm{Wm}^{-2}, 332.2-390 \mathrm{Wm}^{-2}, 353.8-400 \mathrm{Wm}^{-2}$ and $363.7-410 \mathrm{Wm}^{-2}$ for year 2002,2007 , 2012 and 2017 respectively. The ranges over the central BA are $370.1-405 \mathrm{Wm}^{-2}, 380.1-415$ $W^{-2}, 385.1-420 \mathrm{Wm}^{-2}$ and $395.1-445 \mathrm{Wm}^{-2}$ during the study period, are comparatively higher than the ranges over the DL.

Sensible heat flux: The spatial distribution for the SHF over BA and DL are depicted in Fig.8b. The DL, sandy-rocky areas and fallow lands are noticed to possess highest SHF values, the ranges being $110.1-176.6 \mathrm{Wm}^{-2}, 120.1-183.1 \mathrm{Wm}^{-2}, 120.1-186.3 \mathrm{Wm}^{-2}$ and $125.1-197.2$ $W m^{-2}$ during the study period. The ranges of SHF over the BA are $85.1-120 \mathrm{Wm}^{-2}, 90.1-130$ $\mathrm{Wm}^{-2}, 95.1-130 \mathrm{Wm}^{-2}$ and $100.1-135 \mathrm{Wm}^{-2}$, are little lower than that of the DL.

Latent heat flux: The spatial distribution of LHF over BA and DL during the study period is depicted in Fig. 8c. The DL and the fallow lands have lowest range of values $8.1-30 \mathrm{Wm}^{-2}, 4.3-$ $25 \mathrm{Wm}^{-2}, 3.4-20 \mathrm{Wm}^{-2}$ and $5.4-20 \mathrm{Wm}^{-2}$ during the study period. The BA in the central part of the city possess little higher values of ranges $25.1-55 \mathrm{Wm}^{-2}, 20.1-55 \mathrm{Wm}^{-2}, 15.1-50 \mathrm{Wm}^{-2}$ and $15.1-45 \mathrm{Wm}^{-2}$ during 2002, 2007, 2012 and 2017 respectively. 
Residual heat flux: Figure 8d shows the spatial distribution of the residual heat flux over BA and the DL for Jaipur and the ranges over these regions are noticed to be lower with respect to vegetation and water bodies. The DL and the fallow lands possess lowest range of values followed by moderate to higher values over the BA.

\section{Lucknow}

Net Radiation flux: The spatial distribution of net radiation flux for Lucknow over BA and DL is depicted in Fig. 9a. The figure indicates that the lowest range of values of net radiation flux is mostly over the DL, pavements and fallow lands (blue shades). The net radiation flux ranges during the study period are $327.7-370 \mathrm{Wm}^{-2}, 354.6-405 \mathrm{Wm}^{-2}, 362.4-425 \mathrm{Wm}^{-2}$ and $389.8-$ $430 \mathrm{Wm}^{-2}$. The central BA noticed to possess relatively higher values of range $370.1-415 \mathrm{Wm}^{-2}$, $405.1-440 \mathrm{Wm}^{-2}, 425.1-465 \mathrm{Wm}^{-2}$ and $430.1-470 \mathrm{Wm}^{-2}$ during 2002, 2007, 2012 and 2017 respectively.

Sensible heat flux: Figure 9b shows the spatial distribution of the SHF over the BA and the DL of Lucknow. The highest range of values is observed over the dense BA, fallow lands and DL in the outer part of the city. The ranges of SHF over these areas are $115.1-167.2 \mathrm{Wm}^{-2}, 120.1-$ 178.1 $\mathrm{Wm}^{-2}, 125.1-169.2 \mathrm{Wm}^{-2}$ and $130.1-184.9 \mathrm{Wm}^{-2}$ for the years 2002, 2007, 2012 and 2017 respectively. The sparse build up regions are observed to have comparatively lower values of the range $85.1-125 \mathrm{Wm}^{-2}, 90.1-130 \mathrm{Wm}^{-2}, 95.1-135 \mathrm{Wm}^{-2}$ and $95.1-140 \mathrm{Wm}^{-2}$ for the years 2002, 2007, 2012 and 2017 respectively.

Latent heat flux: The spatial distribution of LHF over the BA and DL is shown in Fig. 9c. The figure shows that the DL and the fallow lands possess very low range of LHF values (blue shades). For the years 2002, 2007, 2012, and 2017 the ranges over these areas are $1.2-30 \mathrm{Wm}^{-2}$, $1.7-25 \mathrm{Wm}^{-2}, 2.3-20 \mathrm{Wm}^{-2}$ and $4.9-15 \mathrm{Wm}^{-2}$ respectively. The BA noticed to possess 
moderate values with comparatively higher values over sparse BA close to vegetation and water bodies. The ranges of LHF over BA are observed to be $30.1-60 \mathrm{Wm}^{-2}, 25.1-60 \mathrm{Wm}^{-2}, 20.1-$ $55 \mathrm{Wm}^{-2}$ and $15.1-55 \mathrm{Wm}^{-2}$ during the years 2002, 2007, 2012 and 2017 respectively.

Residual heat flux: The spatial distribution of the residual heat flux over the BA and the DL are depicted in the Fig. 9d. The values of residual heat flux over the BA noticed to be moderate and the DL and the fallow lands have the lowest range of values. The higher values are noticed over the vegetated areas and the water bodies have the highest values.

\section{Nagpur}

Net Radiation flux: The spatial distribution of net radiation flux over the BA and the DL of Nagpur are shown in Fig. 10a. The DL in the outer region of the city are noticed to have lowest ranges of values, $325.1-380 \mathrm{Wm}^{-2}, 334.6-385 \mathrm{Wm}^{-2}, 330.2-390 \mathrm{Wm}^{-2}$ and $351.7-405 \mathrm{Wm}^{-2}$ during the 2002, 2007, 2013 and 2018 respectively. The central BA have comparatively higher values of $370.1-405 \mathrm{Wm}^{-2}, 375.1-410 \mathrm{Wm}^{-2}, 380.1-415 \mathrm{Wm}^{-2}$ and $395.1-435 \mathrm{Wm}^{-2}$ for the duration of the study period. The higher value zones are noticed to be increasing indicating spread of impervious surfaces.

Sensible heat flux: Figure 10b shows the spatial distribution of the SHF over the BA and the DL of Nagpur city. The DL possess the highest range of values, $95.1-148.2 \mathrm{Wm}^{-2}, 100.1-147.3$ $W m^{-2}, 105.1-155.9 W^{-2}$ and $110.1-166.2 W^{-2}$ for the years 2002, 2007, 2013 and 2018 respectively. The values of SHF over BA are of comparatively lower range, $65.1-105 \mathrm{Wm}^{-2}$, $65.1-110 \mathrm{Wm}^{-2}, 75.1-115 \mathrm{Wm}^{-2}$ and $80.1-120 \mathrm{Wm}^{-2}$ for the study period. The low values (blue shades) over the BA are observed to be replaced by high range zones (yellow and brown) during the study period indicate increase in imperviousness. 
Latent heat flux: The spatial distribution for the LHF over the BA and the DL of Nagpur are shown in the Fig. 10c. The DL and the fallow lands are observed to have lowest range of LHF values less than $25 \mathrm{Wm}^{-2}$ during the study period whereas for BA the ranges are $20.1-45 \mathrm{Wm}^{-2}$, $20.1-40 \mathrm{Wm}^{-2}, 20.1-35 \mathrm{Wm}^{-2}$ and $15.1-35 \mathrm{Wm}^{-2}$ for the years 2002, 2007, 2013 and 2018 respectively. The high-value zones over the BA are noticed to be disappearing during the study period indicates gradual loss of moisture content in the surface.

Residual heat flux: The spatial distribution of the residual heat flux over BA and the DL of Nagpur are depicted in the Fig. 10d. The values of residual heat flux over the BA and the DL are lower in comparison to that of the vegetation and the water bodies with DL having the lowest range of values.

\section{Hyderabad}

Net radiation flux: The spatial distribution of net radiation flux over BA and DL for Hyderabad is shown in Fig. 11a. The lowest range of net radiation is observed over the DL and fallow lands and the BA noticed to have comparatively higher values. The ranges over the DL during 2002, 2007, 2012 and 2017 are $371.3-425 \mathrm{Wm}^{-2}, 365.8-420 \mathrm{Wm}^{-2}, 367.2-420 \mathrm{Wm}^{-2}$ and $384.3-$ $430 \mathrm{Wm}^{-2}$ respectively. The ranges over BA observed to be $410.1-450 \mathrm{Wm}^{-2}, 405.1-445 \mathrm{Wm}^{-2}$, $410.1-455 \mathrm{Wm}^{-2}$ and $420.1-455 \mathrm{Wm}^{-2}$ for the years 2002, 2007, 2012 and 2017 respectively.

Sensible heat flux: The spatial variation in the SHF over the BA and the DL are shown in the Fig. 11b for Hyderabad. The highest values of the SHF are observed over the dense BA followed by the DL. The ranges of SHF over BA are $115.1-183.3 \mathrm{Wm}^{-2}, 120.1-190.5 \mathrm{Wm}^{-2}, 125.1-$ $187.7 \mathrm{Wm}^{-2}$ and $130.1-192.7 \mathrm{Wm}^{-2}$ for the years $2002,2007,2012$ and 2017 respectively and the ranges over the DL are $85.1-125 \mathrm{Wm}^{-2}, 90.1-130 \mathrm{Wm}^{-2}, 95.1-135 \mathrm{Wm}^{-2}$ and $100.1-140$ 
$W m^{-2}$ respectively for the same years. The patches of higher values over the BA are noticed to be increased due to increase and spread in imperviousness.

Latent heat flux: The Figure 11c depicts spatial distribution of LHF over BA and DL during the study period. The BA observed to possessing lowest values of LHF ranging $5.5-40 \mathrm{Wm}^{-2}, 6.3-$ $35 \mathrm{Wm}^{-2}, 2.8-30 \mathrm{Wm}^{-2}$ and $3.6-25 \mathrm{Wm}^{-2}$ for the year 2002, 2007, 2012 and 2017 respectively. The LHF over DL have comparatively higher values ranging $30.1-70 \mathrm{Wm}^{-2}, 25.1-70 \mathrm{Wm}^{-2}$, $25.1-65 \mathrm{Wm}^{-2}$ and $20.1-60 \mathrm{Wm}^{-2}$ respectively for the same years. The lower valuezones over the BA are noticed be spreading and can be attributed to the continuous loss of moisture content natural surfaces.

Residual heat flux: The Figure 11 (d) shows the spatial distribution of the residual heat flux over BA and the DL for Hyderabad during the study period. The DL noticed to possess the lowest values of residual flux followed by the BA with moderate values which are much lower than that of the vegetated and the water bodies.

\section{Bengaluru}

Net radiation flux: The spatial distribution of the net radiation flux over the BA and DL are shown in the Fig.12a. The DL observed to possess lowest values of the ranges $418.3-460 \mathrm{Wm}^{-2}$, $408.6-470 \mathrm{Wm}^{-2}, 423.1-465 \mathrm{Wm}^{-2}$ and $428.4-475 \mathrm{Wm}^{-2}$ whereas the central BA possess comparatively higher range of values, $450.1-490 \mathrm{Wm}^{-2}, 460.1-495 \mathrm{Wm}^{-2}, 455.1-510 \mathrm{Wm}^{-2}$ and $465.1-505 \mathrm{Wm}^{-2}$ during the years 2002, 2008, 2013 and 2018 respectively.

Sensible heat flux: The spatial distribution of SHF over the BA and the DL of Bengaluru are shown in Fig. 12b. The DL and the fallow lands are noticed to possess highest ranges of values, $120.1-177.5 \mathrm{Wm}^{-2}, 130.1-184.7 \mathrm{Wm}^{-2}, 140.1-192.5 \mathrm{Wm}^{-2}$ and $140.1-185.2 \mathrm{Wm}^{-2}$ during the 
study period. The central BA observed to have slightly lower range of values $95.1-130 \mathrm{Wm}^{-2}$, $100.1-140 \mathrm{Wm}^{-2}, 110.1-150 \mathrm{Wm}^{-2}$ and $115.1-150 \mathrm{Wm}^{-2}$ during this period.

Latent heat flux: The spatial distribution for LHF over BA and DL are depicted in the Fig. 12c. The LHF values over the DL and the fallow land during the study period are noticed to be as low as $25 \mathrm{Wm}^{-2}$ or less. The ranges over the BA are observed to be slightly higher than DL. During the study period the ranges over the BA are $20.1-55 \mathrm{Wm}^{-2}, 15.1-50 \mathrm{Wm}^{-2}, 15.1-45 \mathrm{Wm}^{-2}$ and $15.1-40 \mathrm{Wm}^{-2}$

Residual heat flux: The values of residual heat flux over the DL patches are lowest and the central BA have slightly high values as shown in Fig. 12d which are much lower than the values over the vegetated and the water bodies.

The energy components estimated for the study regions indicate that the ranges of these components are in agreement with the results of the earlier studies. The Net radiation flux during the study period over the cities for BA and DL are ranged around $200-550 \mathrm{Wm}^{-2}$ agrees with values obtained by Offerle et al., (2005); Hanna et al. (2011), Templeton et al. (2018) and Chrysoulakis et al. (2018). The ranges of the SHF and LHF in the present study are around 50 $200 \mathrm{Wm}^{-2}$ and $0-100 \mathrm{Wm}^{-2}$ respectively for BA and/or DL, these ranges are in well agreement with the results obtained by Offerle et al., (2005); Kato and Yamaguchi (2005 and 2007) and Chrysoulakis et al. (2018).

\subsection{Variation in surface energy component over different LULC classes}

During the study period the artificial surface (build up areas) over the study regions are noticed to be increased significantly (Sultana and Satyanarayana, 2018, 2020). The surface heat fluxes are therefore noticed to vary considerably during this period. In this section the mean net radiation flux $\left(\mathrm{Q}^{*}\right)$, the mean $\operatorname{SHF}\left(\mathrm{Q}_{\mathrm{H}}\right)$, the mean $\mathrm{LHF}\left(\mathrm{Q}_{\mathrm{E}}\right)$ and mean residual heat flux $\left(\mathrm{Q}_{\mathrm{R}}\right)$ 
with respect to different LULC classes such as BA, DL and vegetation over the cities under consideration are discussed. The variations in the mean values of the energy components; $\Delta \mathrm{Q}^{*}$, $\Delta \mathrm{Q}_{\mathrm{H}}$ and $\Delta \mathrm{Q}_{\mathrm{E}}$ during the study period for these cities are tabulated in Table 3 . The $\Delta \mathrm{Q}^{*}$ and $\Delta \mathrm{Q}_{\mathrm{H}}$ are notice to be positive whereas the $\Delta \mathrm{Q}_{\mathrm{E}}$ is found to be negative for all the study regions.

\section{Kolkata}

Figure 13a depicts the variation in the mean of the energy components during the study period with respect to different LULC classes (BA, DL and vegetation) of Kolkata. The $\mathrm{Q}^{*}$ over BA (DL) is observed to be $459.1 \mathrm{Wm}^{-2}\left(426.5 \mathrm{Wm}^{-2}\right)$ in 2002 which increased by $57.7 \mathrm{Wm}^{-2}(47.1$ $\mathrm{Wm}^{-2}$ ) to $516.8 \mathrm{Wm}^{-2}\left(473.6 \mathrm{Wm}^{-2}\right)$ in 2017 . For vegetation the value increases from $509.5 \mathrm{Wm}^{-2}$ in 2002 to $554.0 \mathrm{Wm}^{-2}$ in 2017 and the increase in $\mathrm{Q}^{*}$ is found to be $44.5 \mathrm{Wm}^{-2}$ during this period. In 2002 the $\mathrm{QH}_{\mathrm{H}}$ over BA (DL) was $112.3 \mathrm{Wm}^{-2}\left(89.3 \mathrm{Wm}^{-2}\right)$ and is increased to $136.7 \mathrm{Wm}^{-2}$ (103.4 $\left.W^{-2}\right)$ in 2017 . The $\mathrm{Q}_{\mathrm{H}}$ is noticed to be increased by $24.4 \mathrm{Wm}^{-2}\left(14.1 \mathrm{Wm}^{-2}\right)$ for BA (DL) during the study period. In the vegetated area the values are increased from $46.5 \mathrm{Wm}^{-2}$ to $50.8 \mathrm{Wm}^{-}$ ${ }^{2}$ during $2002-2017$; hence the $\Delta \mathrm{Q}_{\mathrm{H}}$ is $4.3 \mathrm{Wm}^{-2}$ for this LULC class. The $\mathrm{Q}_{\mathrm{E}}$ over BA (DL) was 13.7 $\mathrm{Wm}^{-2}\left(34.6 \mathrm{Wm}^{-2}\right)$ in 2002, and decreased to $9.7 \mathrm{Wm}^{-2}\left(31.4 \mathrm{Wm}^{-2}\right)$ in 2017. Over vegetated area the QE noticed to slightly decreasing from $74.9 \mathrm{Wm}^{-2}$ to $73.3 \mathrm{Wm}^{-2}$ during the study period. The $\Delta \mathrm{Q}_{\mathrm{E}}$ over BA, DL and vegetation are $-3.2 \mathrm{Wm}^{-2},-4.0 \mathrm{Wm}^{-2}$ and $-1.6 \mathrm{Wm}^{-2}$ respectively for the study period.

\section{Visakhapatnam}

The mean of the energy components with respect to different LULC classes (BA, DL and vegetation) over Visakhapatnam is depicted in Fig. 13b for the study period. The Q* over BA (DL) in 2001 is $452.8 \mathrm{Wm}^{-2}\left(406.5 \mathrm{Wm}^{-2}\right)$ and in 2017 it increased to $474.8 \mathrm{Wm}^{-2}\left(426.2 \mathrm{Wm}^{-2}\right)$.

Over vegetated area the mean net radiation flux increased from $505.1 \mathrm{Wm}^{-2}$ to $526.6 \mathrm{Wm}^{-2} \mathrm{during}$ 
$2001-2017$. The overall increase for the duration of $2001-2017$ is $22.0 \mathrm{Wm}^{-2}, 19.7 \mathrm{Wm}^{-2}$ and 21.5 for BA, DL and vegetation respectively. The $\mathrm{Q}_{\mathrm{H}}$ during $2001-2017$ increased from 86.1 $\mathrm{Wm}^{-2}\left(117.6 \mathrm{Wm}^{-2}\right)$ to $104.9 \mathrm{Wm}^{-2}\left(136.2 \mathrm{Wm}^{-2}\right)$ over BA (DL). In vegetated area the values increased from $41.9 \mathrm{Wm}^{-2}$ to $58.2 \mathrm{Wm}^{-2}$ during $2001-2017$. The $\Delta \mathrm{Q}_{\mathrm{H}}$ over BA, DL and vegetation are $18.8 \mathrm{Wm}^{-2}, 18.6 \mathrm{Wm}^{-2}$ and $16.3 \mathrm{Wm}^{-2}$ respectively for the study period. During the study period the QE observed to be decreasing from $39.4 \mathrm{Wm}^{-2}\left(17.3 \mathrm{Wm}^{-2}\right)$ to $29.1 \mathrm{Wm}^{-2}\left(9.6 \mathrm{Wm}^{-}\right.$

${ }^{2}$ ) over BA (DL). In the vegetated area the $\mathrm{Q}_{\mathrm{E}}$ decreases from $87.9 \mathrm{Wm}^{-2}$ to $74.2 \mathrm{Wm}^{-2}$. The variations in mean LHF, $\Delta \mathrm{Q}_{\mathrm{E}}$ during $2001-2017$ are noticed to be $-10.3 \mathrm{Wm}^{-2},-7.7 \mathrm{Wm}^{-2}$ and 13.7 $\mathrm{Wm}^{-2}$ for BA, DL and vegetation respectively. The $\mathrm{Q}_{\mathrm{R}}$ does not appear to be varied much during the study period.

\section{Mumbai}

From Fig.13c the mean net radiation flux over BA (DL) in 2002 is observed to be $483.7 \mathrm{Wm}^{-}$ ${ }^{2}\left(455.8 \mathrm{Wm}^{-2}\right)$ and in 2018 it increased to $529.8 \mathrm{Wm}^{-2}\left(497.3 \mathrm{Wm}^{-2}\right)$ whereas over the vegetation it increased from $524.1 \mathrm{Wm}^{-2}$ to $573.4 \mathrm{Wm}^{-2}$ during the same duration. The $\Delta \mathrm{Q}^{*}$ over BA, DL and vegetated areas of Mumbai for the duration of the study, $2002-2018$ are around $46.1 \mathrm{Wm}^{-2}, 41.5$ $\mathrm{Wm}^{-2}$ and $49.3 \mathrm{Wm}^{-2}$ respectively. The $\mathrm{Q}_{\mathrm{H}}$ during 2002 - 2018 noticed to increase from 140.9 $\mathrm{Wm}^{2}\left(104.4 \mathrm{Wm}^{-2}\right)$ to $163.9 \mathrm{Wm}^{-2}\left(124.3 \mathrm{Wm}^{-2}\right)$ over BA (DL); hence, the $\Delta \mathrm{QH}_{\text {H }}$ over the BA and DL are $23.0 \mathrm{Wm}^{-2}$ and $19.9 \mathrm{Wm}^{-2}$ respectively. In vegetated area the values increased from 48.2 $\mathrm{Wm}^{-2}$ to $64.8 \mathrm{Wm}^{-2}$, the $\Delta \mathrm{Q}_{\mathrm{H}}$ being $16.6 \mathrm{Wm}^{-2}$ during 2002 - 2018. During the study period the Qеover Mumbai observed to be decreasing from $77.2 \mathrm{Wm}^{-2}\left(39.4 \mathrm{Wm}^{-2}\right)$ to $63.7 \mathrm{Wm}^{-2}\left(25.7 \mathrm{Wm}^{-2}\right)$ for BA (DL). In the vegetated area the $\mathrm{Q}_{\mathrm{E}}$ decreased from $130.9 \mathrm{Wm}^{-2}$ to $121.2 \mathrm{Wm}^{-2}$. The $\Delta \mathrm{Q}_{\mathrm{E}}$ over the BA, DL and the vegetation are $-13.5 \mathrm{Wm}^{-2},-13.7 \mathrm{Wm}^{-2}$ and $-9.7 \mathrm{Wm}^{-2}$ respectively.

\section{Kochi}


Figure $13 \mathrm{~d}$ depicts the variation in the mean of the energy components during the study period with respect to LULC classes, BA, DL and vegetation of Kochi. The Q* over BA (DL) is observed to be $390.8 \mathrm{Wm}^{-2}\left(429.7 \mathrm{Wm}^{-2}\right)$ in 2002 which is increased by $15.9 \mathrm{Wm}^{-2}\left(19.5 \mathrm{Wm}^{-2}\right)$ to $406.7 \mathrm{Wm}^{-2}\left(449.2 \mathrm{Wm}^{-2}\right)$ in 2018 . For vegetation the value increases from $484.8 \mathrm{Wm}^{-2}$ in 2002 to 505.6 $\mathrm{Wm}^{-2}$ in 2018 . The $\Delta \mathrm{Q} *$ for the vegetated areas is $20.8 \mathrm{Wm}^{-2}$ for the study period. In 2002 the $\mathrm{Q}_{\text {н }}$ over BA (DL) was $113.6 \mathrm{Wm}^{-2}\left(83.1 \mathrm{Wm}^{-2}\right)$ and is increased to $133.1 \mathrm{Wm}^{-2}\left(97.2 \mathrm{Wm}^{-2}\right)$ in 2018. In the vegetated area the values are increased from $42.4 \mathrm{Wm}^{-2}$ to $51.9 \mathrm{Wm}^{-2}$ during $2002-$ 2018. The $\Delta \mathrm{Q}_{\mathrm{H}}$ over the $\mathrm{BA}$, DL and vegetation are observed to be $19.5 \mathrm{Wm}^{-2}, 14.1 \mathrm{Wm}^{-2}$ and 9.5 $W^{-2}$ respectively during the study period. The Q $\mathrm{E}_{\mathrm{E}} \mathrm{ever} \mathrm{BA}(\mathrm{DL})$ was $16.6 \mathrm{Wm}^{-2}\left(44.2 \mathrm{Wm}^{-2}\right)$ in 2002, and decreased to $11.4 \mathrm{Wm}^{-2}\left(33.4 \mathrm{Wm}^{-2}\right)$ in 2017. Over vegetated area the QEdecreased from $91.2 \mathrm{Wm}^{-2}$ to $79.2 \mathrm{Wm}^{-2}$ during the study period. The $\Delta \mathrm{Q}_{\mathrm{E}}$ during the study period is observed to be $-5.2 \mathrm{Wm}^{-2},-10.8 \mathrm{Wm}^{-2}$ and $-12.0 \mathrm{Wm}^{-2}$ over the BA, DL and the vegetation respectively.

\section{Delhi}

Figure 14a depicts the variation in the mean values of the energy components during the study period with respect to different LULC classes (BA, DL and vegetation) of Delhi. The Q* shows an increasing trend during $2002-2017$ for all the classes. For 2002 over BA (DL) the Q* value is $334.2 \mathrm{Wm}^{-2}\left(304.7 \mathrm{Wm}^{-2}\right)$ which increased to $388.4 \mathrm{Wm}^{-2}\left(350.7 \mathrm{Wm}^{-2}\right)$ in 2017. For vegetation the value increases from $385.9 \mathrm{Wm}^{-2}$ in 2002 to $440.5 \mathrm{Wm}^{-2}$ in 2017. The $\Delta \mathrm{Q}^{*}$ over the BA, DL and the vegetation for the study period are $54.2 \mathrm{Wm}^{-2}, 46.0 \mathrm{Wm}^{-2}$ and $54.6 \mathrm{Wm}^{-2}$ respectively. In 2002 the Qноver BA (DL) was $84.6 \mathrm{Wm}^{-2}\left(117.5 \mathrm{Wm}^{-2}\right)$ and is increased to $112.8 \mathrm{Wm}^{-2}(157.2$ $\mathrm{Wm}^{-2}$ ) in 2017. Over the vegetation the values are increased from $36.2 \mathrm{Wm}^{-2}$ to $51.4 \mathrm{Wm}^{-2}$ during 2002 - 2017. The $\Delta \mathrm{Q}_{\mathrm{H}}$ over the BA, DL and vegetation are observed to be $28.2 \mathrm{Wm}^{-2}, 39.7 \mathrm{Wm}^{-2}$ 
and 15.2 $\mathrm{Wm}^{-2}$ respectively for the study period. The QEOver the BA (DL) was $38.2 \mathrm{Wm}^{-2}(23.2$ $\left.W^{-2}\right)$ in 2002, and slightly decreased to $32.6 \mathrm{Wm}^{-2}\left(14.9 \mathrm{Wm}^{-2}\right)$ in 2017 . Over the vegetated area the QE showed small decrease from 79.5 $\mathrm{Wm}^{-2}$ to $70.5 \mathrm{Wm}^{-2}$ during the study period. During the study period the $\Delta \mathrm{Q}_{\mathrm{E}}$ over the BA, DL and the vegetated area found to be $-5.6 \mathrm{Wm}^{-2},-8.3 \mathrm{Wm}^{-2}$ and $-9.0 \mathrm{Wm}^{-2}$ respectively. The $\mathrm{Q}_{\mathrm{R}}$ observed to be increasing for all the LULC classes over Delhi.

\section{Chandigarh}

For Chandigarh, Fig. 14b depicts the variation in the mean values of the energy components during the study period with respect to different LULC classes (BA, DL and vegetation). The $\mathrm{Q}^{*}$ is noticed increased during $2000-2018$ for all the classes. For 2000 over BA (DL) the value is 287.3 $\mathrm{Wm}^{-2}\left(252.6 \mathrm{Wm}^{-2}\right)$ which increased to $319.2 \mathrm{Wm}^{-2}\left(290.4 \mathrm{Wm}^{-2}\right)$ in 2018. For vegetation the value increases from $331.5 \mathrm{Wm}^{-2}$ in 2000 to $366.5 \mathrm{Wm}^{-2}$ in 2018.The $\Delta \mathrm{Q}^{*}$ during the study period over the BA, DL and the vegetation are observed to be $31.9 \mathrm{Wm}^{-2}, 37.8 \mathrm{Wm}^{-2}$ and 35.0 $W^{-2}$ respectively. In 2000, the $\mathrm{Q}_{\mathrm{H}}$ over BA (DL) was $98.2 \mathrm{Wm}^{-2}\left(130.7 \mathrm{Wm}^{-2}\right)$ and is increased to 108.6 $\mathrm{Wm}^{-2}\left(145.2 \mathrm{Wm}^{-2}\right)$ in 2018 and over the vegetated area the value increased from $52.2 \mathrm{Wm}^{-}$ ${ }^{2}$ to $62.1 \mathrm{Wm}^{-2}$ during this period. The $\Delta \mathrm{Q}_{\mathrm{H}}$ found to be $10.4 \mathrm{Wm}^{-2}, 14.5 \mathrm{Wm}^{-2}$ and $9.9 \mathrm{Wm}^{-2}$ over BA, DL and vegetation respectively during the study period. The QE over BA (DL) was 43.7 $\mathrm{Wm}^{-2}\left(16.7 \mathrm{Wm}^{-2}\right)$ in 2000 , and decreased to $28.1 \mathrm{Wm}^{-2}\left(7.4 \mathrm{Wm}^{-2}\right)$ in 2018. Over vegetated area the $\mathrm{Q}_{\mathrm{E}}$ decreased from 83.9 $\mathrm{Wm}^{-2}$ to $72.1 \mathrm{Wm}^{-2}$ during the study period. The $\Delta \mathrm{Q}_{\mathrm{E}}$ during the study period over the BA, DL and vegetation are observed to be $-15.6 \mathrm{Wm}^{-2},-9.3 \mathrm{Wm}^{-2}$ and -11.8 $W m^{-2}$ respectively. The $\mathrm{Q}_{\mathrm{R}}$ does not appear to be increasing during the study period.

\section{Jaipur}


The mean of the energy components respect to different LULC classes (BA, DL and vegetation) is depicted in Fig. 14c for Jaipur for the study period. The Q* over BA (DL) in 2002 is 392.4 $\mathrm{Wm}^{-2}\left(352.7 \mathrm{Wm}^{-2}\right)$ and in 2017 it increased to $427.6 \mathrm{Wm}^{-2}\left(386.7 \mathrm{Wm}^{-2}\right)$. Over vegetated area the Q* increased from $438.9 \mathrm{Wm}^{-2}$ to $480.2 \mathrm{Wm}^{-2}$ during $2002-2017$. The $\Delta \mathrm{Q}^{*}$ over the BA, DL and vegetation are found to be $35.2 \mathrm{Wm}^{-2}, 34.0 \mathrm{Wm}^{-2}$ and $41.3 \mathrm{Wm}^{-2}$ respectively. The $\mathrm{Q}_{\mathrm{H}}$ during 2002 - 2017 increased from $101.1 \mathrm{Wm}^{-2}\left(145.4 \mathrm{Wm}^{-2}\right)$ to $114.6 \mathrm{Wm}^{-2}\left(161.5 \mathrm{Wm}^{-2}\right)$ over BA (DL). In vegetated area the values increased from $53.1 \mathrm{Wm}^{-2}$ to $63.3 \mathrm{Wm}^{-2}$ during the study period. The $\Delta \mathrm{Q}_{\mathrm{H}}$ during the study period are found to be $13.5 \mathrm{Wm}^{-2}, 16.1 \mathrm{Wm}^{-2}$ and $10.2 \mathrm{Wm}^{-2}$ over the BA, DL and the vegetation respectively. During the study period the $\mathrm{Q}_{\mathrm{E}}$ observed to be decreasing from $42.8 \mathrm{Wm}^{-2}\left(18.7 \mathrm{Wm}^{-2}\right)$ to $32.4 \mathrm{Wm}^{-2}\left(9.8 \mathrm{Wm}^{-2}\right)$ over BA (DL). In the vegetated area the $\mathrm{Q}_{\mathrm{E}}$ decreased from $90.9 \mathrm{Wm}^{-2}$ to $77.9 \mathrm{Wm}^{-2}$. The $\Delta \mathrm{Q}_{\mathrm{E}}$ during the study period over the BA, DL and the vegetated areas are observed to be $-10.4 \mathrm{Wm}^{-2},-8.9 \mathrm{Wm}^{-2}$ and $-13.0 \mathrm{Wm}^{-2}$ respectively.

\section{Lucknow}

Figure $14 \mathrm{~d}$ shows the variation in the mean values of the energy components during the study period with respect to different LULC classes (BA, DL and vegetation) for Lucknow. For 2002 over BA (DL) the $\mathrm{Q}^{*}$ value observed to be $398.4 \mathrm{Wm}^{-2}\left(354.4 \mathrm{Wm}^{-2}\right)$ which increased to 454.8 $\mathrm{Wm}^{-2}\left(414.6 \mathrm{Wm}^{-2}\right)$ in 2017 and for vegetation the value increases from $454.1 \mathrm{Wm}^{-2}$ in 2002 to $501.7 \mathrm{Wm}^{-2}$ in 2017 . The $\Delta \mathrm{Q}^{*}$ over the BA, DL and vegetation as observed for the study period are $56.4 \mathrm{Wm}^{-2}, 60.2 \mathrm{Wm}^{-2}$ and $47.6 \mathrm{Wm}^{-2}$ respectively. In 2002 the $\mathrm{QH}_{\mathrm{H}}$ over BA (DL) was 101.4 $\mathrm{Wm}^{-2}\left(142.3 \mathrm{Wm}^{-2}\right)$ and is increased to $116.7 \mathrm{Wm}^{-2}\left(157.3 \mathrm{Wm}^{-2}\right)$ in 2017. In the vegetated area the values are increased from $53.1 \mathrm{Wm}^{-2}$ to $66.7 \mathrm{Wm}^{-2}$ during $2002-2017$. The $\Delta \mathrm{Q}_{\mathrm{H}}$ is observed to be $15.3 \mathrm{Wm}^{-2}, 15.0 \mathrm{Wm}^{-2}$ and $13.6 \mathrm{Wm}^{-2}$ over the $\mathrm{BA}$, DL and vegetation respectively during the study period. The QE over BA (DL) was $44.8 \mathrm{Wm}^{-2}\left(15.7 \mathrm{Wm}^{-2}\right)$ in 2002 , and noticed to be 
decreased to $37.8 \mathrm{Wm}^{-2}\left(10.6 \mathrm{Wm}^{-2}\right)$ in 2017. Over vegetated area the $\mathrm{Q}_{\mathrm{E}}$ decreased from 94.1 $W m^{-2}$ to $85.8 \mathrm{Wm}^{-2}$ during the study period. The $\Delta \mathrm{Q}_{\mathrm{E}}$ during the study period over the BA, DL and vegetation are found to be $-7.0 \mathrm{Wm}^{-2},-5.1 \mathrm{Wm}^{-2}$ and $-8.3 \mathrm{Wm}^{-2}$ respectively.

\section{Nagpur}

Figure 15a depicts the variation in the mean values of the energy components with respect to different LULC classes over Nagpur during the study period. The Q* over BA (DL) in 2002 is $388.1 \mathrm{Wm}^{-2}\left(349.6 \mathrm{Wm}^{-2}\right)$ and in 2018 it increased to $419.6 \mathrm{Wm}^{-2}\left(378.6 \mathrm{Wm}^{-2}\right)$. The $\mathrm{Q}^{*}$ over the vegetation is noticed to increase from $431.8 \mathrm{Wm}^{-2}$ to $471.7 \mathrm{Wm}^{-2}$ during $2002-2018$. The $\Delta \mathrm{Q}^{*}$ as estimated over the BA, DL and vegetation are $31.5 \mathrm{Wm}^{-2}, 29.0 \mathrm{Wm}^{-2}$ and $39.9 \mathrm{Wm}^{-2}$ respectively. The Qнduring 2002 - 2018 increased from $85.2 \mathrm{Wm}^{-2}\left(122.8 \mathrm{Wm}^{-2}\right)$ to $99.1 \mathrm{Wm}^{-2}\left(142.9 \mathrm{Wm}^{-2}\right)$ over BA (DL). For the vegetated area the values increased from $38.6 \mathrm{Wm}^{-2}$ to $53.9 \mathrm{Wm}^{-2}$ during 2002 - 2018. The $\Delta \mathrm{Q}_{\mathrm{H}}$ over the BA, DL and the vegetated areas are found to be $13.9 \mathrm{Wm}^{-2}, 20.1$ $\mathrm{Wm}^{-2}$ and $15.3 \mathrm{Wm}^{-2}$ respectively. During the study period the QEOver Nagpur observed to be decreasing from $33.2 \mathrm{Wm}^{-2}\left(14.7 \mathrm{Wm}^{-2}\right)$ to $26.2 \mathrm{Wm}^{-2}\left(8.5 \mathrm{Wm}^{-2}\right)$ over BA (DL). In the vegetated area the $\mathrm{Q}_{\mathrm{E}}$ decreased from $67.8 \mathrm{Wm}^{-2}$ to $54.7 \mathrm{Wm}^{-2}$. The $\Delta \mathrm{Q}_{\mathrm{E}}$ over the $\mathrm{BA}$, DL and vegetation as estimated for the study period are $-7.0 \mathrm{Wm}^{-2},-6.2 \mathrm{Wm}^{-2}$ and $-13.1 \mathrm{Wm}^{-2}$ respectively.

\section{Hyderabad}

For Hyderabad, Fig. 15b depicts the variation in the mean of the energy components during the study period with respect to different LULC classes (BA, DL and vegetation). The Q* over BA (DL) is observed to be $424.1 \mathrm{Wm}^{-2}\left(386.4 \mathrm{Wm}^{-2}\right)$ in 2002 which is slightly increased to 439.1 $\mathrm{Wm}^{-2}\left(405.2 \mathrm{Wm}^{-2}\right)$ in 2017 and for vegetation the value increases from $487.2 \mathrm{Wm}^{-2}$ in 2002 to 498.8 $\mathrm{Wm}^{-2}$ in 2017 . The $\Delta \mathrm{Q}^{*}$ during the study period over the BA, DL and vegetation as estimated are $15.0 \mathrm{Wm}^{-2}, 18.8 \mathrm{Wm}^{-2}$ and $11.6 \mathrm{Wm}^{-2}$ respectively. In 2002, the QHover BA (DL) 
was $152.3 \mathrm{Wm}^{-2}\left(103.8 \mathrm{Wm}^{-2}\right)$ and is increased to $163.9 \mathrm{Wm}^{-2}\left(116.4 \mathrm{Wm}^{-2}\right)$ in 2017 . For the vegetated area the values are increased from $52.1 \mathrm{Wm}^{-2}$ to $63.9 \mathrm{Wm}^{-2}$ during $2002-2017$. The $\Delta \mathrm{Q}_{\mathrm{H}}$ during the study period over the $\mathrm{BA}, \mathrm{DL}$ and vegetated areas are $11.6 \mathrm{Wm}^{-2}, 12.6 \mathrm{Wm}^{-2}$ and 11.8 $\mathrm{Wm}^{-2}$ respectively. The QE over BA (DL) was $21.5 \mathrm{Wm}^{-2}\left(54.2 \mathrm{Wm}^{-2}\right)$ in 2002 , and noticed to decreased to $14.3 \mathrm{Wm}^{-2}\left(42.5 \mathrm{Wm}^{-2}\right)$ in 2017. Over vegetated area the QE decreased from 101.9 $W m^{-2}$ to $93.4 W^{-2}$ during the study period. The $\Delta \mathrm{Q}_{\mathrm{E}}$ during the study period found to be -7.2 $W m^{-2},-11.7 W^{-2}$ and $-8.5 W^{-2}$ over the BA, DL and vegetation respectively.

\section{Bengaluru}

Figure $15 \mathrm{c}$ depicts the variation in the mean values of the energy components during the study period with respect to different LULC classes (BA, DL and vegetation) of Bengaluru. For 2002 over BA (DL) the value is $474.5 \mathrm{Wm}^{-2}\left(436.7 \mathrm{Wm}^{-2}\right)$ which is noticed to increased to $486.2 \mathrm{Wm}^{-}$ ${ }^{2}\left(451.2 \mathrm{Wm}^{-2}\right)$ in 2018 . For vegetation the value increases from $529.9 \mathrm{Wm}^{-2}$ in 2002 to $538.3 \mathrm{Wm}^{-2}$ in 2018. The $\Delta \mathrm{Q}^{*}$ during the study period over the BA, DL and vegetation are $11.7 \mathrm{Wm}^{-2}, 14.5$ $W^{-2}$ and $8.4 W^{-2}$ respectively. In 2002, the $\mathrm{Q}_{\mathrm{H}}$ over BA (DL) observed to be $113.5 \mathrm{Wm}^{-2}$ (151.9 $\left.\mathrm{Wm}^{-2}\right)$ and is increased to $131.8 \mathrm{Wm}^{-2}\left(168.9 \mathrm{Wm}^{-2}\right)$ in 2018 . In the vegetated area the values are increased from $58.2 \mathrm{Wm}^{-2}$ to $76.9 \mathrm{Wm}^{-2}$ during $2002-2018$. The $\Delta \mathrm{Q}_{\mathrm{H}}$ as estimated for the study duration over the BA, DL and vegetation are $18.3 \mathrm{Wm}^{-2}, 17.0 \mathrm{Wm}^{-2}$ and $18.7 \mathrm{Wm}^{-2}$ respectively. The QE over BA (DL) was $38.7 \mathrm{Wm}^{-2}\left(13.4 \mathrm{Wm}^{-2}\right)$ in 2002 , and decreased to $28.4 \mathrm{Wm}^{-2}\left(9.7 \mathrm{Wm}^{-}\right.$ ${ }^{2}$ ) in 2018. Over vegetated areas the QE decreased from $88.9 \mathrm{Wm}^{-2}$ to $71.9 \mathrm{Wm}^{-2}$ during the study period. The $\Delta \mathrm{Q}_{\mathrm{E}}$ during the study period over the BA, DL and vegetation are $-10.3 \mathrm{Wm}^{-2},-3.7$ $W m^{-2}$ and $-17.0 \mathrm{Wm}^{-2}$ respectively.

The above analysis indicate that the mean SHF, $\mathrm{Q}_{\mathrm{H}}$ is increasing significantly over the BA and the DL during the study period with maximum increase of $28.2 \mathrm{Wm}^{-2}\left(39.7 \mathrm{Wm}^{-2}\right)$ over the BA 
(DL) of Delhi. The $\Delta \mathrm{Q}_{\mathrm{H}}$ over the BA of Kolkata $\left(24.4 \mathrm{Wm}^{-2}\right)$ and Mumbai $\left(23.0 \mathrm{Wm}^{-2}\right)$ are also found to be higher. On the other hand the mean LHF, $Q_{E}$ is noticed to slightly decrease $(<20$ $W m^{-2}$ ) over all the LULC classes during the study period. The $\mathrm{Q}^{*}$ is also observed to increase considerably during the study period.

\subsection{SHF and LHF values with respect to LST over different LULC classes}

The above results indicate that the LHF values are small due to absence of moisture over the BA and the DL over the study regions and the SHF is dominating over these areas. The vegetated areas are noticed to possess the higher LHF values and smaller SHF values. In our earlier studies the estimated LST values over the BA and the DL are observed to be higher than the vegetations and the hotspots are identified mostly over the DL and dense BA for the study regions (Sultana and Satyanarayana, 2018, 2020).

In this section the SHF and the LHF values are analyzed with respect to the LST ranges over Different LULC classes (Table 4 - 9). For Kolkata (Table 4), Kochi (Table 5) and Hyderabad (Table 9) the SHF (LHF) values are higher (lower) over the BA than the DL but the LST as noticed in the earlier studies are higher over the DL than that of BA (Sultana and Satyanarayana, 2018, 2020), whereas for the rest of the cites SHF (LHF) have higher (lower) ranges over the DL than that of the BA like the LST ranges. On the other hand, the vegetated areas are found to possess higher (lower) LHF (SHF) and thus LST ranges are noticed to be considerably lower than the BA and DL. It is also noticed that the SHF and LHF ranges over the BA and the DL are slightly overlapping which is also featured in LST values for all cities.

\subsection{Estimation of proportion of the heat fluxes with respect to the net radiation flux}

In this section the ratio of the mean heat fluxes to the mean net radiation flux is analyzed and compared with earlier studies. The ratio of the mean SHF, $\mathrm{Q}_{\mathrm{H}}$, mean LHF, QE and mean residual 
heat flux, $Q_{R}$ to the mean net radiation flux, $Q^{*}$ is estimated for the urban regions of the cities under consideration for the duration of the study period (Table 10). The proportion of SHF is noticed to be about 19\% (Visakhapatnam in 2001) to 33\% (Kochi in 2018) of the net radiation flux and are found to increased slightly $(1 \%-4 \%)$ during the study period, with maximum increase for Delhi and Kochi (4\% for each). Though Kochi is a coastal city rich in estuaries, the high SHF proportion can be attributed to the soil-type which is mostly loamy sand and poor in water holding capacity (http://www.keralasoils.gov.in/index.php/2016-04-27-09-26-39/soils-ofkerala). For Delhi and Mumbai where higher SHF proportion is noticed are densely-packed in built up areas with negligible moisture-content surfaces. On the other hand, the LHF are noticed to be $1.9 \%$ (Kolkata in 2017) to $15 \%$ (Chandigarh in 2000) of the net radiation flux and are found to be decreasing for all the cities during the study period. The residual heat flux is found to be about $60 \%$ to $80 \%$ of the net radiation flux. For Hyderabad the residual heat is found to be higher among the cities under consideration, which can be due to the dense BA and the rocky terrain of granites over the suburban area. Delhi and Kochi also possess higher proportion of residual heat which can be attributed to the dense BA and the soil types of the cities.

The proportion of the heat flux with respect to net radiation flux found in the present study is compared with the earlier studies for winter season in the Table 11. It indicates that the present study agrees well with Oke et al., 1999; Moriwaki and Kanda, 2004; Kato and Yamaguchi, 2005, 2007; Kato et al., 2008; Hanna et al., 2011. The residual flux as estimated by Kato and Yamaguchi, 2005 appeared to be over-estimated whereas the SHF and LHF over commercial area by Kato and Yamaguchi, 2007 appear to be underestimated and the residual heat flux is found to be overestimated. Comparison of present results with the published ground observation might appear not suitable as they are mean daytime values over different cities, but the 
comparison could be considered significant as the surface heat fluxes are mostly subjected to surface characteristics.

\section{Summary and Conclusion}

Though the present study concentrated on the BA and DL, the net all wave radiation flux as estimated over the vegetation and the water bodies are observed to be higher due to lower albedo in comparison to the BA and the DL. The DLs are notices to possess lowest range of net radiation flux values followed by BA for all the cities under consideration except Kochi where BA possess lowest range of values. The SHF is observed to be higher over the BA and DL in comparison to vegetation and water bodies, whereas the LHF is found to be lower over BA and DL due to presence of artificial impervious surfaces lower in moisture contents. The SHF values are noticed to be higher over BA than that of the DLfor the cities like Kolkata, Mumbai, Kochi and Hyderabad whereas for rest of the cities under study the highest SHF values are observed over DL. Similarly, the LHF over the BA are noticed to be lowest for Kolkata, Kochi and Hyderabad and for the rest of the cities the LHF is lowest over DL. The residual heat flux over all the cities under consideration noticed to be higher for the water bodies and vegetation due to higher heat capacity property of water whereas the BA possess moderate values and DL possess the lowest values.

For all the cities under consideration the net radiation flux and the SHF are observed to be increased over all the LULC classes during the study period of $2000-2018$. The SHF is noticed to be increased significantly during the study period over the BA and the DL of the cities, but the LHF is noticed to be slightly decreased over these regions. The increase in SHF and the decreasing trend in LHF can be attributed to the increase of artificial materials and loss of moisture in the surface. 
The analysis of the relation between SHF/LHF with the LST indicate that the SHF (LHF) values are higher (lower) over the BA than the DL for Kolkata, Kochi and Hyderabad whereas the LST ranges are higher over the DL than that of BA. For rest of the cities the SHF and LHF ranges are noticed to be in linear with the LST ranges. In the present study the estimated proportion of heat flux with respect to net radiation flux indicate that the SHF is about $19 \%-33 \%$ with higher values over Mumbai, Kochi and Delhi. The LHF is found to be about $1.9 \%-15 \%$ of the net radiation flux for the study regions. In addition to that the results also indicate that about $60 \%-$ $80 \%$ of net radiation flux is end up as residual heat flux. The proportion of SHF is noticed to be slightly increased (by $4 \%$ for both Delhi and Kochi) and the proportion of LHF is decreased during the study period. The comparison between present results with the earlier studies appears to be in good agreement.

The surface energy balance components estimated in the present study are based on earth observation and are could not be validated with the ground observations due to unavailability of high resolution data. In addition to that the energy balance components estimated over the water bodies found to be containing error for few study areas. Hence, the satellite imageries and the ground observations of higher resolution are essential for better estimation of the energy balance components and ultimately the surface dynamics over the fast developing cities. Inferences from the results emanated from the present study has shown substantial variations of surface energy fluxes related to different LULC classes and would certainly influence the energy exchange mechanism from the $\mathrm{BA}$ and results in change in the regional climate on the city scale. 


\section{Acknowledgements}

The first author of the manuscript would gratefully acknowledge the Indian Institute of Technology, Kharagpur for providing fellowship and necessary facilities to conduct $\mathrm{PhD}$ work. Authors are thankful to USGS Earth Resources Observation Systems (EROS) data Centre for freely providing Landsat imageries used in the study. Authors are thankful to the Wyoming Weather Web - Atmospheric sounding (University of Wyoming) and Weather Underground for freely availing atmospheric soundings. Authors are also thankful to the NOAA data archive for freely availing NCEP-DOE Reanalysis 2 data sets.

Author Contribution: SS and ANVS designed and framed the study. SS analyzed the data and wrote the manuscript. ANVS provided the intellectual advice and work directions along with review and editing of the manuscript.

Funding: Not applicable.

Data availability: The data utilized for the study are available freely for users in the corresponding websites as mentioned in the 'data' section of the manuscript.

Code availability: Software: ArcGIS 10.3, ERDAS Imagine, Matlab

\section{Declarations}

Ethics approval and consent to participate: The authors confirm that this article is an original research and is not been published in any journal earlier.

Consent to publication: The authors agree to submit the manuscript in the current form for publication in the journal.

Conflict of interest: The authors declare no conflict of interest. 


\section{References}

Allen R., Waters R., Tasumi M., Trezza R., and Bas-tiaanssen W. (2002) SEBAL, Surface energy balance algorithms for land, Idaho Implementation. Advanced Training and User's manual, version 1.0.

Allen, R. G., Tasumi, M., Trezza, R. (2007). Satellite-based energy balance for mapping evapotranspiration with internalized calibration (METRIC) - Model. Journal of Irrigation and Drainage Engineering, v.133, p.380-394. http://dx.doi.org/10.1061/(ASCE)07339437133:4(380).

An N., Hemmati S., Cui Y., (2017). Assessment of the methods for determining net radiation at different time-scales of meteorological variables, Journal of Rock Mechanics and Geotechnical Engineering, 9 (2), 239 - 246, https://doi.org/10.1016/j.jrmge.2016.10.004

Bastiaanssen, W. G. M., (1995). "Regionalization of surface flux densities and moisture indicators in composite terrain: A remote sensing approach under clear skies in Mediterranean climates.” Ph.D. Dissertation, CIP Data KoninklijkeBibliotheek, Den Haag, The Netherlands.

Bastiaanssen, W. G. M., (2000). "SEBAL-based sensible and latent heat fluxes in the irrigated Gediz Basin, Turkey.” J. Hydrol., 229, 87-100.

Brenner C., Thiem C. E., Wizemann H., Bernhardt M., Schulz K., (2017). Estimating spatially distributed turbulent heat fluxes from high-resolution thermal imagery acquired with a UAV system, International Journal of Remote Sensing, 38, 8-10, 3003-3026. DOI: $10.1080 / 01431161.2017 .1280202$

Brutsaert, W. (1982). In Evaporation into the atmosphere -Theory, History and Applications-; Reidel, D., Ed.; publishing Company: Dordrecht. 
Carlson, T. N., and D. A. Ripley. (1997). On the Relation between NDVI, Fractional Vegetation Cover, and Leaf Area Index. Remote Sensing of Environment 62 (3): 241-252. doi:10.1016/S0034-4257 (97)00104-1.

Census 2011 of India. Accessed 29 June 2020.http://www.censusindia.gov.in

Chen, S. and Hu, D., (2017). Parameterizing Anthropogenic Heat Flux with an EnergyConsumption Inventory and Multi-Source Remote Sensing Data. Remote Sens.9, 1165.

Christen, A. and Vogt, R. (2004). Energy and radiation balance of a central European city. Int. J. Climatol.,24, 1395-1421.

Chrysoulakis N., et al., (2018). Urban energy exchanges monitoring from space.Scientific Reports8:11498. DOI:10.1038/s41598-018-29873-x

Crawford T.M., Bluestein H. B., (2000). An Operational, Diagnostic Surface Energy Budget Model, Journal of Applied Meteorology, 39, 1196 - 1217.

Duijm N.J. (1999). Estimation of roughness parameters for arrays of obstacles. Boundary-Layer Meteorol., 91, 1-22.

Eswar, R.,Sekhar, M., Bhattacharya, B. K., (2017). Comparison of three remotesensing based models for the estimation of latent heat flux over India, Hydrological SciencesJournal, 62:16, 2705-2719, DOI: 10.1080/02626667.2017.1404067

Goldreich Y. (1992). Urban climate studies in Johannesburg, a subtropical city located on a ridge - a review. Atmospheric Environment 26B: 407-420.

Grimmond, C.S.B., (1992). The suburban energy balance: methodological considerations and results for a mid-latitude west coastcity under winter and spring conditions. Int. J. Climatol. 12, 481-497. 
Grimmond, C.S.B., Oke, T.R. (1999). Aerodynamic properties of urban areas derived from analysis of surface form. J. Appl. Meteorol., 38, 1262-1292.

Grimmond, C.S.B.; Salmond, J.A.; Oke, T.R.; Offerle, B.; Lemonsu, A. (2004). Flux and turbulence measurements at a densely build-up site in Marseille: Heat, mass (water and carbon dioxide), and momentum. J. Geophys. Res., 109, doi: 10.1029/2004JD004936.

Grimmond, S., (2007). Urbanization and global environmental change: Local effects of urban warming, Geogr. J., 173(1), 83-88, doi:10.1111/j.1475-4959.2007.232_3.x.

Grimmond, C.S.B., Ward, H.C. and Kotthaus, S., (2016) How is urbanization altering local and regional climate? In: Seto, K.C., Solecki, W. D. and Griffith, C. A. (eds.). The Routledge Handbook of Urbanization and Global Environmental Change. Routledge. ISBN 9780415732260

Hanna, S., Marciotto, E., Britter, R., (2011) Urban Energy Fluxes in Build-Up Downtown Areas and Variations across the Urban Area, for Use in Dispersion Models.J. Appl. Meteor. Climatol., 50 (6), 1341-1353. DOI:10.1175/2011JAMC2555.1

Hrisko, J., Ramamurthy, P., Gonzalez J. E., (2021) Estimating heat storage in urban areas using multispectral satellite data and machine learning. Remote Sensing of Environment, 252, 112125. DOI: $10.1016 /$ j.rse.2020.112125

Kato, S.; Yamaguchi, Y., (2005) Analysis of urban heat-island effect using ASTER and ETM+ data: Separation of anthropogenic heat discharge and natural heat radiation from sensible heat flux. Remote Sens. Environ.,99, 44-54.

Kato, S.; Yamaguchi, Y., (2007) Estimation of storage heat flux in an urban area using ASTER data. Remote Sens. Environ.,110, 1-17. 
Kato, S., Yamaguchi, Y., Liu, C. C. \& Sun, C. Y., (2008).Surface Heat Balance Analysis of Tainan City on March 6, 2001 Using ASTER and Formosat-2 Data. Sensors 8, 6026-6044.

Kotthaus, S., Grimmond, C.S.B., (2014). Energy exchange in a dense urban environment - Part I: Temporal variability of long-term observations in central London, Urban Climate, 10, $261-280$.

Kuang, W., Y. Dou, C. Zhang, W. Chi,A. Liu, Y. Liu, R. Zhang, and J. Liu (2015). Quantifying the heat flux regulation ofmetropolitan land use/land covercomponents by coupling remotesensing modeling with in situmeasurement, J. Geophys. Res. Atmos., 120, 113-130, doi:10.1002/2014JD022249.

Landsat 7 (L7) Data Users Handbook, version 2.0, November 2019. Document owner: Ihlen, V., LSRD Project Manager, U.S. Geological Survey. Approved by: Zanter, K., LSDS CCB Chair, U.S. Geological Survey. https://www.usgs.gov/media/files/landsat-7-data-usershandbook

Landsat 8 (L8) Data Users Handbook, version 5.0, November 2019, Document owner: Ihlen, V., LSRD Project Manager, U.S. Geological Survey. Approved by: Zanter, K., LSDS CCB Chair, U.S. Geological Survey. https://www.usgs.gov/land-resources/nli/landsat/landsat-8data-users-handbook

Liang, S, Wang D, He T, Yu Y, (2019) Remote sensingof earth's energy budget: synthesis and review, Int. J. of Digital Earth, 12:7, 737-780,DOI: 10.1080/17538947.2019.1597189

Macdonald, R.W., Griffiths, R.F., Hall, D.J. (1998) An improved method for the estimation of surface roughness of obstacle arrays. Atmos.Environ., 32, 1857-1864 
Masson, V., C.S.B. Grimmond and T.R. Oke, (2002) Evaluation of the Town Energy Balance (TEB) scheme with direct measurements from dry districts in two cities. J. Appl. Meteorol., 41, 1011-1026.

Mathew, A., Khandelwal, S., Kaul N., (2016) Spatial and temporal variations of urban heat island effect and theeffect of percentage impervious surface area and elevation on landsurface temperature: Study of Chandigarh city, India. Sustainable Cities and Society, 26, 264-277. http://dx.doi.org/10.1016/j.scs.2016.06.018

Mathew, A., Khandelwal, S., Kaul N., (2017) Investigating spatial and seasonal variations of urban heat island effect overJaipur city and its relationship with vegetation, urbanization and elevation parameters. Sustainable Cities and Society, 35, 157-177. http://dx.doi.org/10.1016/j.scs.2017.07.013.

Mauder, M., Foken, T., Cuxart, J., (2020) Surface-Energy-Balance Closure over Land: A Review. Boundary-Layer Meteorology. https://doi.org/10.1007/s10546-020-00529-6

Moriwaki, R., and Kanda, M., (2004) Seasonal and Diurnal Fluxes of Radiation, Heat, Water Vapor, and Carbon Dioxide over a Suburban Area. Journal of Applied Meteorology, 43, $1700-1710$.

Munn, R.E., (1966) Descriptive micrometeorology. New York: Academic Press.

Myrup, L.O. (1969) A numerical model of the urban heat island. Journal of Applied Meteorology 8, 896-907.

Naserikia, M., Shamsabadi, E. A., Rafieian, M., Filho,W. L., (2019) The urban heat island in an urban context: a case study of Mashhad, Iran. Int. J. Environ. Res.Public Health, 16, 313.doi:10.3390/ijerph16030313. 
Nelli, N.R.,Temimi, M., Fonseca, R.M., et al., (2019) Micrometeorological measurements in an arid environment: Diurnal characteristics andsurface energy balance closure, Atmospheric Research, https://doi.org/10.1016/j.atmosres.2019.104745

Nishida, K., Nemani, R. R., Running, S. W. \& Glassy, J. M. (2003) An operational remote sensing algorithm of land surface evaporation.J. Geophys. Res. 108, 4720.

Offerle B, Jonsson P, Eliasson I, Grimmond C. S. B., (2005) Urban modification of the surface energy balance in the West African Sahel: Ouagadougou, Burkina Faso. Journal of Climate 18: 3983-3995.

Oke, T.R., Yap, D. and Fuggle, R.F. (1972) Determination of urban sensible heat fluxes. In Adams, W.P. and Helleiner, F.M., editors, International geography, University of Toronto: Toronto Press, 176-78.

Oke, T. R. (1982). The Energetic Basis of the Urban Heat Island.Quarterly Journal of the Royal Meteorological Society 108: 1-24.

Oke, T.R., (1988). The urban energy balance.Prog. Phys. Geogr. 12: 471-508.

Oke T R, Zeuner G, Jauregui E. (1992). The surface energy balance in Mexico City.Atmospheric Environment 26B: 433-444.

Oke T.R.; Spronken-Smith, R.A.; Jáuregui, E.; Grimmond, C.S.B., (1999).The energy balance of central Mexico City during the dry season.Atmos.Environ.,33, 3919-3930.

Paulson C. A., (1970). "The mathematical representation of wind speed and temperature profiles in the unstable atmospheric surface layer.” J. Appl. Meteorol., 9, 857-861.

Pearlmutter D, Bitan A, Berliner P. (1999). Microclimatic analysis of "compact" urban canyons in an arid zone.Atmospheric Environment33: 4143-4150. 
Pearlmutter D, Berliner P, Shaviv E. (2005). Evaluation of Urban surface energy fluxes using an open-air scale model. Journal of Applied Meteorology, 44, 532-545.

Pearlmutter D, Berliner P, Shaviv E. (2006). Physical modeling of the pedestrian energy exchange within the urban canopy. Building an dEnvironment, 41, 783-795.

Probald, F., (1971): The energy balance as the basis of the urban climate of Budapest. Annales Universitatis Scientiarum Budapestinensis, Sectio Geographica 7, 51-68.

Prueger, John H. and Kustas, William P. (2005). Aerodynamic Methods for Estimating Turbulent Fluxes.Publications from USDAARS / UNL Faculty. 1394.

Rahman, M., M., and Zhang, W., (2019).Review on estimation methods of the Earth's surface energy balance components from ground and satellite measurements. J. Earth Syst. Sci. 128:84.https://doi.org/10.1007/s12040-019-1098-5.

Roth M., (2007).Review of urban climate research in (sub)tropical regions. Int. J. Climatol.27: 1859-1873. DOI: 10.1002/joc.1591

Roth, M., (2013). Handbook of Environmental Fluid Dynamics, Volume Two, edited by Harindra Joseph Shermal Fernando. ISBN: 978-1-4665-5601-0, pp. 143-159.

Roupioz L., Jia L., Nerry F. and Menenti M., (2016). Estimation of Daily Solar Radiation Budget at Kilometer Resolution over the Tibetan Plateau by Integrating MODIS Data Products and a DEM, Remote Sens., 8, 504; doi:10.3390/rs8060504

Salmond J. (1999). Bibliography of urban climate 1996-1999, Available at: http://www.urbanclimate.org (last accessed: 20 April 2020).

Salmond J. (2005). Bibliography of urban climate 2000-2004, Available at: http://www.urbanclimate.org (last accessed: 20 April 2020). 
Seto, K. C.,Güneralp, B., and Hutyra, L. R., (2012).Global forecasts of urban expansion to 2030 and direct impacts on biodiversity and carbon pools, Proc. Natl. Acad. Sci. U.S.A., 109(40), 16,083-16,088, doi:10.1073/pnas.1211658109.

Silva, B.B.d., Braga, A.C., Braga, C.C., Oliveira, L. M. M. d., Montenegro, S.M.G.L., Barbosa Junior, B. (2016). Procedures for calculation of the albedo with OLI-Landsat 8 images: Application to the Brazilian semi-arid. Revista Brasileira de EngenhariaAgrícola e Ambiental, 20, 3 .

Sobrino, J.A., Oltra-Carrió, R., Sòria, G., Bianchi, R., Paganini, M., (2012). Impact of spatial resolution and satellite overpass time on evaluation of the surface urban heat island effects. Remote Sens. Environ. 117, 50-56.

Spronken-Smith, R.A., (2002).Comparison of summer- and winter-time suburban energy fluxes in Christchurch, New Zealand. Int. J. Climatol., 22, 979-992.

Sultana, S., and A.N.V. Satyanarayana. (2018). Urban heat island intensity during winter over metropolitan cities of India using remote-sensing techniques: impact of urbanization, Int. J. Rem. Sens., 39, 6692-6730. DOI:10.1080/01431161.2018.1466072

Sultana, S., and A.N.V. Satyanarayana. (2019). Impact of urbanisation on urban heat island intensity during summer and winter over Indian metropolitan cities. Environ Monit Assess., 191 (Suppl 3): 789. https://doi.org/10.1007/s10661-019-7692-9

Sultana, S., and A.N.V. Satyanarayana. (2020). Assessment of urbanisation and urban heat island intensities using Landsat imageries during 2000-2018 over a sub-tropical Indian City. Sustainable Cities and Society, 52, 101846. https://doi.org/10.1016/j.scs.2019.101846

Sundborg, A., (1951). Climatological studies in Uppsala with special regard to the temperature conditions in the urban area. Geographica 22. Geographical Institute, Uppsala University. 
Tag, P.M. (1968). Surface temperatures in an urban environment. Pennsylvania State University, unpublished thesis.

Templeton, N.P., Vivoni, E.R., Wang, Z.H., Schreiner-McGraw, A.P., (2018). Quantifying water and energy fluxes over different urban land covers in Phoenix, Arizona. Journal of Geophysical Research: Atmospheres, 123, 2111 - 2128. DOI: 10.1002/2017JD027845.

Voogt, J.A., and Oke, T.R., (2003). Thermal remote sensing of urban climates.Remote Sensing of Environment. 86, 370-384.

Webb, E. K. (1970)."Profile relationships: the log-linear range, and extensionto strong stability."Q. J. R. Meteorol. Soc., 96, 67-90.

Weng, Q., Hu, X., Quattrochi, D. \& Liu, H., (2014). Assessing intra-urban surface energy fluxes using remotely sensed aster imagery and routine meteorological data: A case study in Indianapolis, USA. IEEE J. Sel. Top.Appl. Earth Obs. Remote Sens.7, 4046-4057.

Wetherley, E. B., Roberts, D. A., Tague, C. L., Jones, C., Quattrochi, D. A., McFadden, J. P., (2021). Remote sensing and energy balance modeling of urban climate variability across a semi-arid megacity, Urban Clim., 35, 100757. https://doi.org/10.1016/j.uclim.2020.100757

World Bank, 2017. The World Bank Annual Report (2017). Washington, DC: World Bank. https://openknowledge.worldbank.org/handle/10986/27986 License: CC BY-NC-ND 3.0 IGO. http://hdl.handle.net/10986/27986.

Yang J., Wong M. S., Menenti M., (2016). Effects of Urban Geometry on Turbulent Fluxes: A Remote Sensing Perspective, IEEE Geoscience and Remote Sensing Letters, 13 (12), 1767-1771, Dec., doi: 10.1109/LGRS.2016.2607759. 
Yang J., Menenti M., Krayenhoff E., S., Wu Z., Shi Q., Ouyang X., (2019). Parameterization of Urban Sensible Heat Flux from Remotely Sensed Surface Temperature: Effects of Surface Structure, Remote Sens., 11, 1347; doi:10.3390/rs11111347

\section{Figure Captions}

Fig. 1 Map of India and location of study regions, the Indian metropolitan cities

Fig. 2 (a) Net radiation flux, (b) sensible heat flux, (c) latent heat flux, and (d) residual heat flux over Kolkata for year 2002, 2007, 2012 and 2017 
Fig. 3 (a) Net radiation flux, (b) sensible heat flux, (c) latent heat flux, and (d) residual heat flux over Visakhapatnam for year 2001, 2008, 2012 and 2017

Fig. 4 (a) Net radiation flux, (b) sensible heat flux, (c) latent heat flux, and (d) residual heat flux over Mumbai for year 2002, 2008, 2012 and 2018

Fig. 5 (a) Net radiation flux, (b) sensible heat flux, (c) latent heat flux, and (d) residual heat flux over Kochi for year 2002, 2007, 2013 and 2018

Fig. 6 (a) Net radiation flux, (b) sensible heat flux, (c) latent heat flux, and (d) residual heat flux over Delhi for year 2002, 2007, 2013 and 2017

Fig. 7 (a) Net radiation flux, (b) sensible heat flux, (c) latent heat flux, and (d) residual heat flux over Chandigarh for year 2000, 2005, 2010, 2013 and 2018

Fig. 8 (a) Net radiation flux, (b) sensible heat flux, (c) latent heat flux, and (d) residual heat flux over Jaipur for year 2002, 2007, 2012 and 2017

Fig. 9 (a) Net radiation flux, (b) sensible heat flux, (c) latent heat flux, and (d) residual heat flux over Lucknow for year 2002, 2007, 2012 and 2017

Fig. 10 (a) Net radiation flux, (b) sensible heat flux, (c) latent heat flux, and (d) residual heat flux over Nagpur for year 2002, 2007, 2013 and 2018

Fig. 11 (a) Net radiation flux, (b) sensible heat flux, (c) latent heat flux, and (d) residual heat flux over Hyderabad for year 2002, 2007, 2012 and 2017

Fig. 12 (a) Net radiation flux, (b) sensible heat flux, (c) latent heat flux, and (d) residual heat flux over Bengaluru for year 2002, 2008, 2013 and 2018 
Fig. 13 The variation of surface energy components with respect to build up area, dry lands and vegetation over (a) Kolkata, (b) Visakhapatnam, (c) Mumbai and (d) Kochi

Fig. 14 The variation of surface energy components with respect to build up area, dry lands and vegetation over (a) Delhi, (b) Chandigarh, (c) Jaipur and (d) Lucknow

Fig. 15 The variation of surface energy components with respect to build up area, dry lands and vegetation over (a) Nagpur, (b) Hyderabad, and (c) Bengaluru

\section{Table Captions}

Table 1 Details of Landsat images used in the study.

Table 2 Typical Parameters for different surface cover types. 
Table 3 Changes in the urban energy balance (UEB) components during the study period over the buildup area, dry lands and vegetated areas of the study regions.

Table 4 Comparison of the land surface temperature (LST) ranges with the ranges of the sensible heat flux (SHF) and the latent heat flux (LHF) for Kolkata and Visakhapatnam.

Table 5 Comparison of the land surface temperature (LST) ranges with the ranges of the sensible heat flux (SHF) and the latent heat flux (LHF) for Mumbai and Kochi.

Table 6 Comparison of the land surface temperature (LST) ranges with the ranges of the sensible heat flux (SHF) and the latent heat flux (LHF) for Delhi and Jaipur.

Table 7 Comparison of the land surface temperature (LST) ranges with the ranges of the sensible heat flux (SHF) and the latent heat flux (LHF) for Chandigarh.

Table 8 Comparison of the land surface temperature (LST) ranges with the ranges of the sensible heat flux (SHF) and the latent heat flux (LHF) for Lucknow and Nagpur.

Table 9 Comparison of the land surface temperature (LST) ranges with the ranges of the sensible heat flux (SHF) and the latent heat flux (LHF) for Hyderabad and Bengaluru.

Table 10 Ratios of sensible heat flux $\left(\mathrm{Q}_{\mathrm{H}}\right)$, latent heat flux $\left(\mathrm{Q}_{\mathrm{E}}\right)$ and residual heat flux $\left(\mathrm{Q}_{\mathrm{R}}\right)$ to the net radiation flux $\left(\mathrm{Q}^{*}\right)$ over the built up area of the study regions.

Table 11 Ratios of heat flux to the net radiation flux as estimated in the present study over urban areas for winter seasons and comparison with the corresponding earlier studies. 
Figures

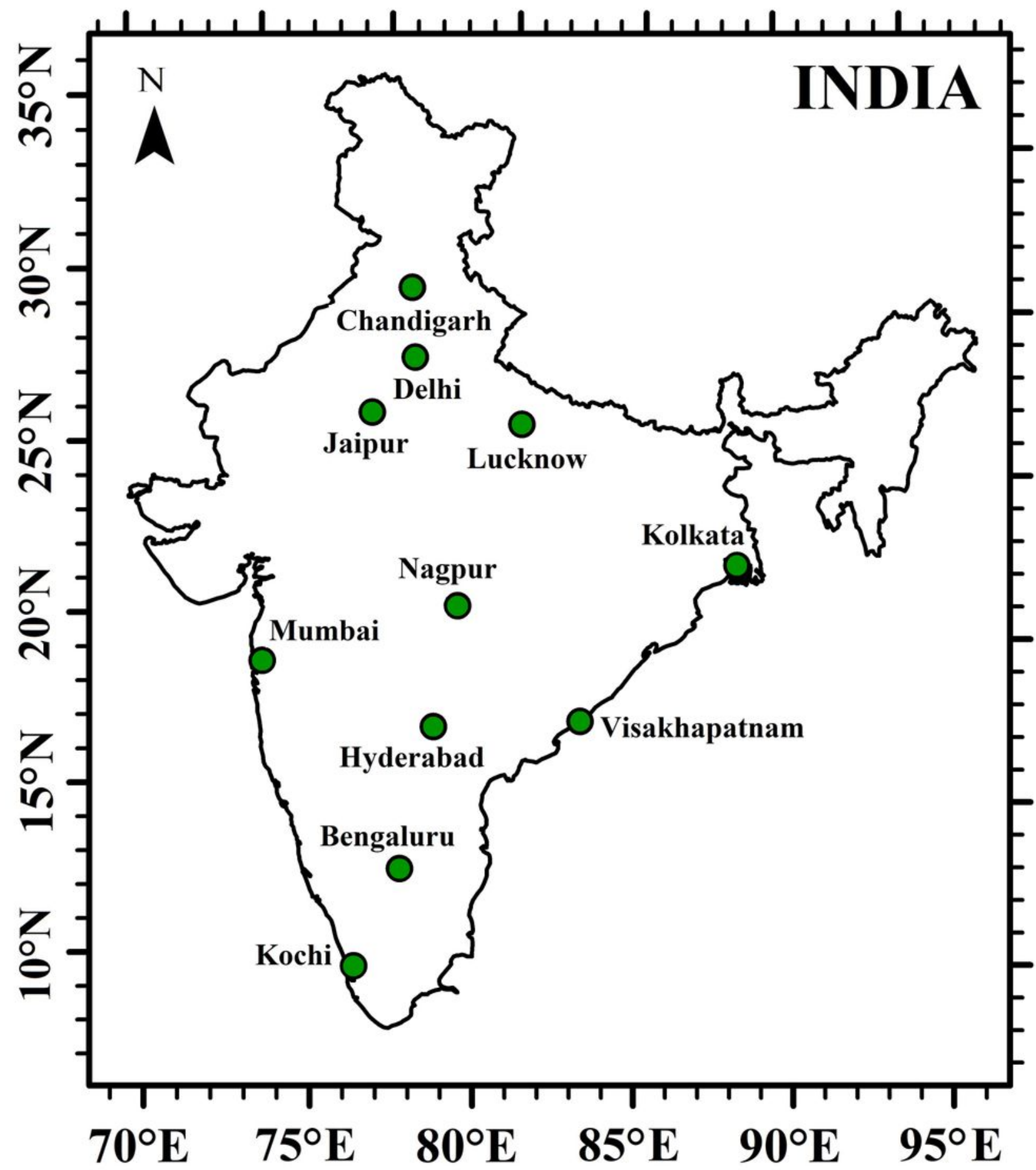

Figure 1

Map of India and location of study regions, the Indian metropolitan cities 
(a)
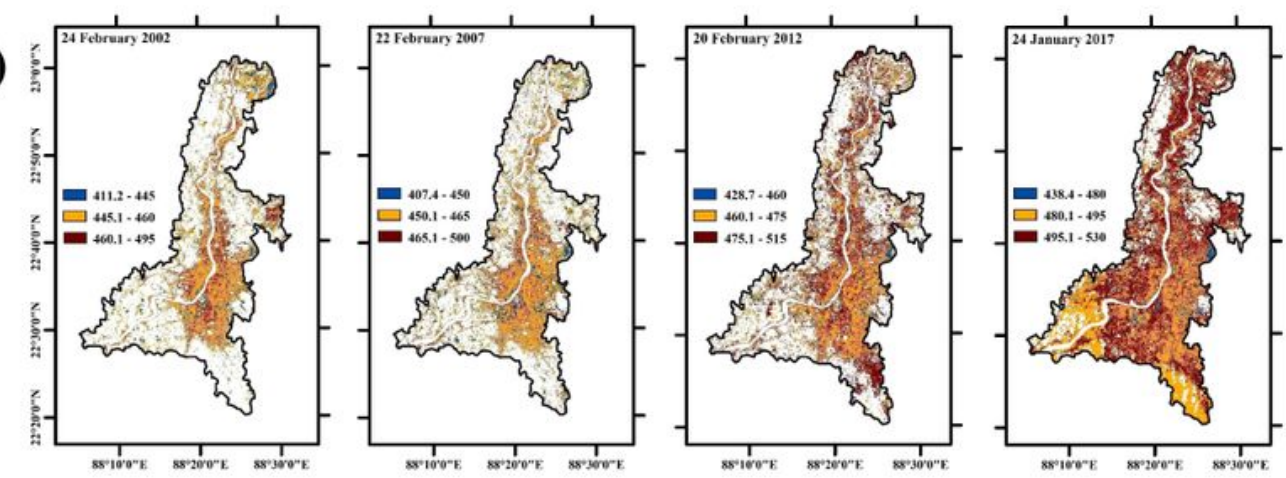

(b)
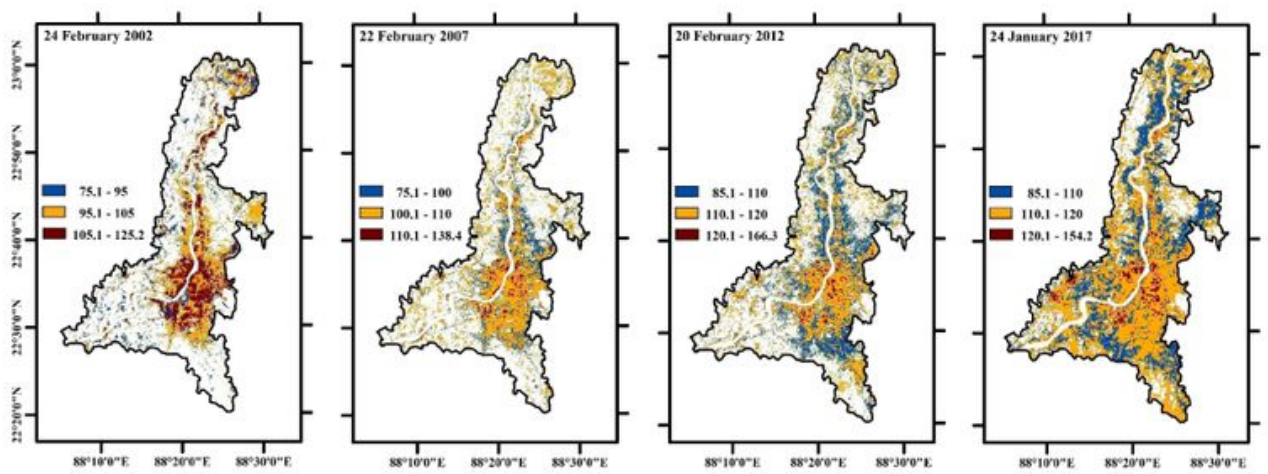

(c)
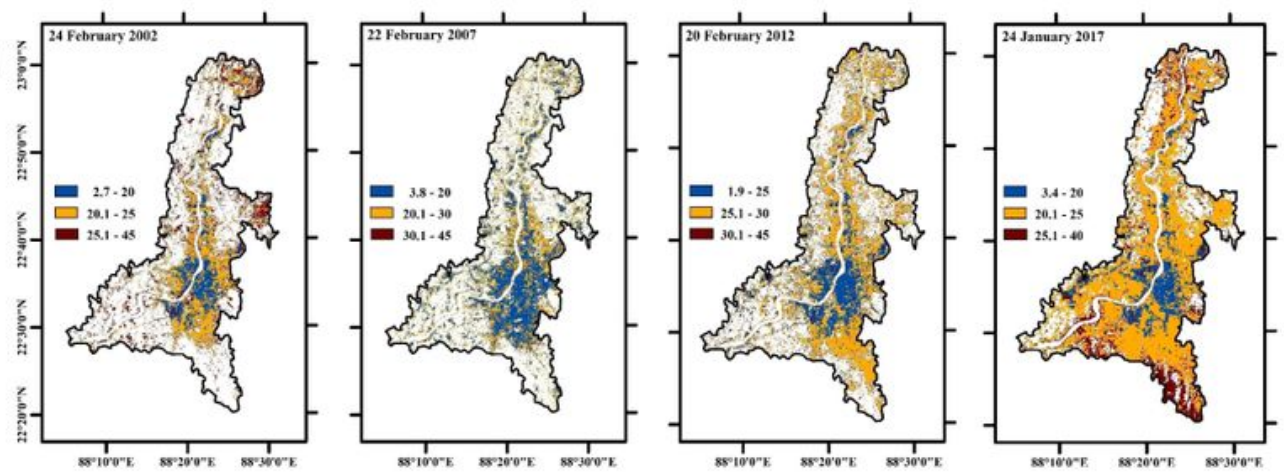

(d)
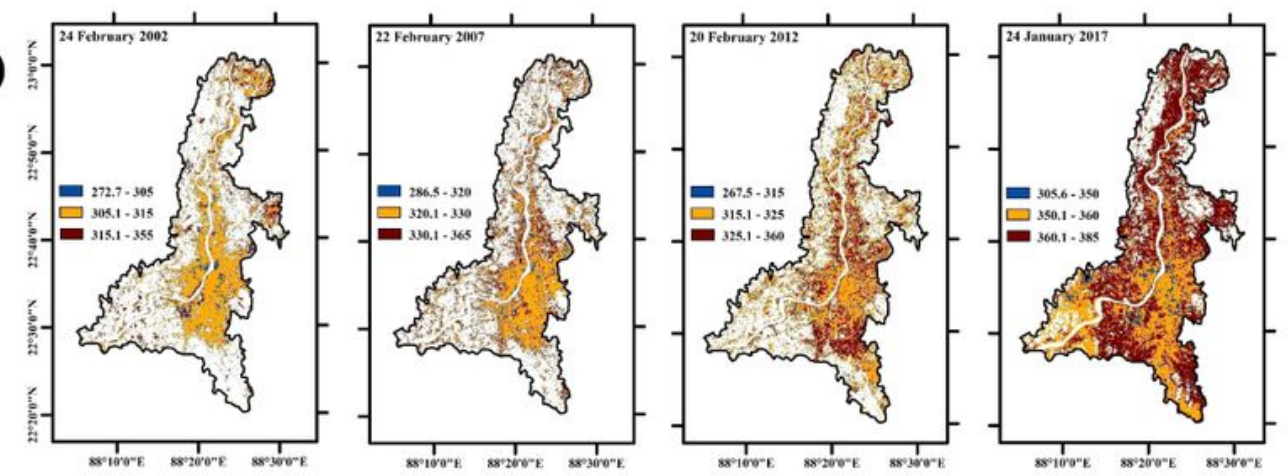

\section{Figure 2}

(a) Net radiation flux, (b) sensible heat flux, (c) latent heat flux, and (d) residual heat flux over Kolkata for year 2002, 2007, 2012 and 2017 
(a)

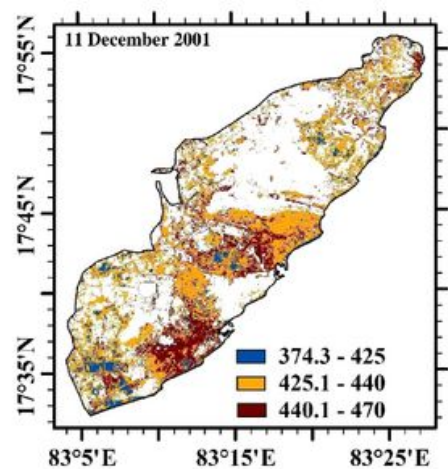

(b)

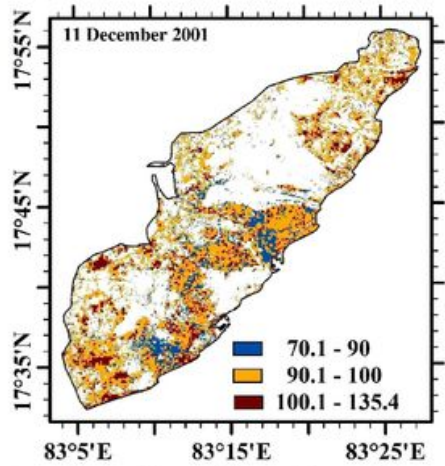

(c)

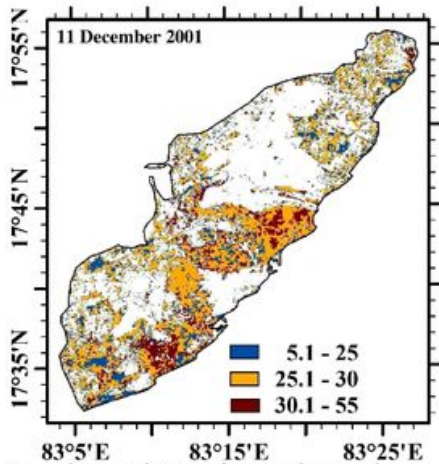

(d)

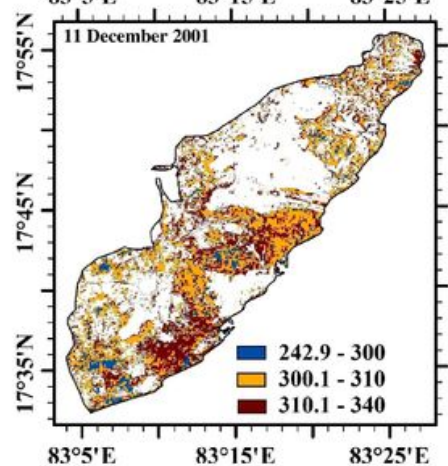

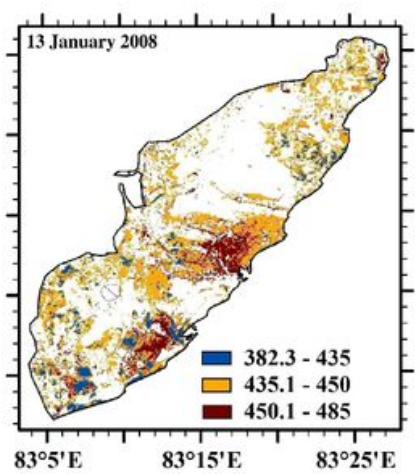
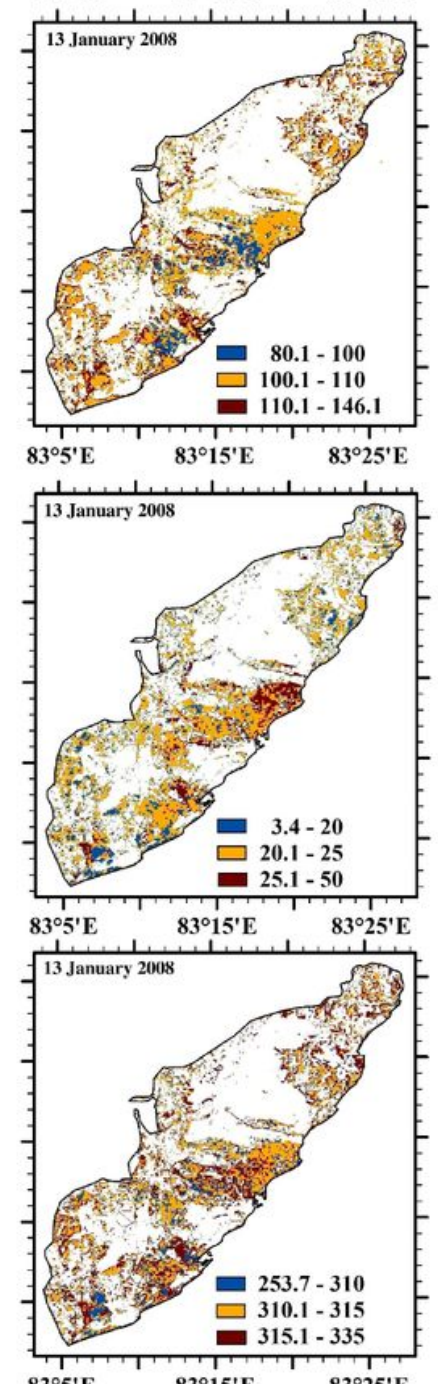
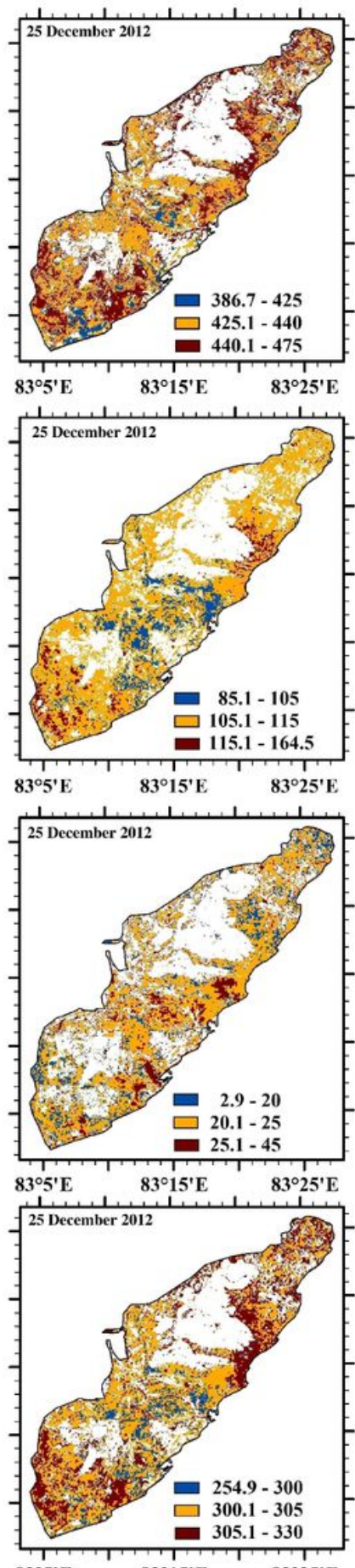
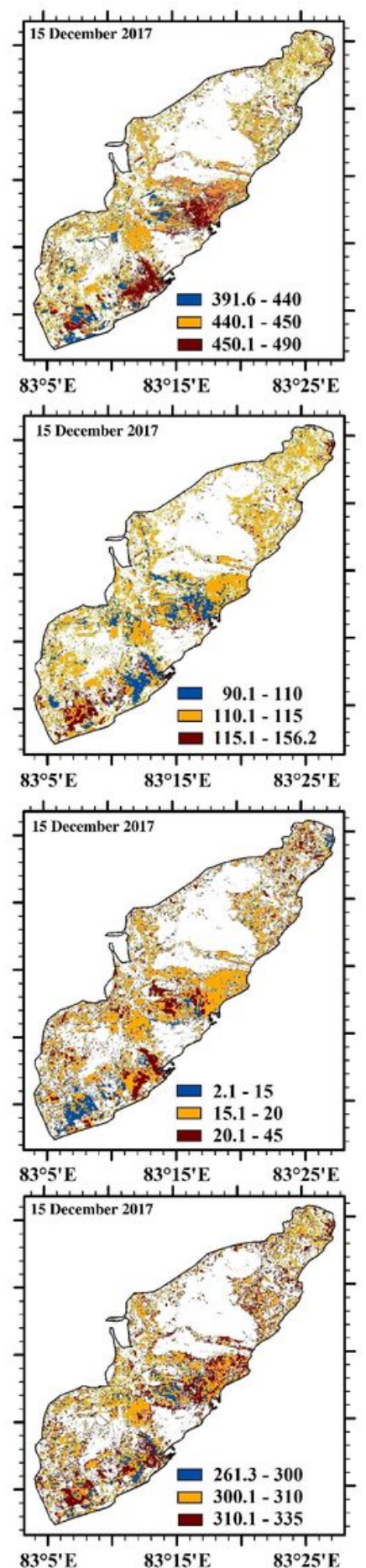

Figure 3

(a) Net radiation flux, (b) sensible heat flux, (c) latent heat flux, and (d) residual heat flux over Visakhapatnam for year 2001, 2008, 2012 and 2017 
(a)

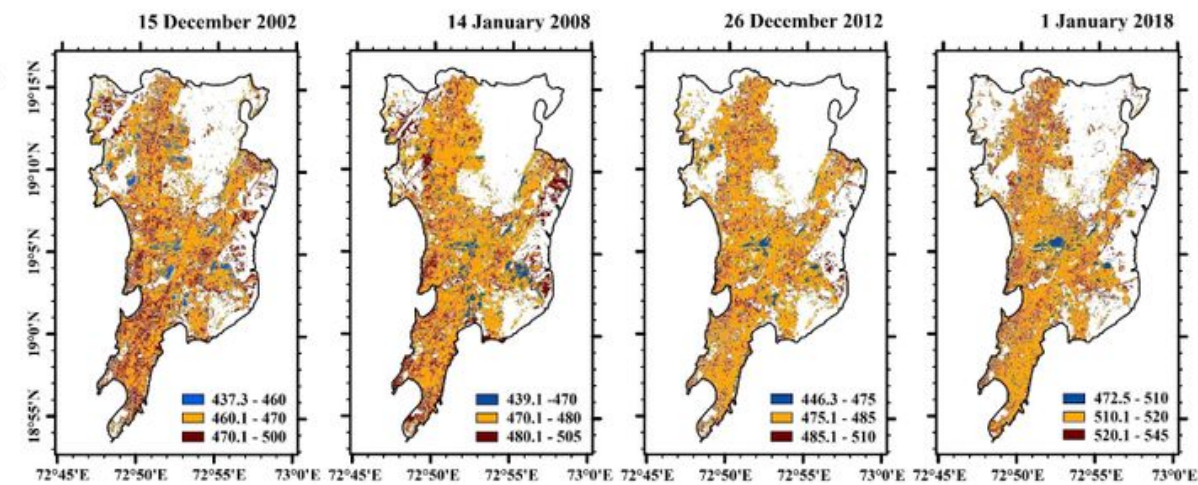

(b)

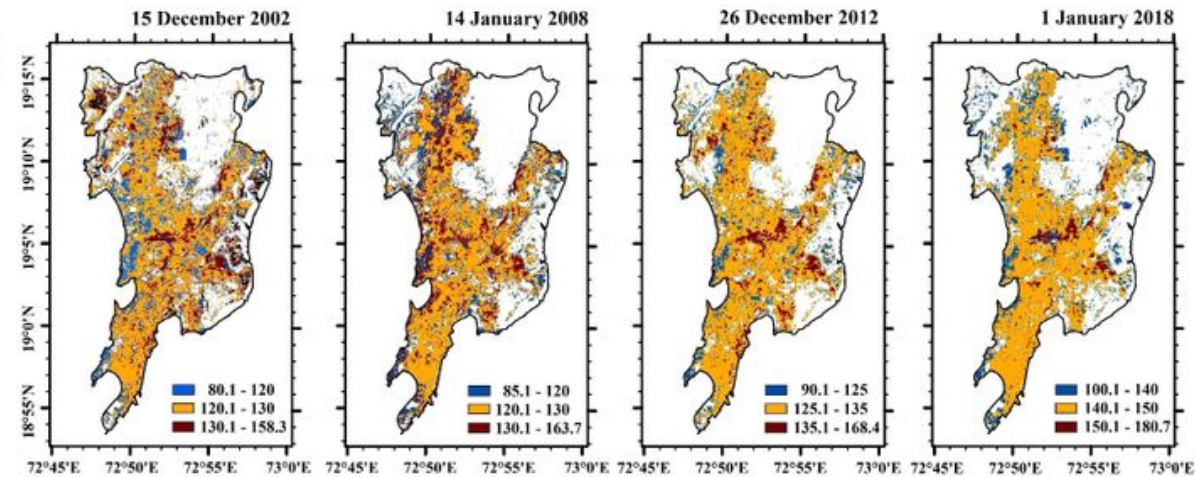

(c)
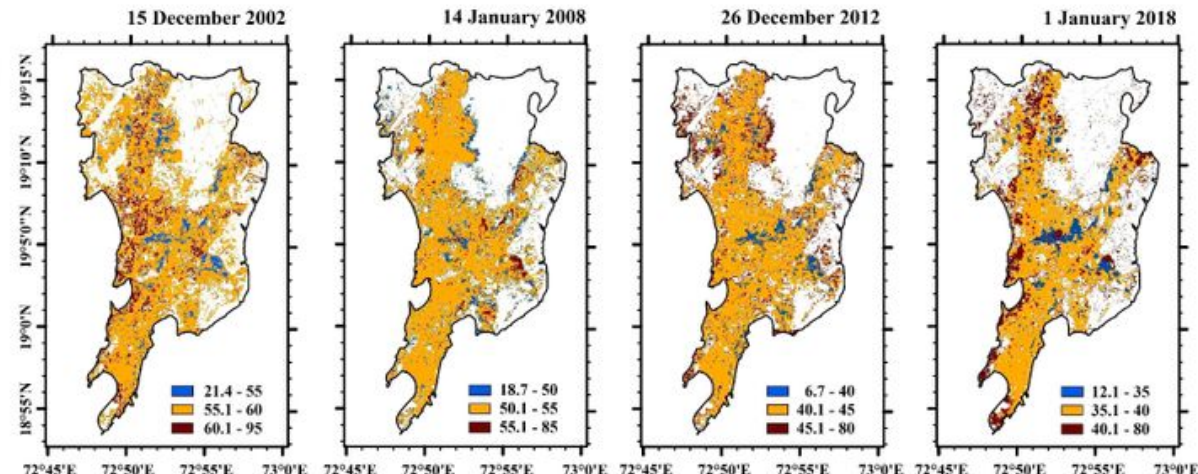

(d)
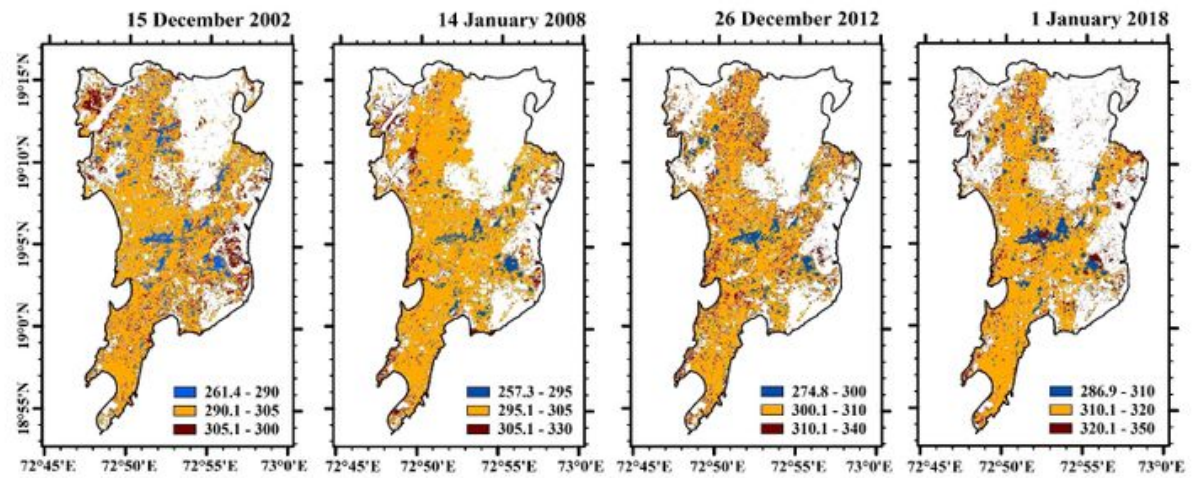

Figure 4

(a) Net radiation flux, (b) sensible heat flux, (c) latent heat flux, and (d) residual heat flux over Mumbai for year 2002, 2008, 2012 and 2018 

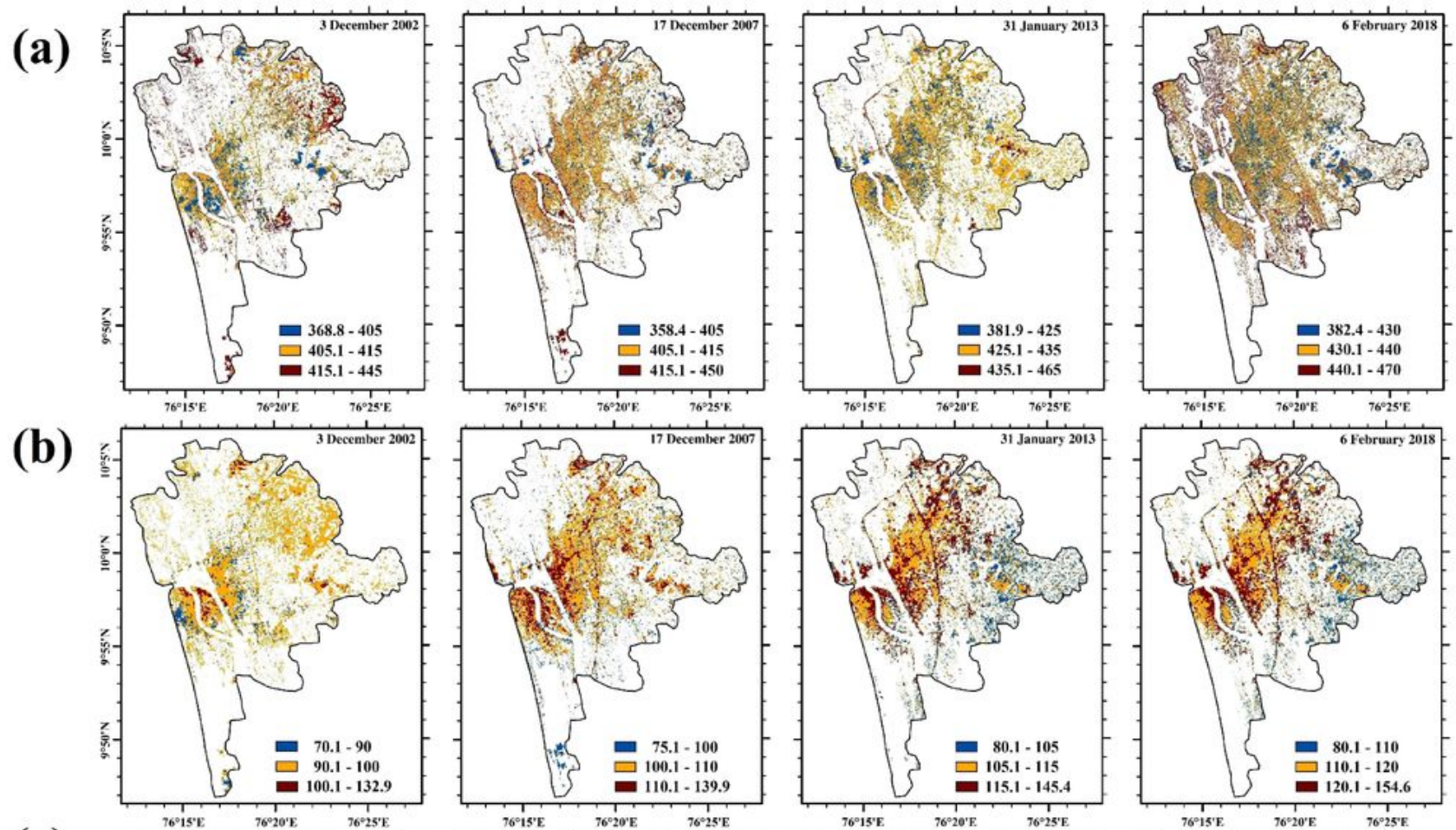

(c)
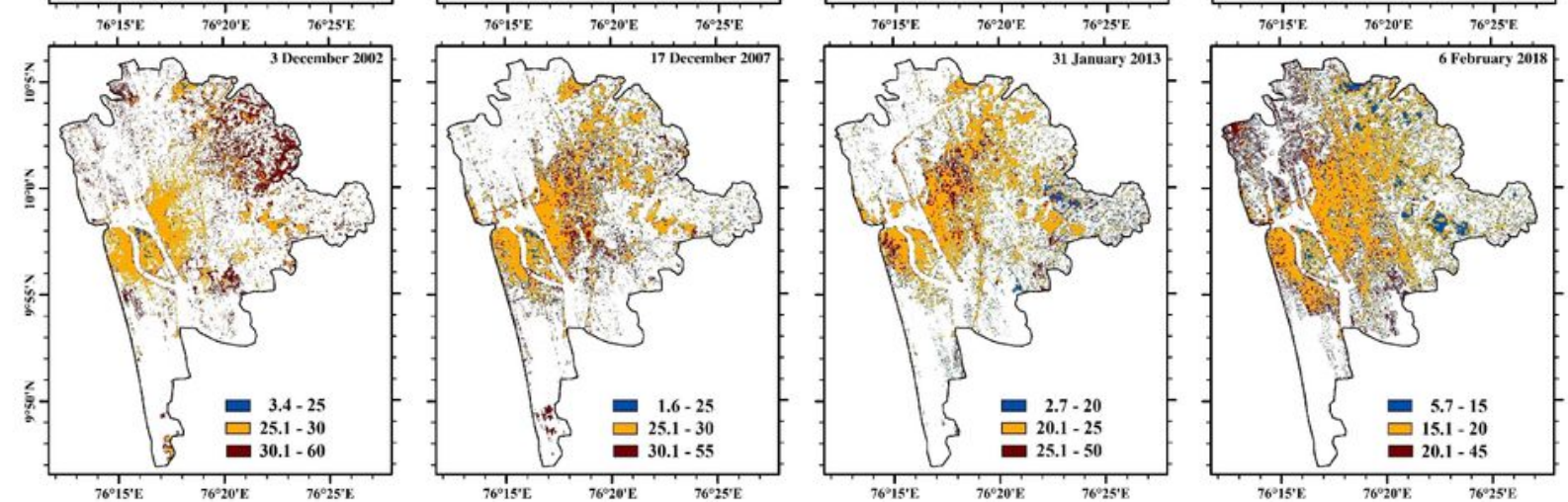

(d)
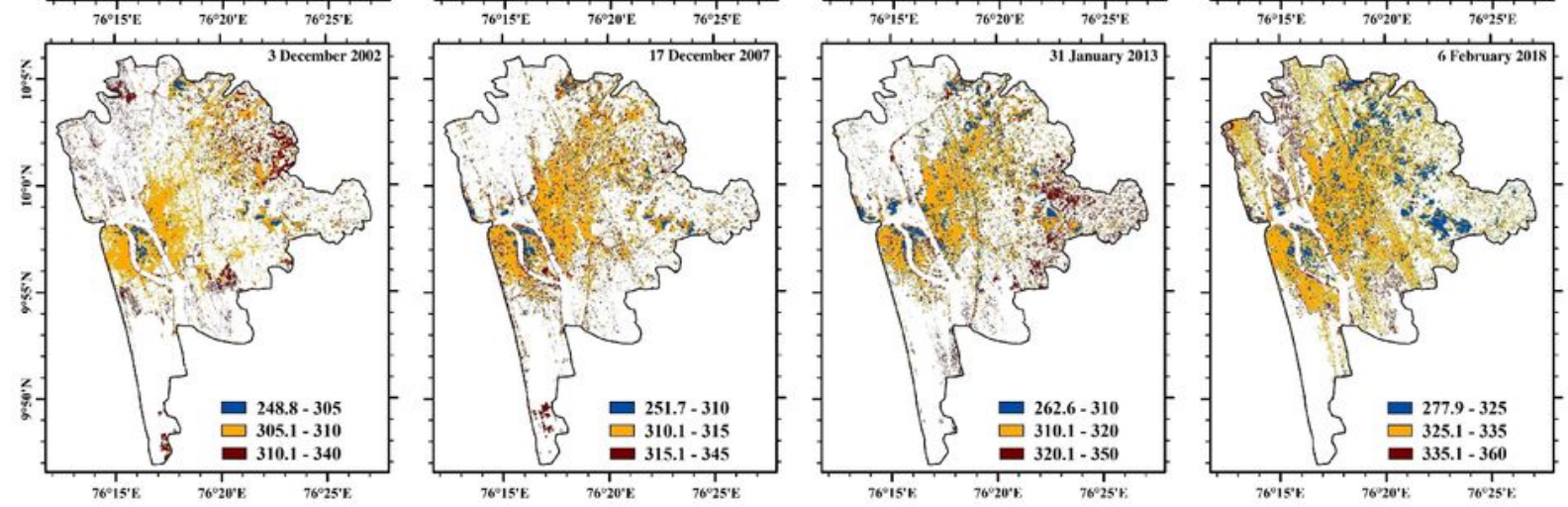

\section{Figure 5}

(a) Net radiation flux, (b) sensible heat flux, (c) latent heat flux, and (d) residual heat flux over Kochi for year 2002, 2007, 2013 and 2018 
(a)
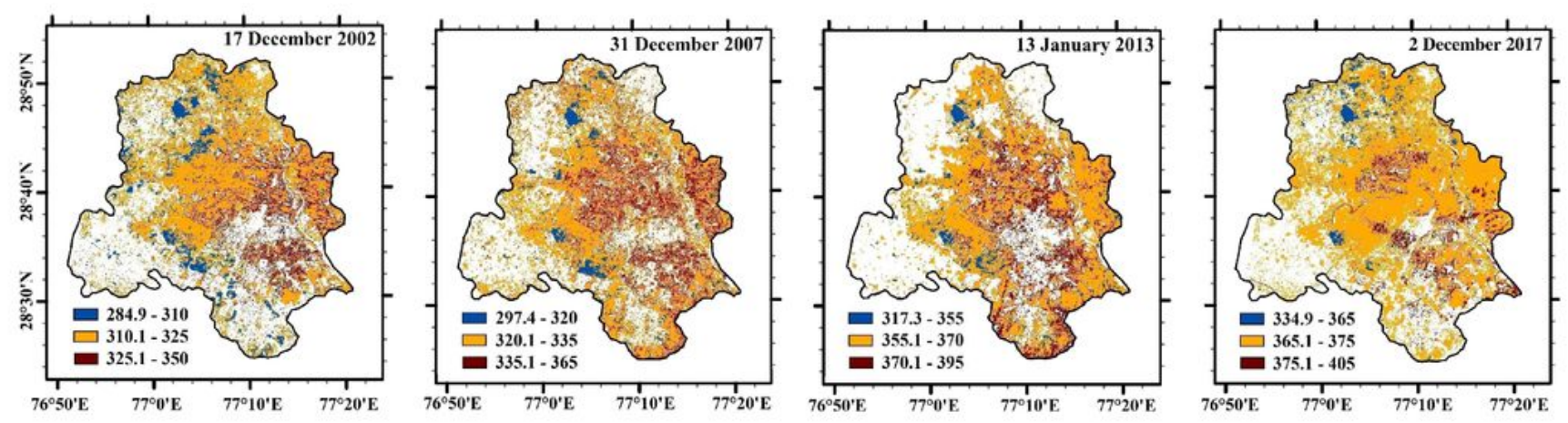

(b)
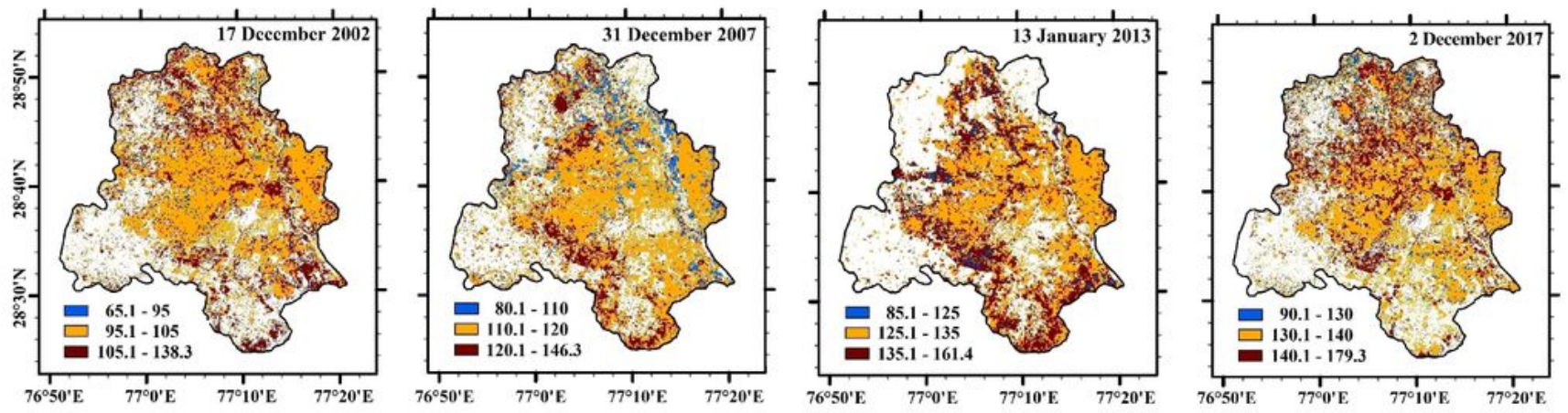

(c)
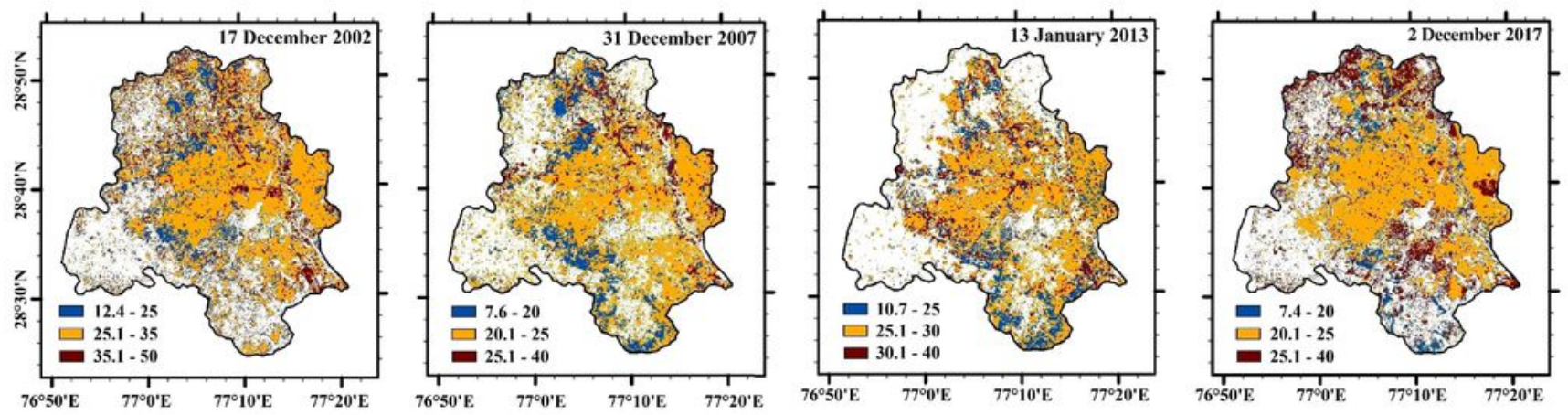

(d)
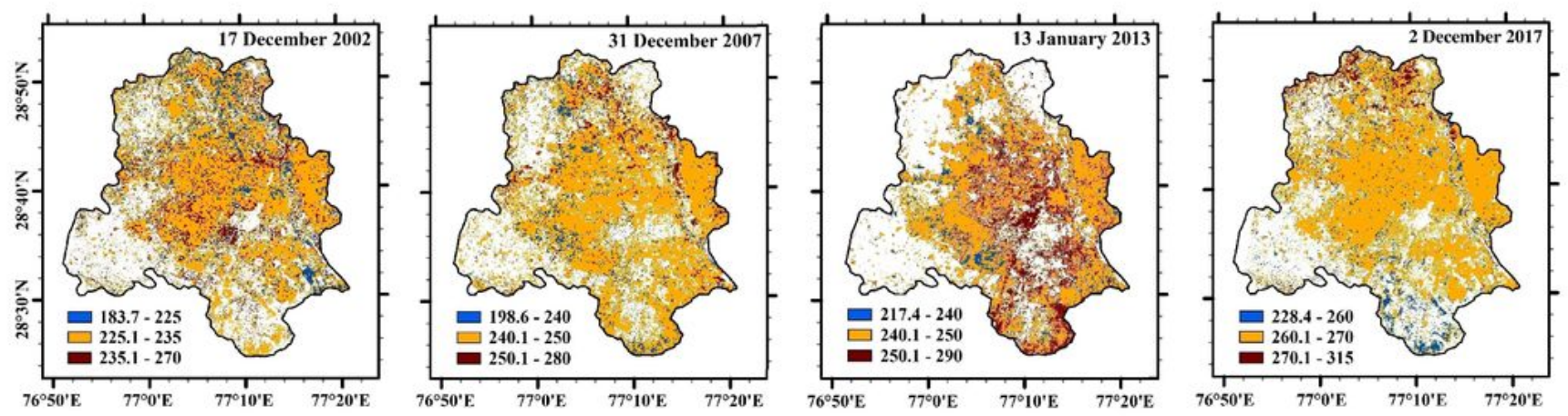

Figure 6

(a) Net radiation flux, (b) sensible heat flux, (c) latent heat flux, and (d) residual heat flux over Delhi for year 2002, 2007, 2013 and 2017 
(a)
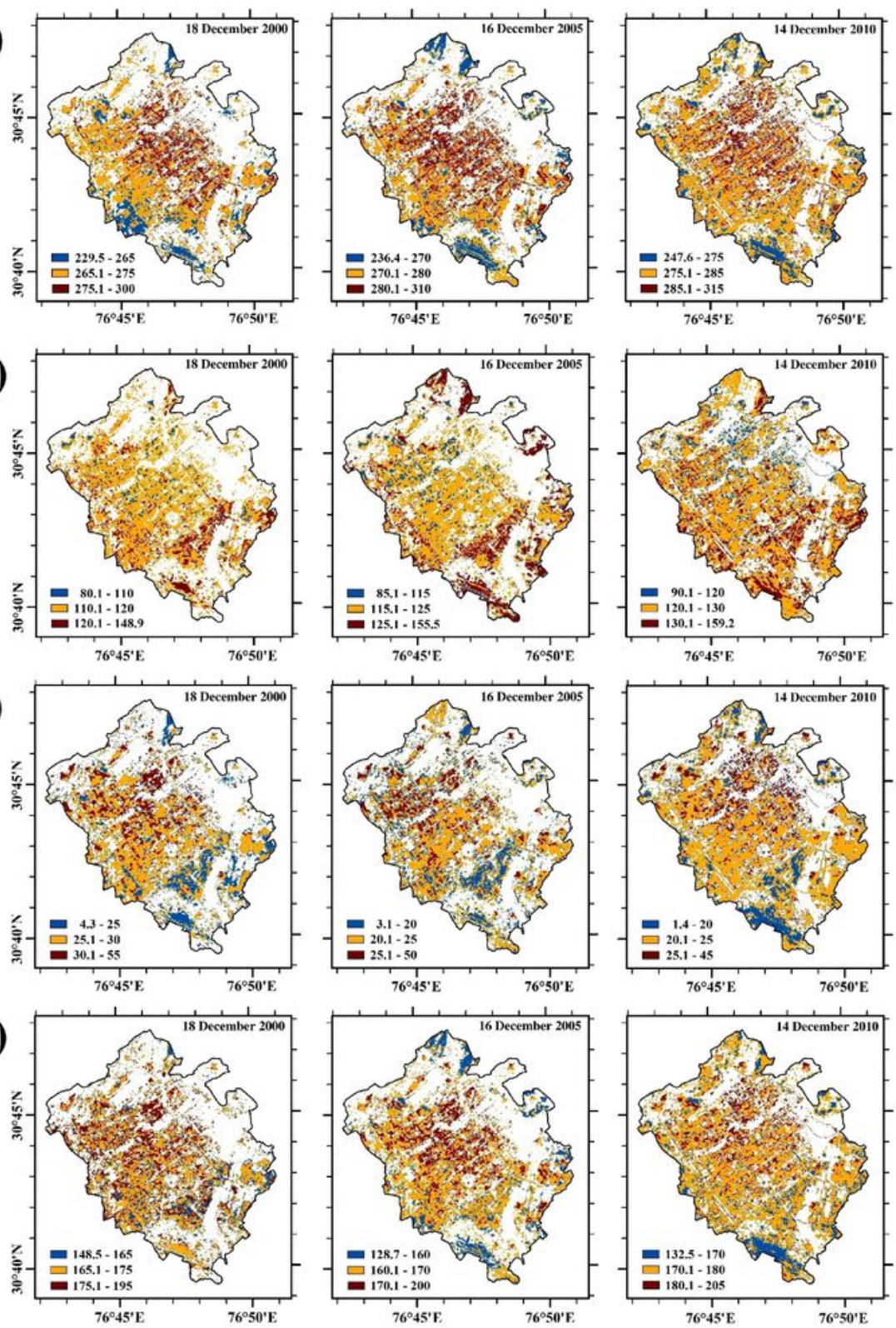
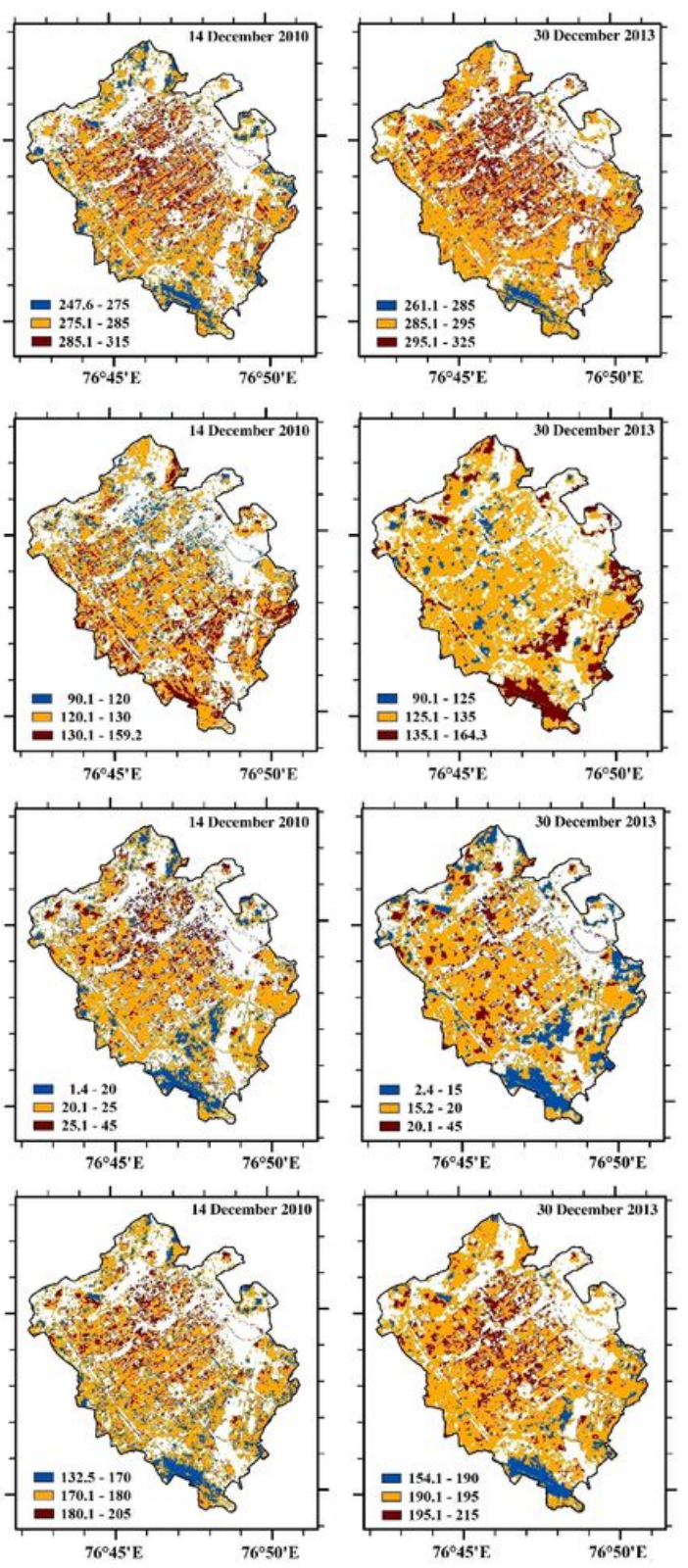
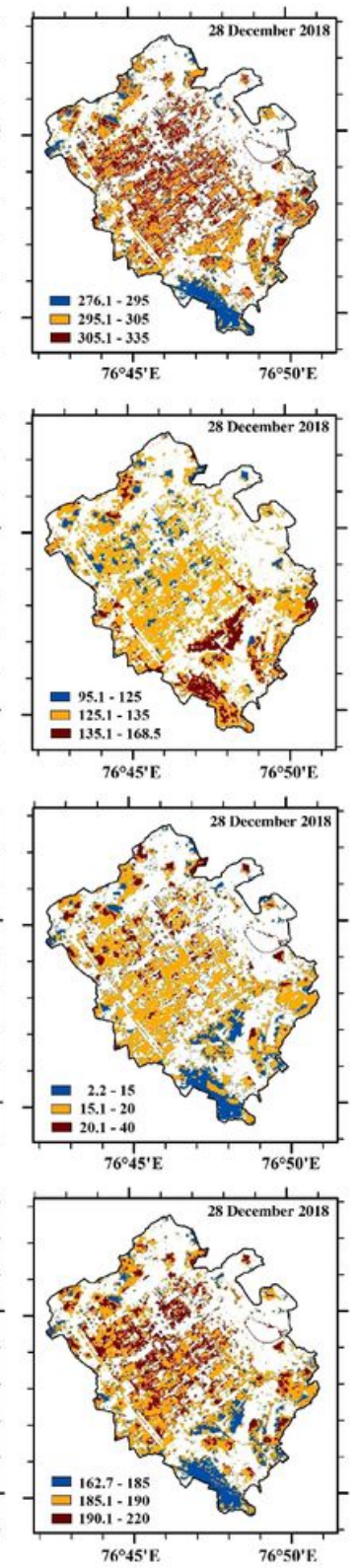

Figure 7

(a) Net radiation flux, (b) sensible heat flux, (c) latent heat flux, and (d) residual heat flux over Chandigarh for year 2000, 2005, 2010, 2013 and 2018 
(a)

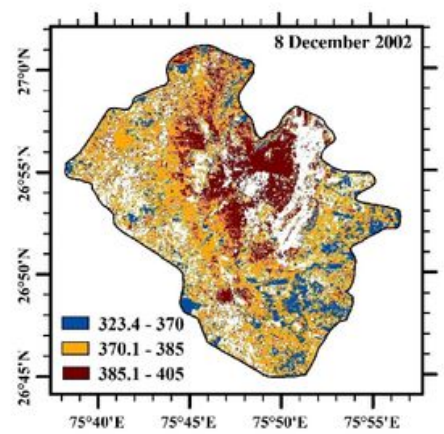

(b)

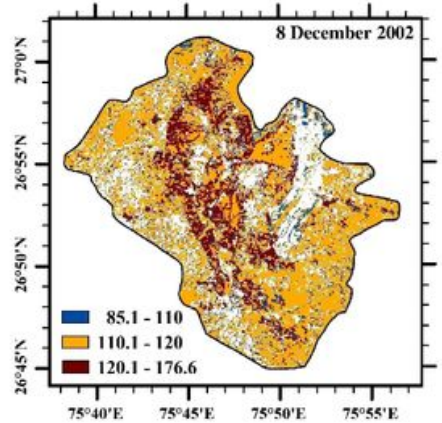

(c)

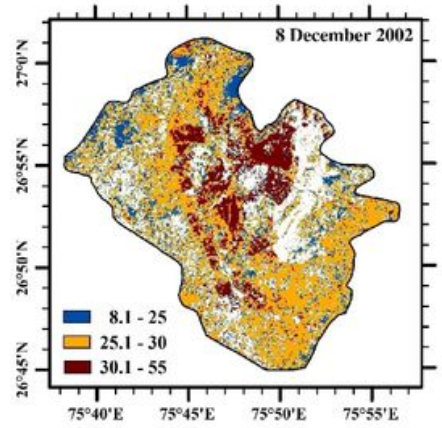

(d)

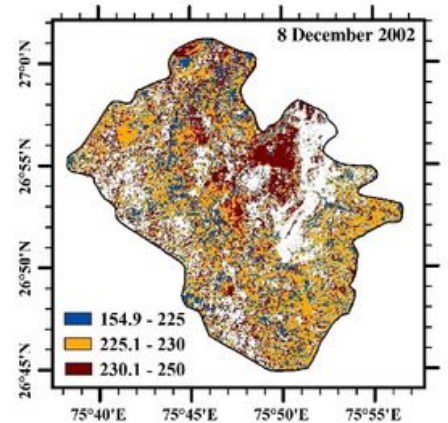

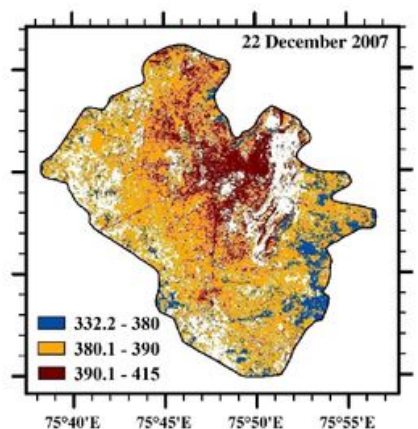
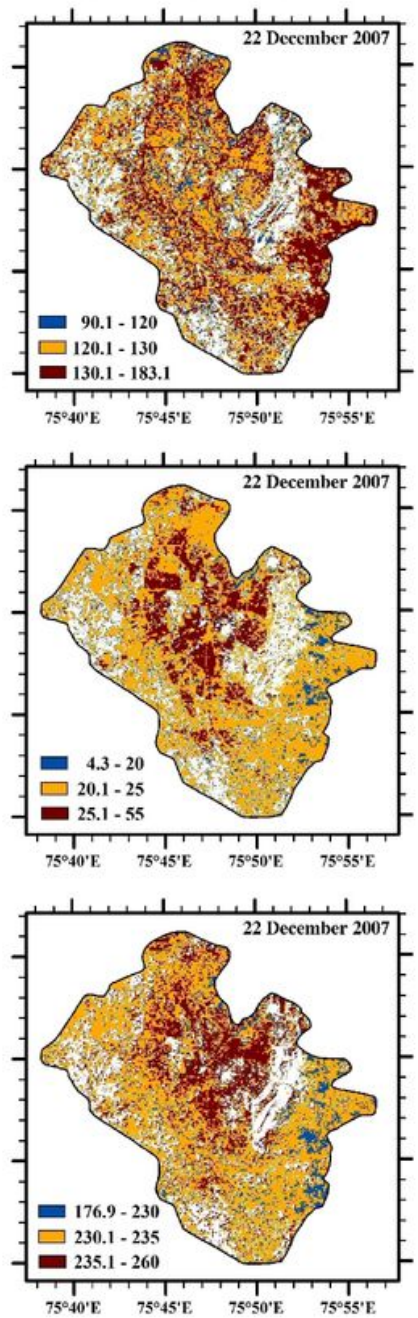
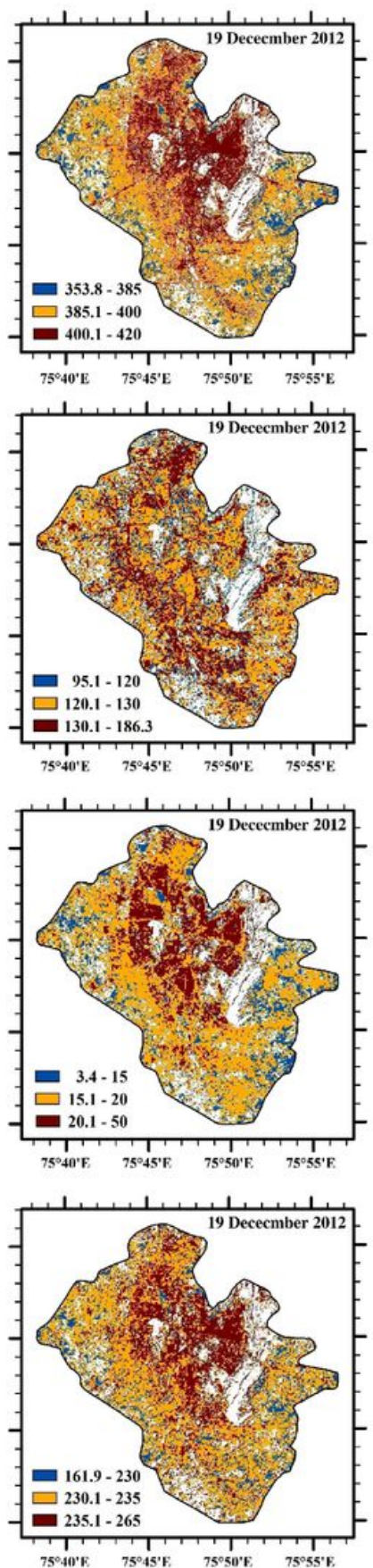
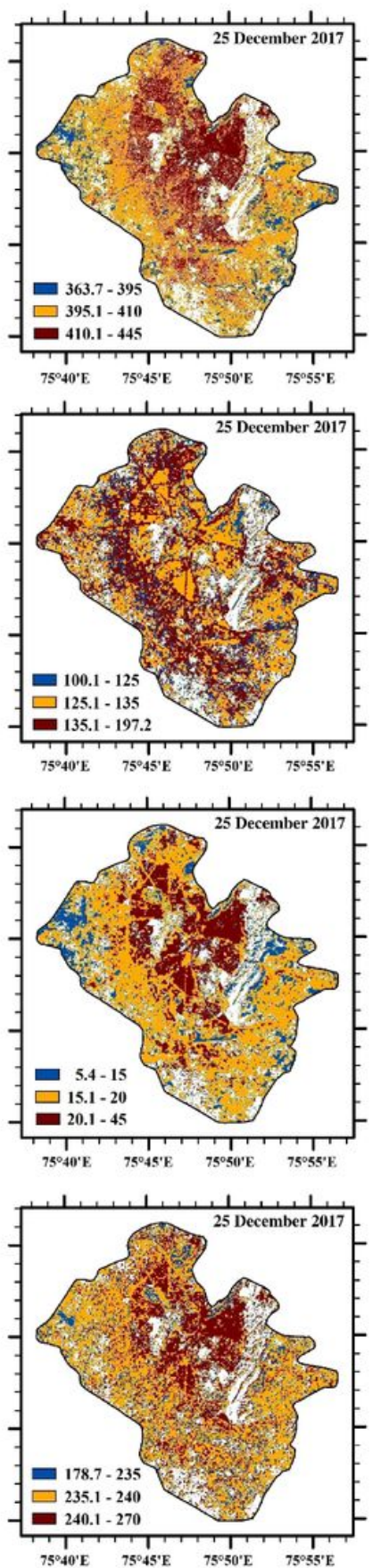

Figure 8

(a) Net radiation flux, (b) sensible heat flux, (c) latent heat flux, and (d) residual heat flux over Jaipur for year 2002, 2007, 2012 and 2017 
(a)

(b)
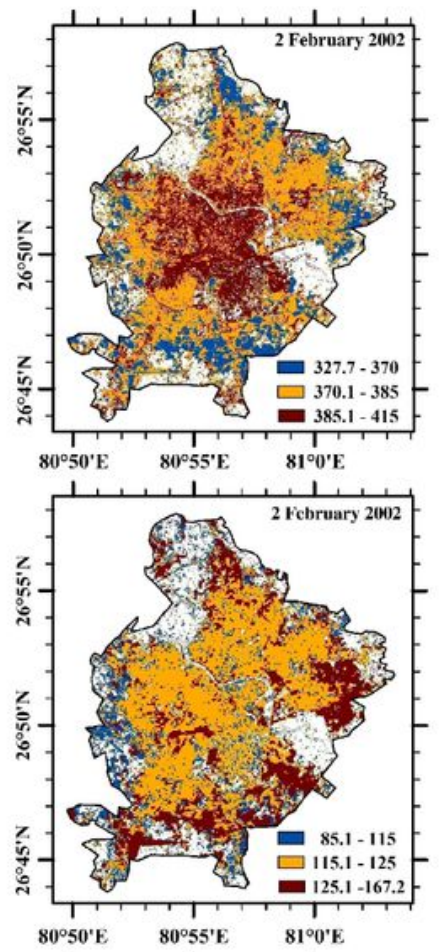

(c)

(d)
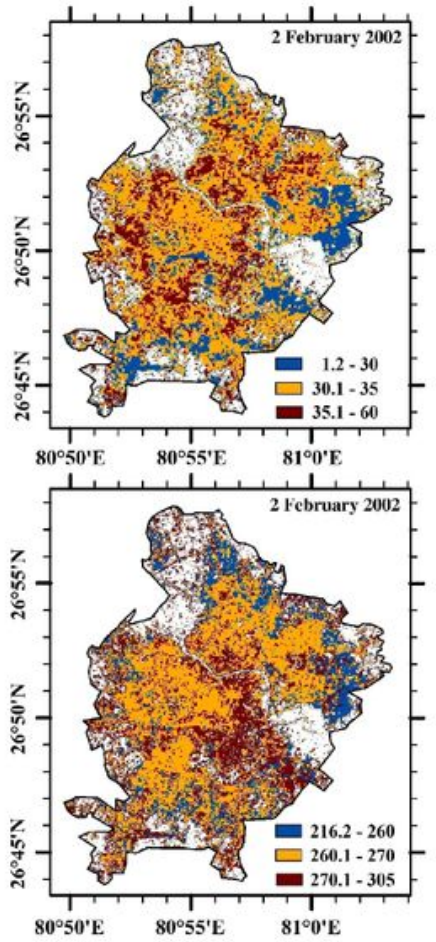
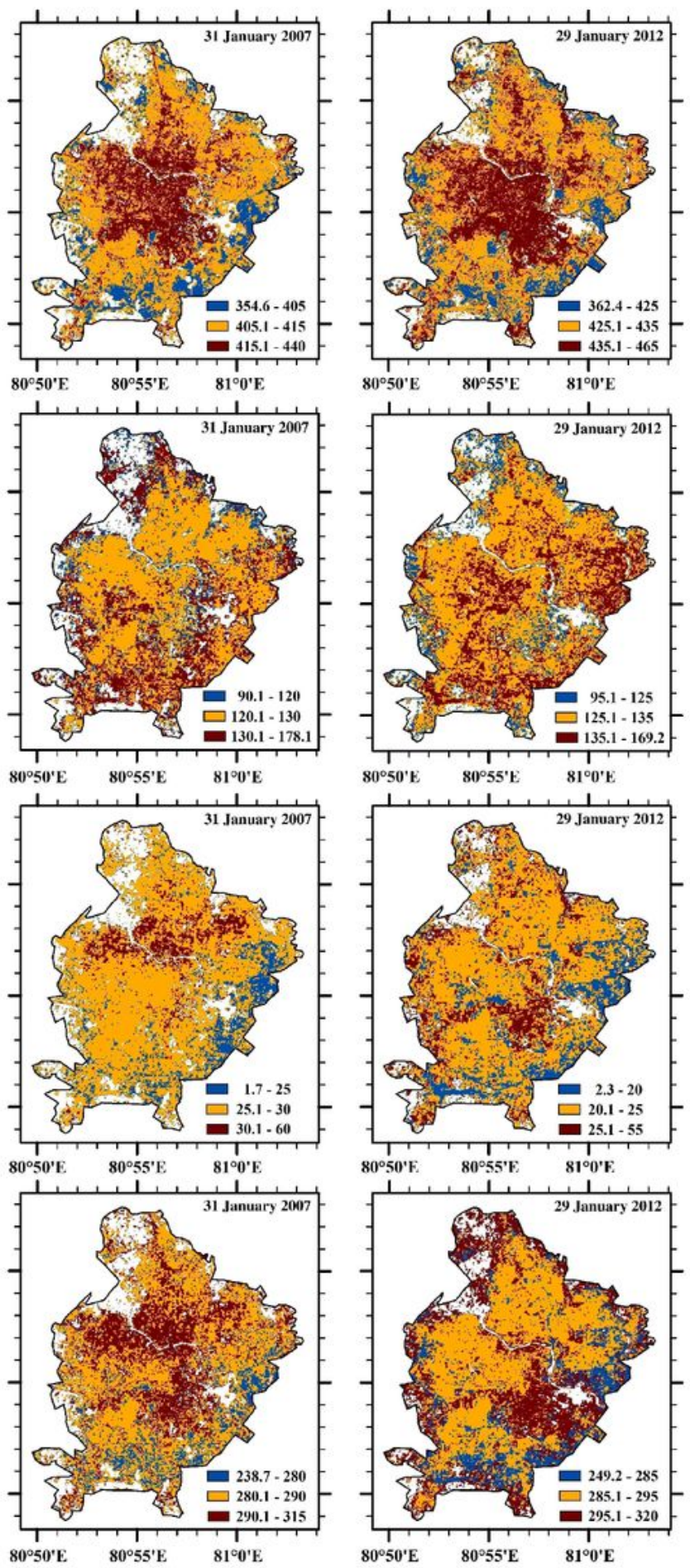
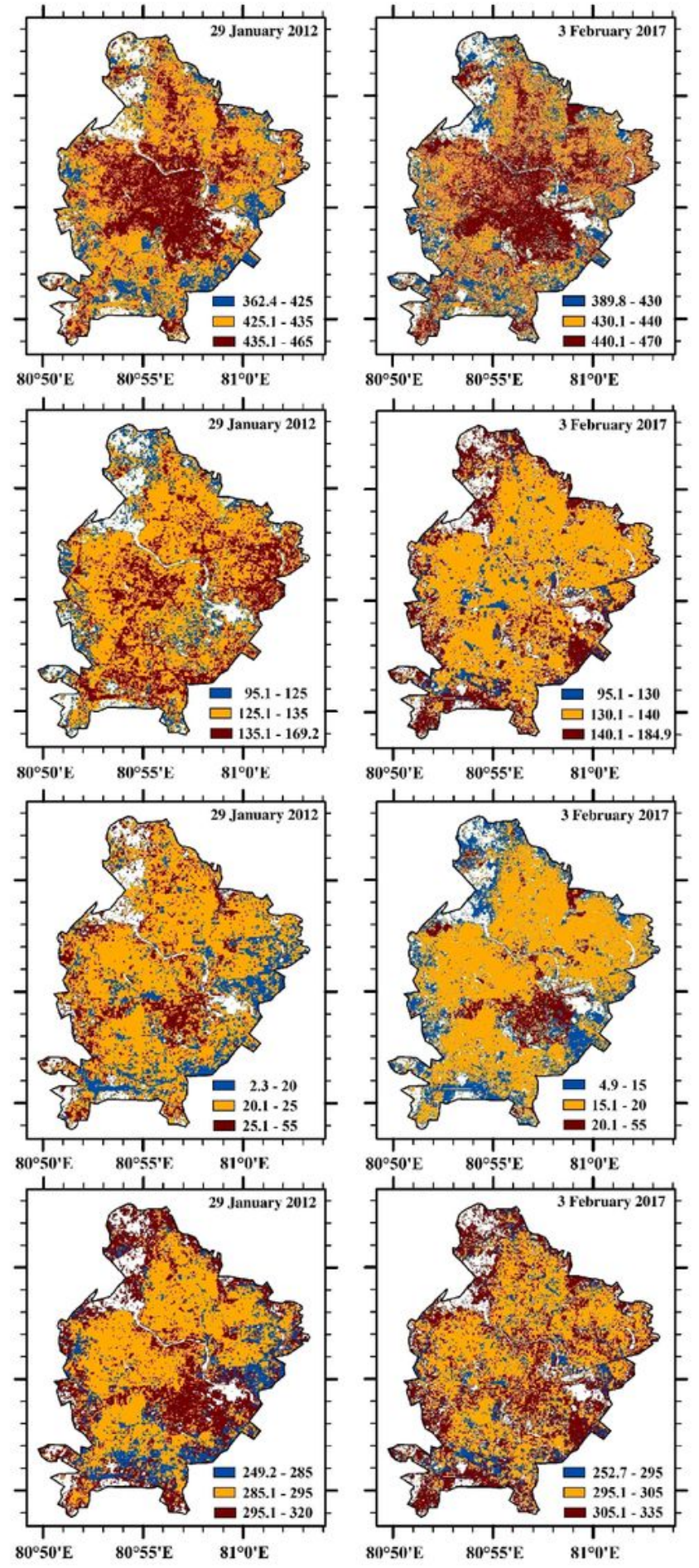

\section{Figure 9}

(a) Net radiation flux, (b) sensible heat flux, (c) latent heat flux, and (d) residual heat flux over Lucknow for year 2002, 2007, 2012 and 2017 
(a)

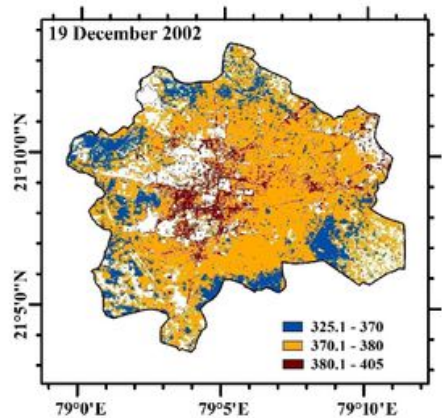

(b)

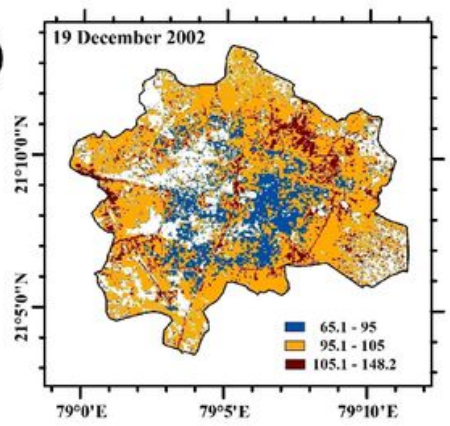

(c)

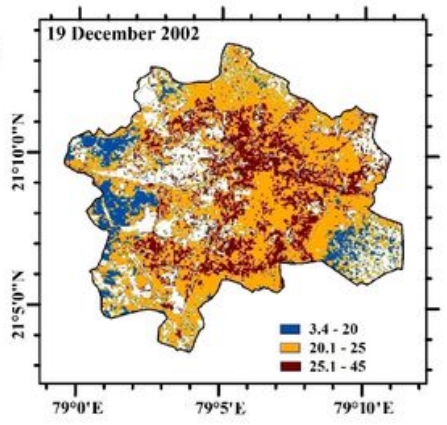

(d)

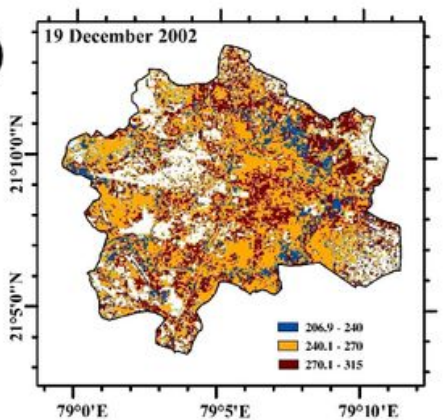

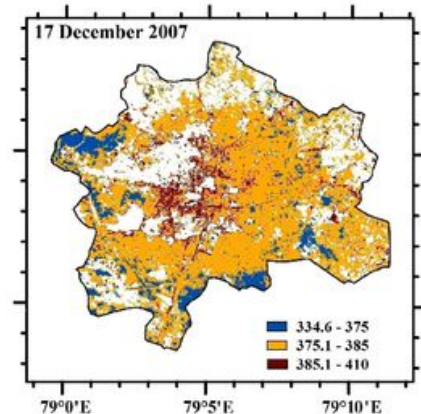
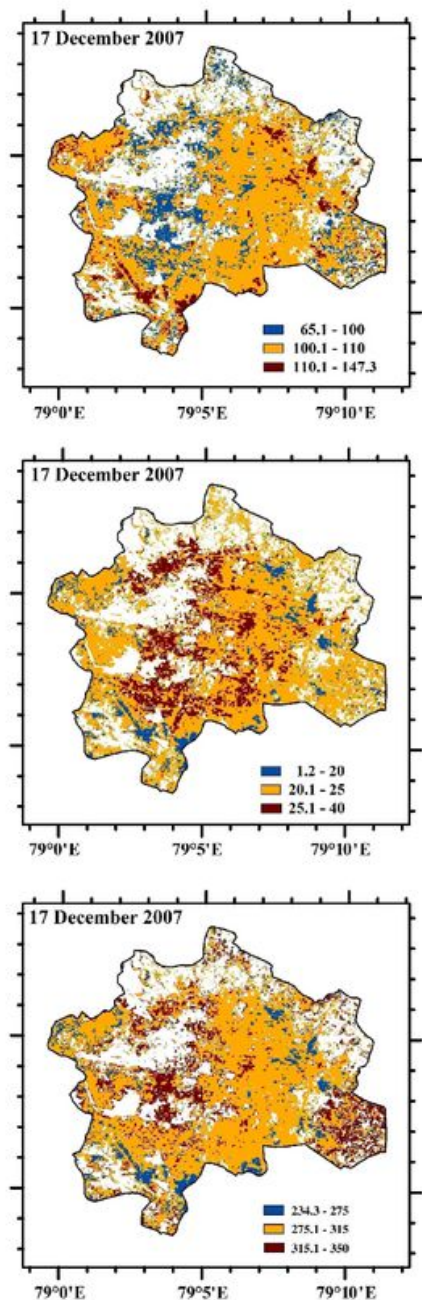
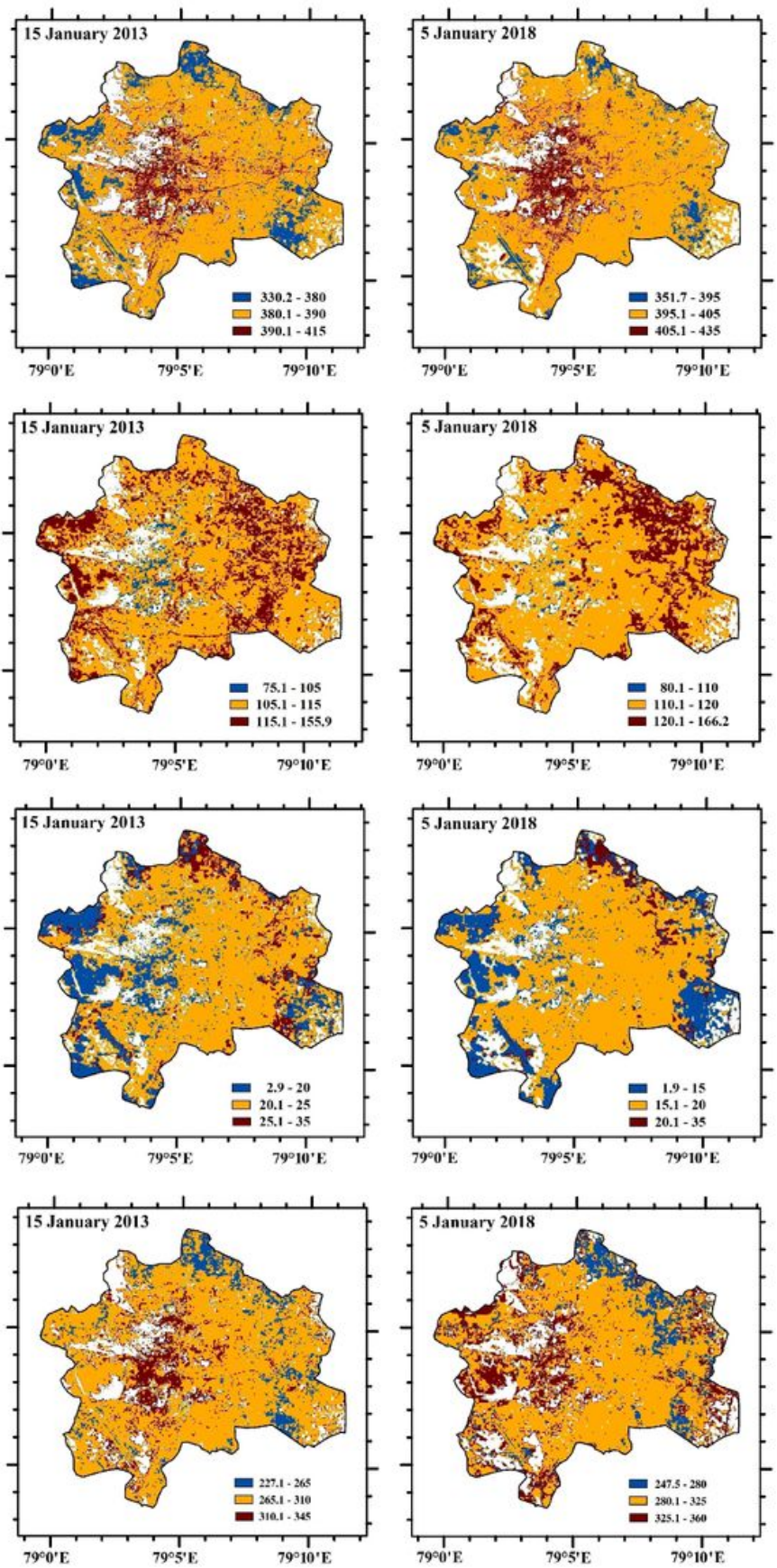

Figure 10

(a) Net radiation flux, (b) sensible heat flux, (c) latent heat flux, and (d) residual heat flux over Nagpur for year 2002, 2007, 2013 and 2018 
(a)
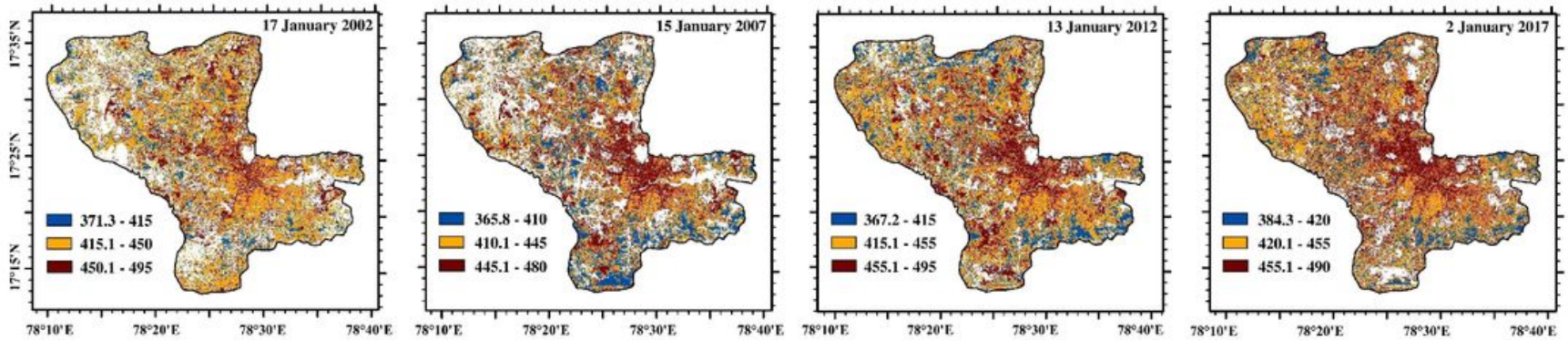

(b)
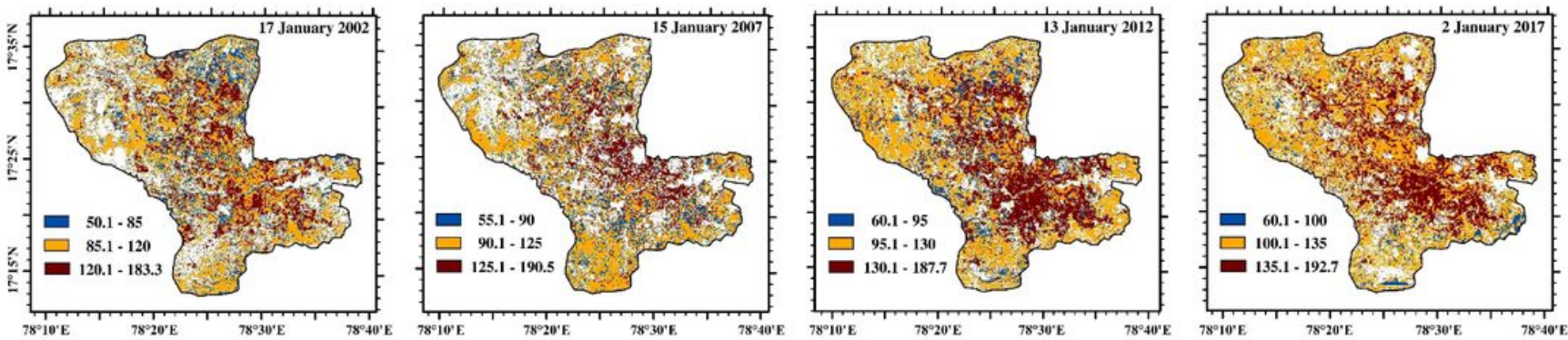

(c)
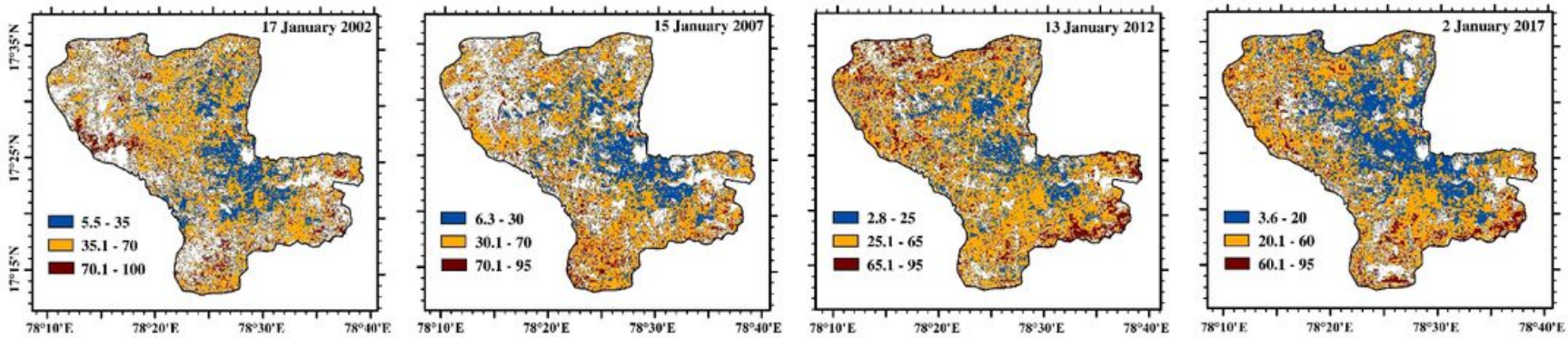

(d)
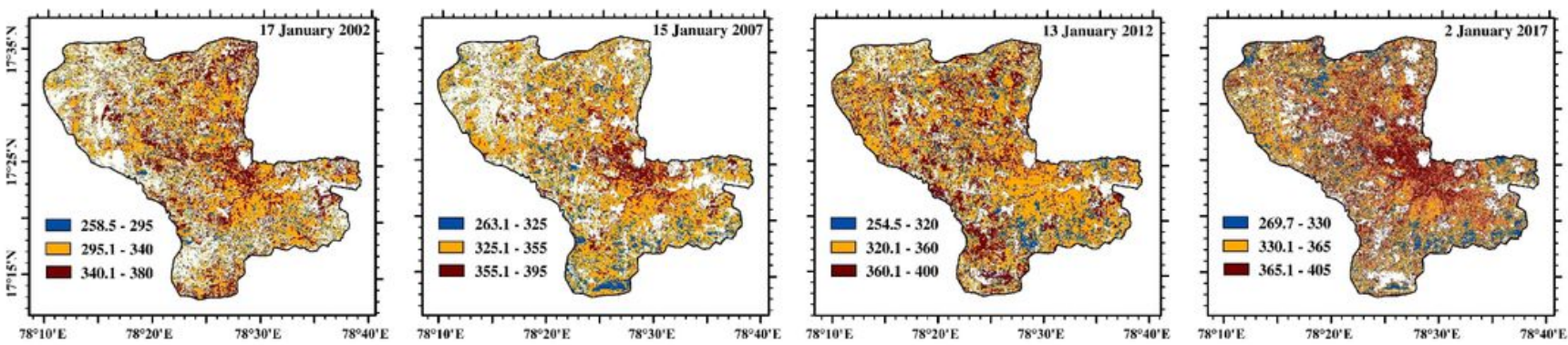

Figure 11

(a) Net radiation flux, (b) sensible heat flux, (c) latent heat flux, and (d) residual heat flux over Hyderabad for year 2002, 2007, 2012 and 2017 
(a)

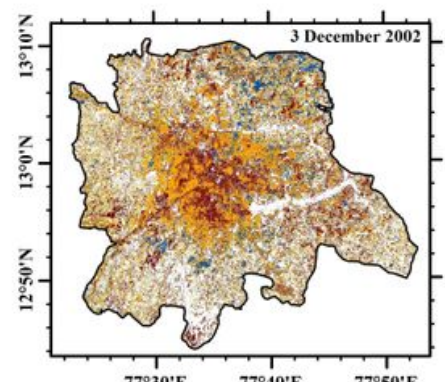

(b)

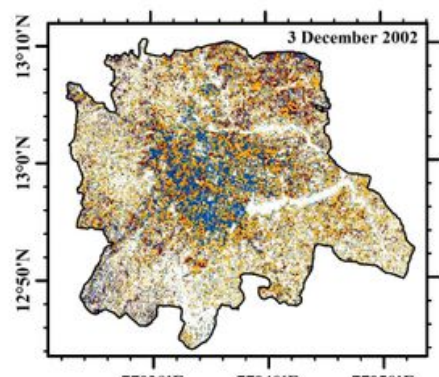

(c)

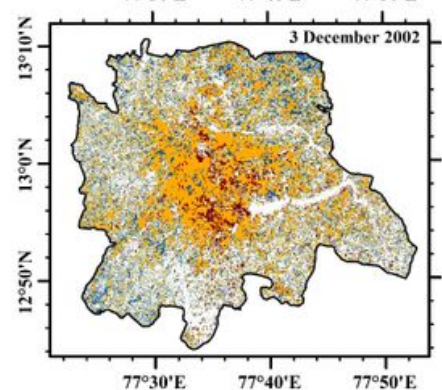

(d)

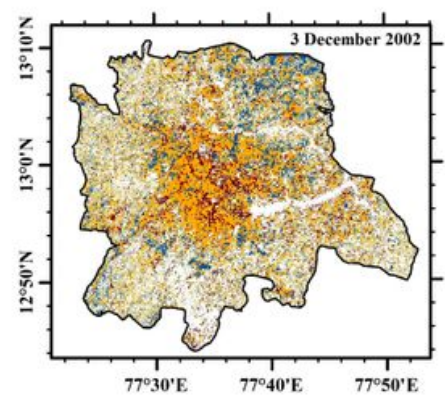

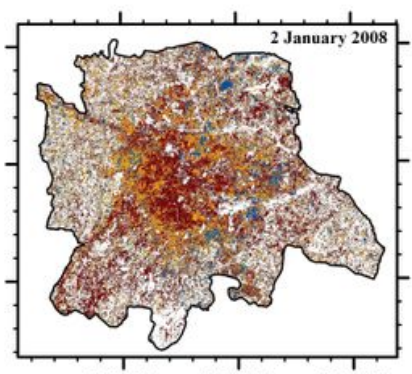

$7^{\circ} 30^{\prime} \mathrm{E} \quad 77^{\circ} 40^{\prime} \mathrm{E} \quad 7^{\circ} 50^{\prime} \mathrm{E}$

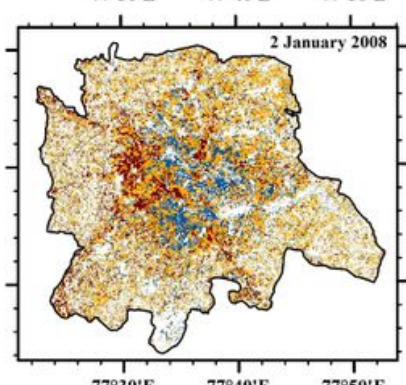

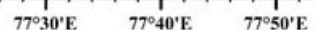

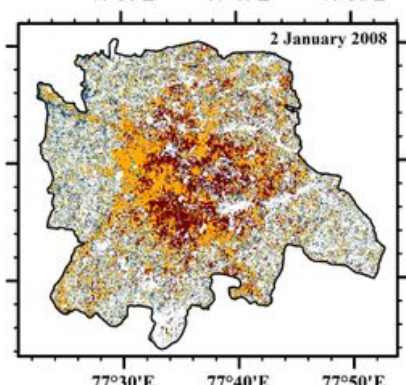

$77^{\circ} 30^{\prime} \mathrm{E} \quad 77^{\circ} 40^{\prime} \mathrm{E} \quad 77^{\circ} 50^{\prime} \mathrm{E}$

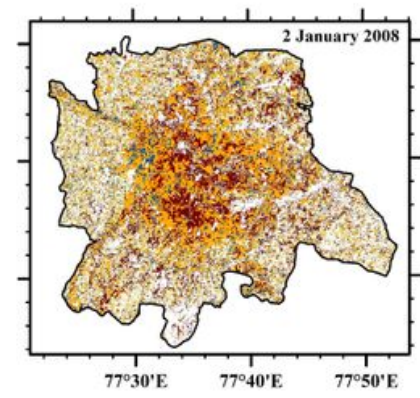

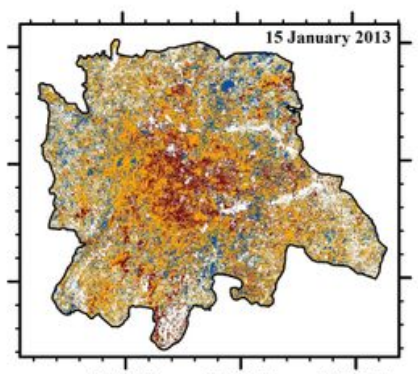

$77^{\circ} 30^{\prime} \mathrm{E} \quad 77^{\circ} 40^{\circ} \mathrm{E} \quad 77^{\circ} 50^{\circ} \mathrm{E}$
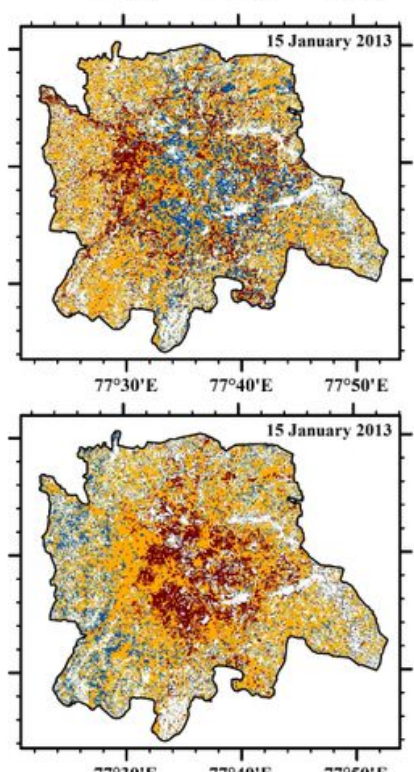

$77^{\circ} 30^{\prime} \mathrm{E} \quad 77^{\circ} 40^{\prime} \mathrm{E} \quad 77^{\circ} 50^{\prime} \mathrm{E}$

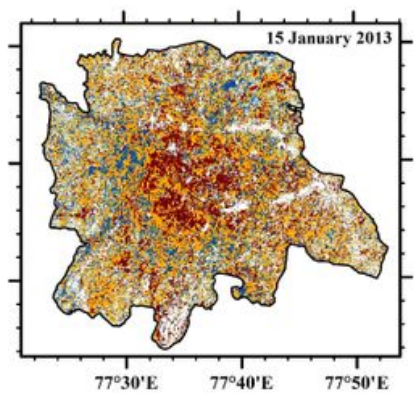

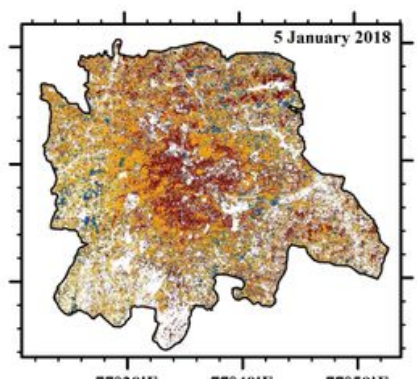

$7^{\circ} 7^{\circ} 30^{\circ} \mathrm{E} \quad 77^{\circ} 40^{\circ} \mathrm{E} . \quad 77^{\circ} 50^{\circ} \mathrm{E}$
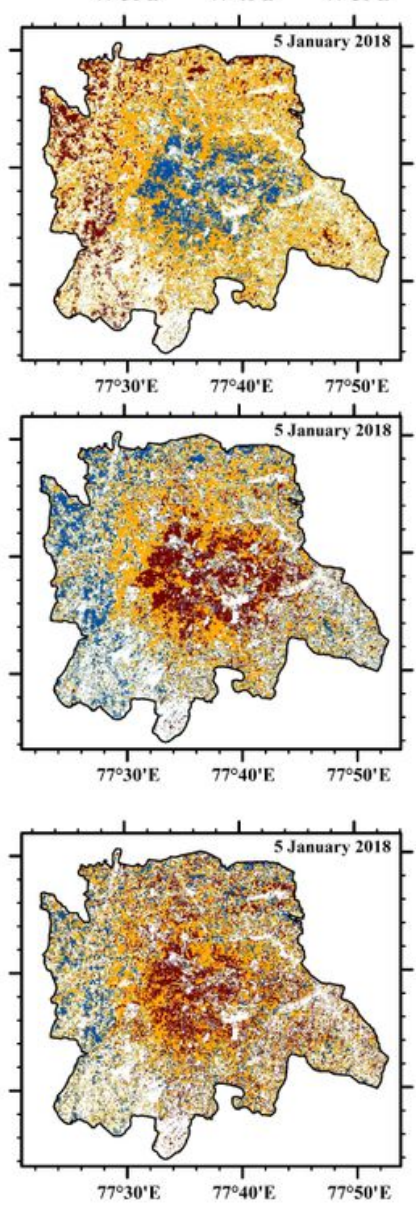

Figure 12

(a) Net radiation flux, (b) sensible heat flux, (c) latent heat flux, and (d) residual heat flux over Bengaluru for year 2002, 2008, 2013 and 2018 


\section{Kolkata}

(a)

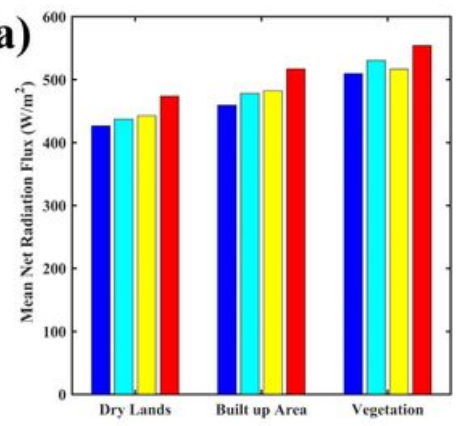

(b)

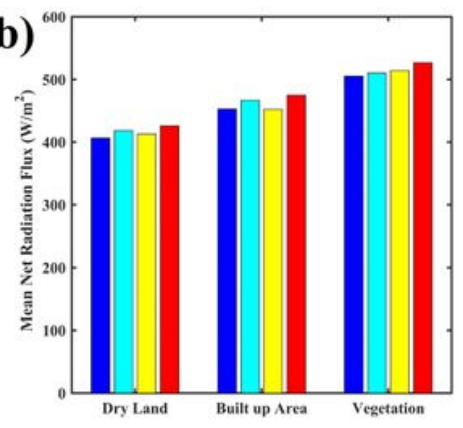

(c)

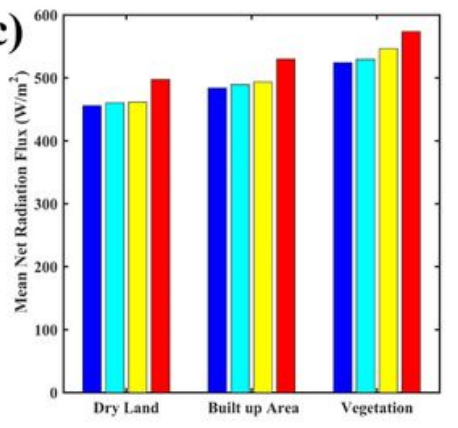

(d)

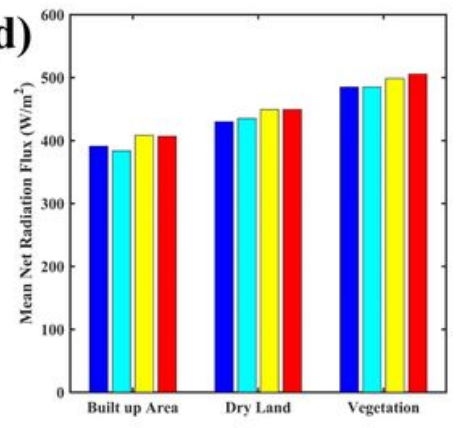

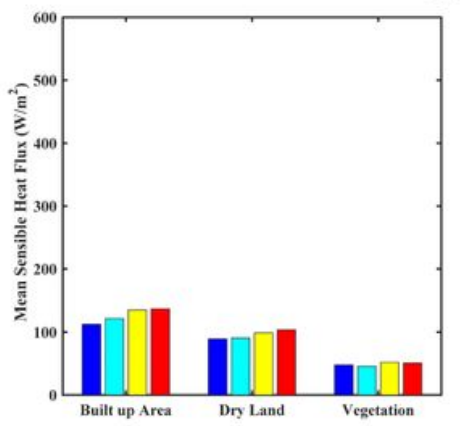
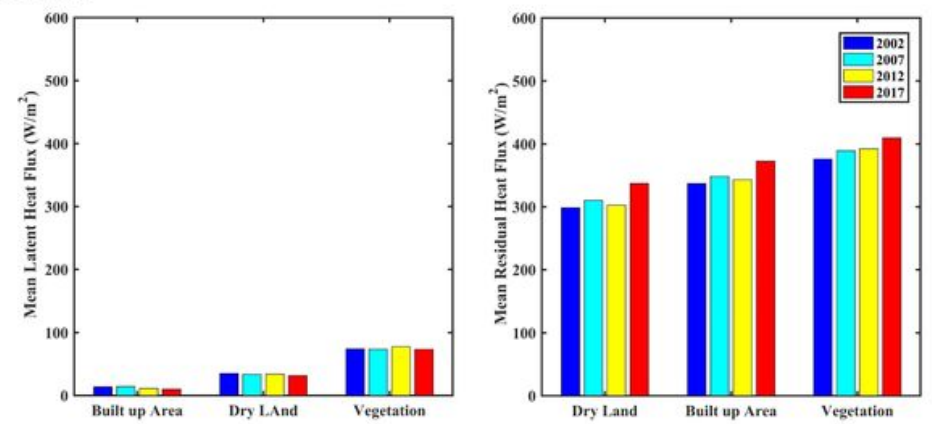

Visakhapatnam
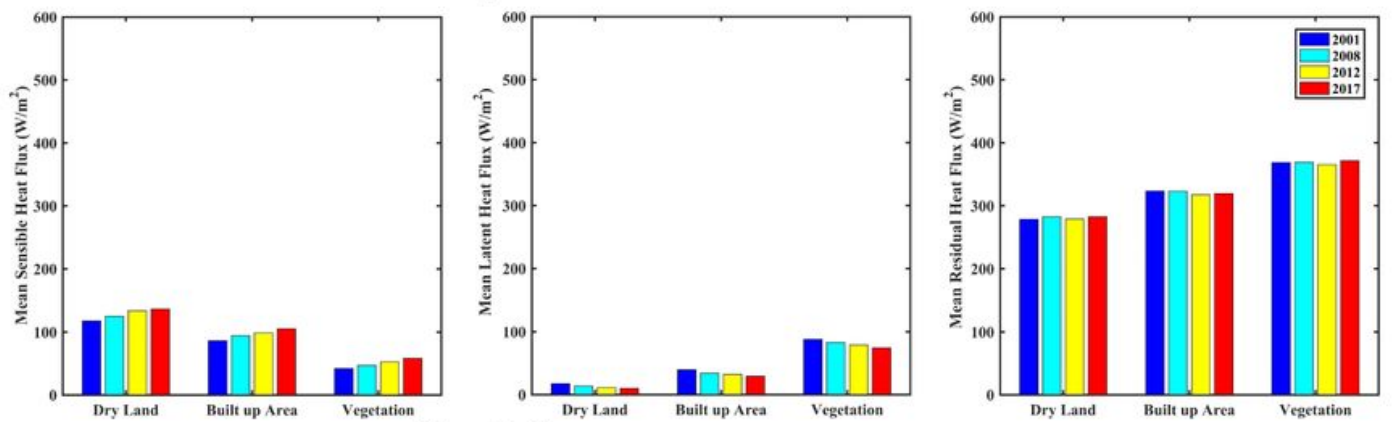

Mumbai
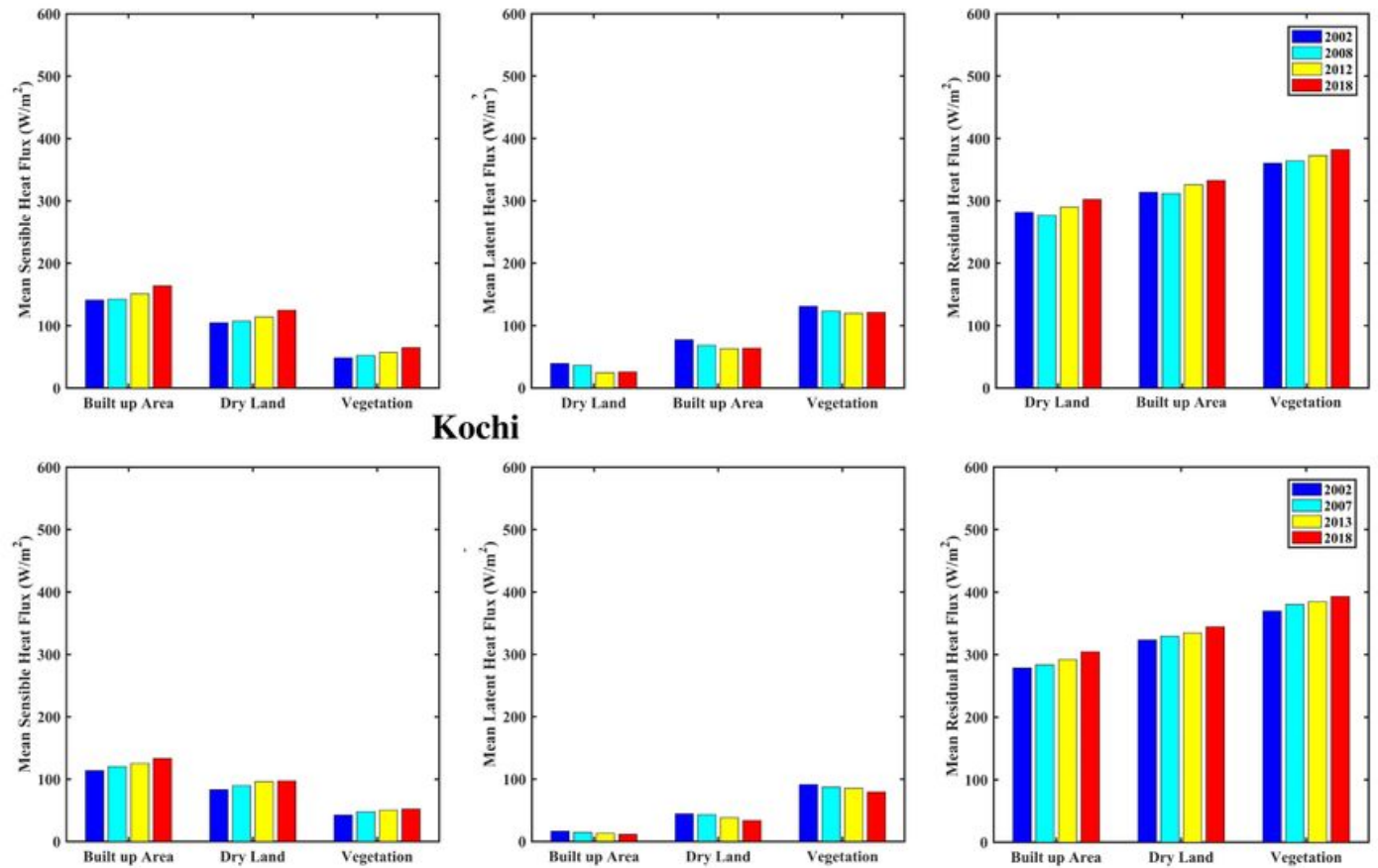

Figure 13

The variation of surface energy components with respect to build up area, dry lands and vegetation over (a) Kolkata, (b) Visakhapatnam, (c) Mumbai and (d) Kochi 

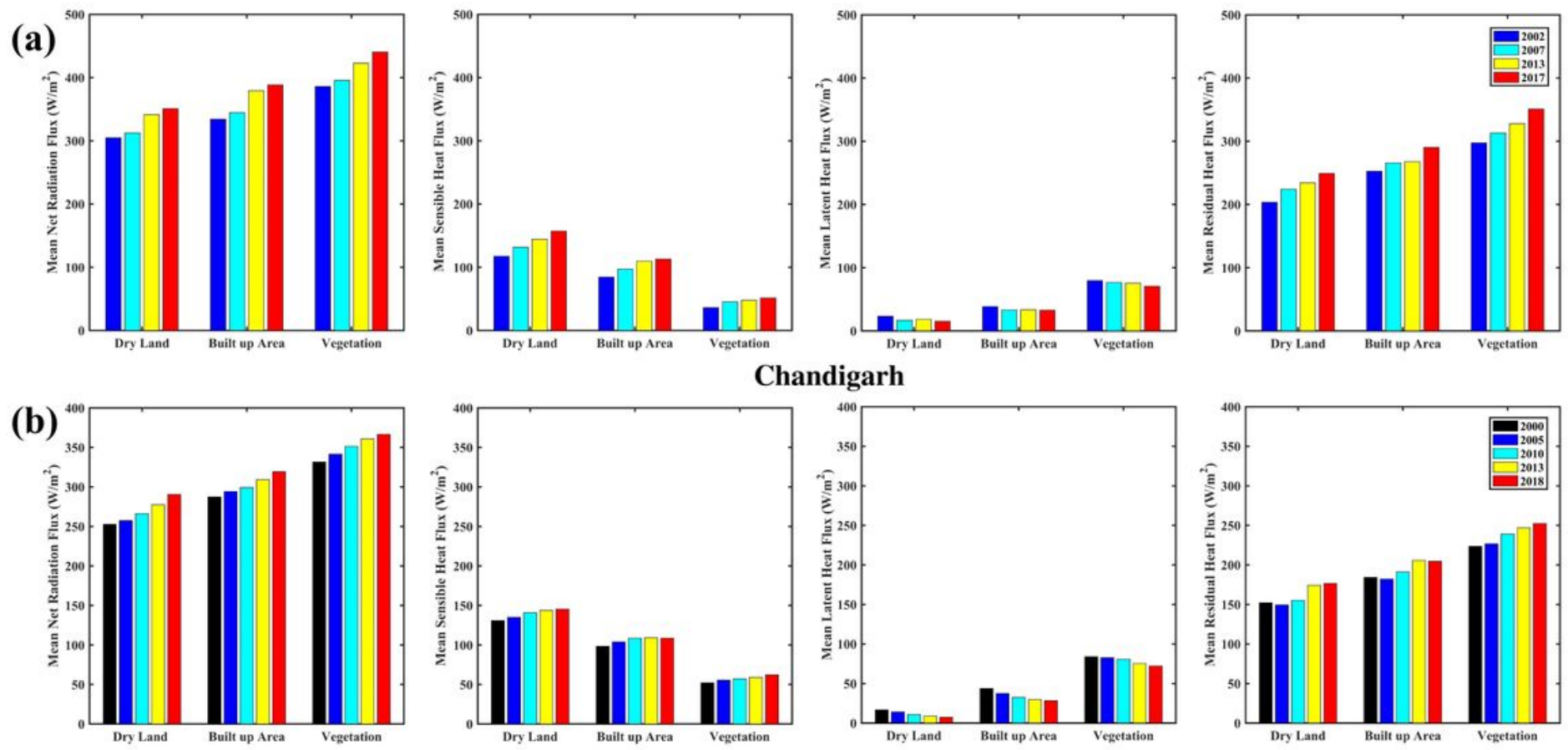

(c)
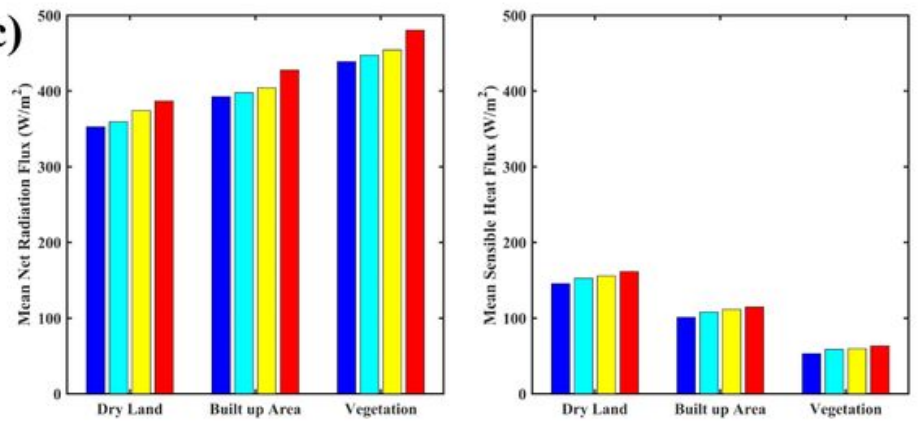

Jaipur
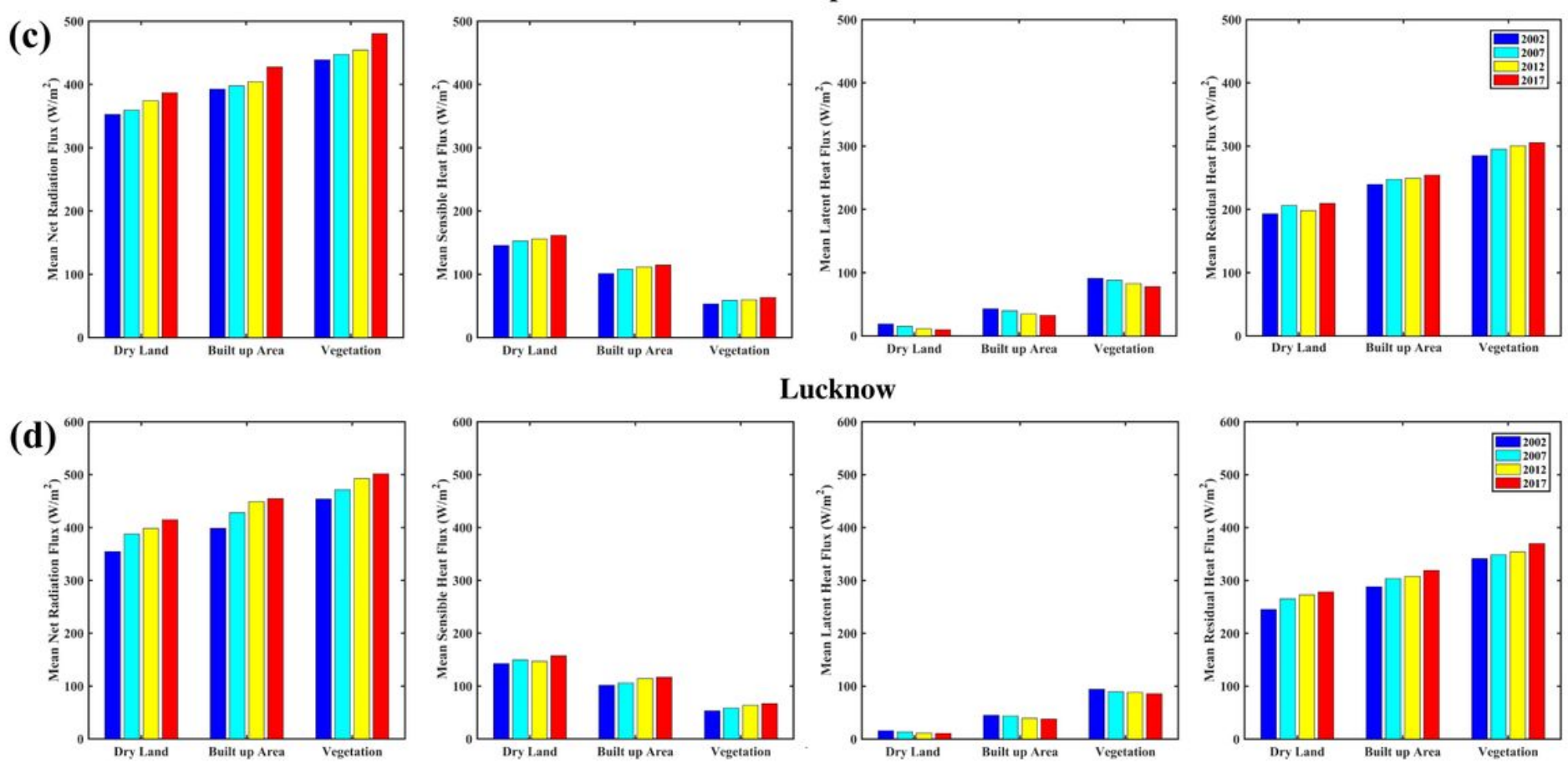

\section{Lucknow}
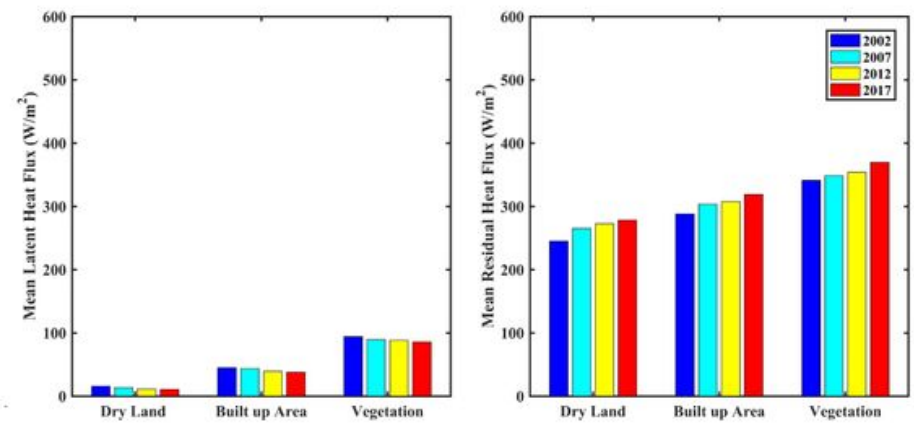

Figure 14

The variation of surface energy components with respect to build up area, dry lands and vegetation over (a) Delhi, (b) Chandigarh, (c) Jaipur and (d) Lucknow 
Nagpur
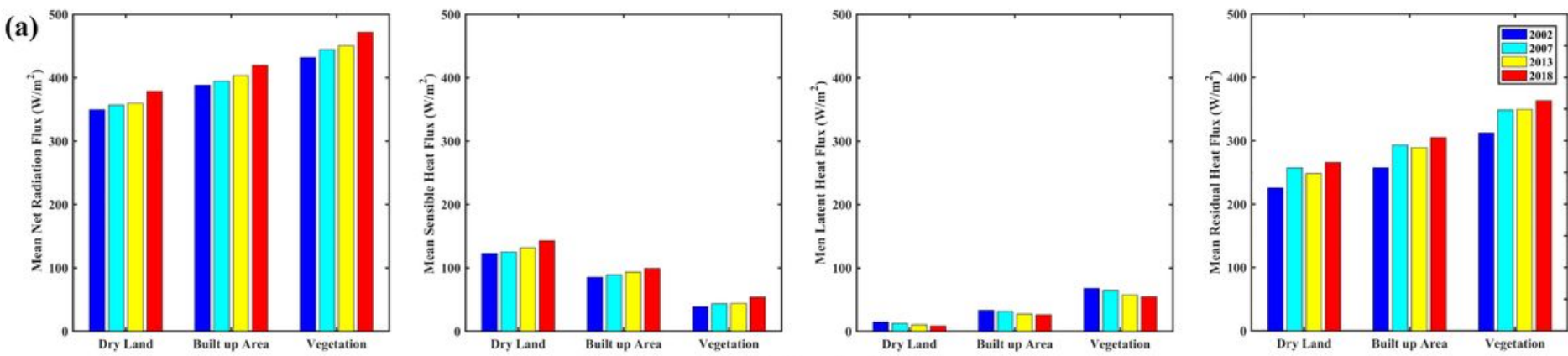

Hyderabad
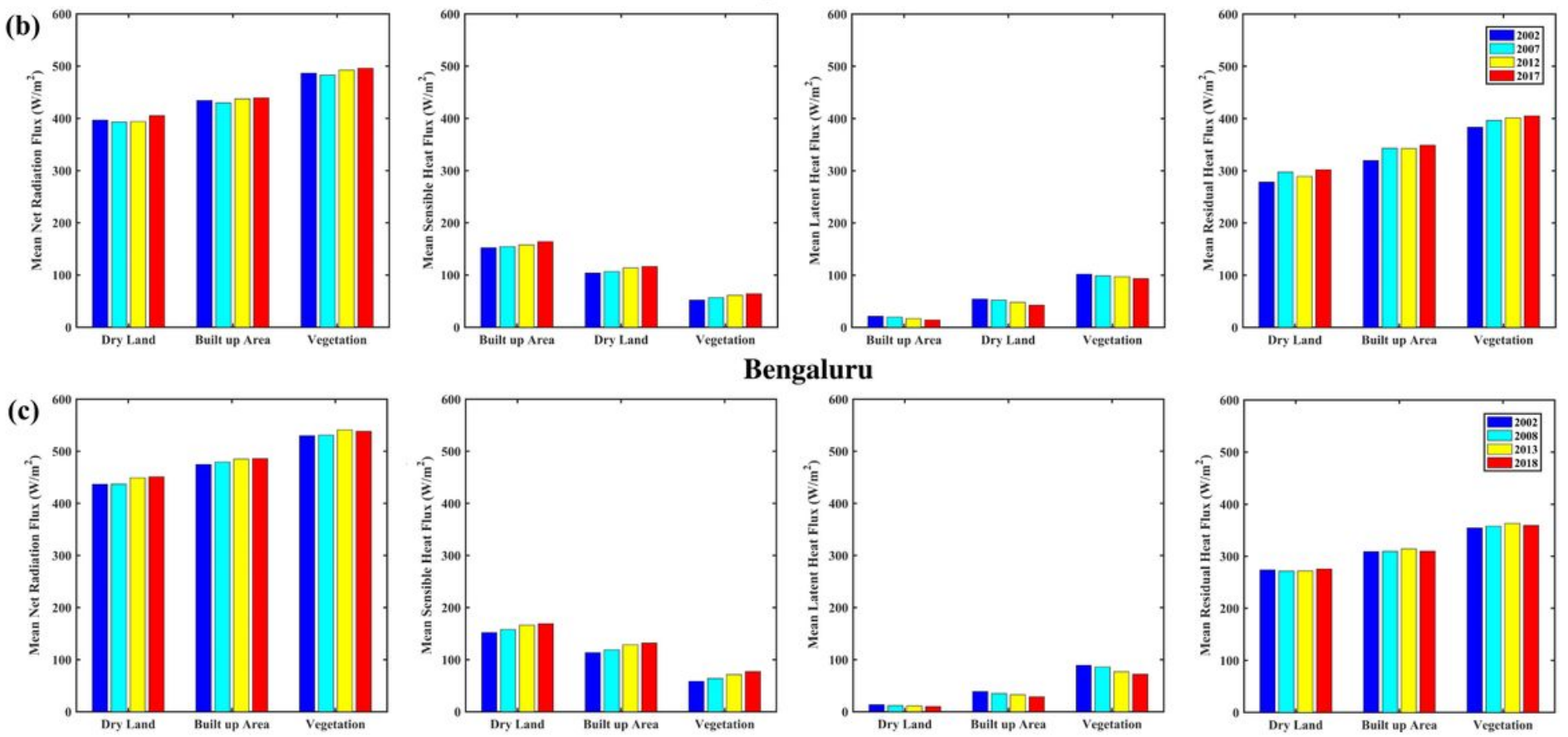

Figure 15

The variation of surface energy components with respect to build up area, dry lands and vegetation over (a) Nagpur, (b) Hyderabad, and (c) Bengaluru 